\title{
Das Leben poetisieren oder "Poesie leben «? Zur Bedeutung des metaphorischen Prozesses im Surrealismus
}

\section{Einleitung}

Bedeutet das Interesse akademischer Gelehrsamkeit und die kommerzielle Vermarktung den Tod des Surrealismus? Haben seine selbstgewählten Feinde, der bürgerliche Rationalismus und das darauf fußende kapitalistische Wirtschaftssystem, über ihn triumphiert und seinen wahren ideologischen Standort innerhalb, nicht außerhalb dieses Systems offenkundig gemacht? Oder lebt er noch bzw. lohnt es sich, ihn am Leben zu erhalten, obwohl er schon einige Zeit gewinnbringend verkauft und zum Gegenstand wissenschaftlicher Untersuchungen gemacht wird? Das Verhältnis zwischen Surrealismus auf der einen und Wissenschaft und Kommerz auf der anderen Seite läßt sich vielleicht auch weniger adversativ sehen: die massenhafte Verbreitung surrealistischer Produkte, Techniken und Gedanken kann vielmehr als Chance, die wissenschaftliche Beschäftigung mit ihnen als Möglichkeit aufgefaßt werden, ihr Verständnis kritisch zu fördern und eventuell ihre Wirkung zu vertiefen.

Die Literaturwissenschaft - um beim eigenen Leisten zu bleiben - braucht sich nicht auf bloßes Beschreiben und Etiketten-Kleben zu beschränken, sie kann auch und im Hinblick auf den Surrealismus ist dies sogar der einzig gangbare Weg - den Leser an die Literatur sheranführen. (nicht umgekehrt!), ihn zu aktiver, produktiver Rezeption anregen. Wenn sie ihn da Sinn konstituieren lehrt, wo zunächst Fremdes, Unverständliches zum Sprechen gebracht werden muß, dann könnte sie, falls sie es überhaupt für sinnvoll hält, in aller Bescheidenheit durchaus mithelfen, das Ziel des Surrealismus zu erreichen: die Erweiterung des menschlichen Bewußteins über die ihm von Positivismus, Rationalismus und der darauf beruhenden Gesellschaftsverfassung gesetzten Grenzen hinaus zur revolutionären Veränderung des Lebens in allen seinen Bereichen.

Auf dem Weg zu diesem Ziel haben nicht wenige Surrealisten extremere Wege gewählt als das Haupt der Bewegung, A. Breton; sei es, daß sie aus Aggression gegen die ihre Selbstverwirklichung verweigernde Gesellschaft mit Selbstzerstörung oder Wahnsinn reagierten, sei es, daß sie ihr Können bedingungslos in den Dienst einer politischen Partei stellten. Breton versucht sich dagegen, mit kurzen Abstechern bzw. Ausrutschern hierhin und dahin, begleitet von einer stark fluktuierenden und dann und wann durch Säuberungen dezimierten, aber immer wieder erneuerten Schar von 
Freunden, auf dem schmalen Grat zwischen absolutem Nonkonformismus und Konformismus zu behaupten.

Breton ist allerdings nur eine Spitze des abwechslungs- und facettenreichen Massivs von Autoren, das sich aus sehr unterschiedlichen poetischen, künstlerischen und politischen Meinungen und Aktivitäten aufbaut. Die Vielfalt surrealistischer Tätigkeit und der Schwung ihres subversiven und innovatorischen Potentials werden, will man sich nicht an die gigantische Arbeit einer Gesamtinterpretation der Einzelwerke wagen, noch am ehesten erkennbar in der Reihe der wichtigsten Zeitschriften der Bewegung, wie Littérature (1919-1924), La Révolution surréaliste (1924-1929), Le Surréalisme au service de la révolution (1929-1933), die allerdings noch einer umfassenden und systematischen Erschließung harren.

Beides, der Gesamtüberblick über surrealistische Werke und über die Produktion der surrealistischen Zeitschriften, ist im Rahmen eines Aufsatzes nicht möglich. Es kann auch nicht darum gehen, die gesamte turbulente Geschichte der Bewegung nachzuzeichnen - das ist bereits material- und anekdotenreich durch M. Sanouillet und M. Nadeau geschehen - noch darum, einzelne Autoren auch nur annähernd serschöpfend ‘ zu behandeln oder das in sich widersprüchliche Gedankengebäude, die ,Philosophie des Surrealismus, mit ihren Anleihen bei der Psychoanalyse, der Parapsychologie, Astrologie, Philosophie und Politökonomie zu zergliedern. Die erzwungene Bescheidenheit legt es nahe, aus ihr eine Tugend zu machen und von einem einzigen zentralen literaturwissenschaftlichen Gesichtspunkt aus ein erhellendes Licht auf einige wesentliche Bestandteile surrealistischer Theorie und Praxis zu werfen: auf die Produktion ("écriture automatique ") und Funktion des surrealistischen Bildes als konsequente, bis ins Extrem getriebene Verwirklichung des metaphorischen Prozesses; auf seine Verwandtschaft mit Formen der literarischen Makrostruktur und der bildenden Kunst (Collage) sowie mit der surrealistischen Einstellung zum Leben ("hasard objectif ", "trouvaille", " amour fou « etc.).

Für eine historisch-soziologische Betrachtung eignet sich der Surrealismus aus zwei Gründen besonders gut. Erstens ist der Zeitbezug oft expressis verbis gegeben, er muß nicht rekonstruiert werden aus sogenannten zeitlosen oder historisierenden Themen. Die unmittelbare Gegenwart der Autoren mit ihren privaten, sozialen, politischen und künstlerischen Ereignissen und ihrer bewußten und unbewußten Verarbeitung liefert den Surrealisten die Themen ihrer Texte. Zum zweiten wird der Vorgang der ästhetischen Vermittlung eben dieser Erfahrungen vornehmlich mit Hilfe des surrealistischen Bildes in diesen Texten selbst fortgesetzt reflektiert. Der Zusammenhang zwischen dem ästhetischen Verfahren und dem Weltmodell des Autors muß in surrealistischen Werken nicht erst mühsam erschlossen werden, etwa als Analogie zwischen Form und Inhalt, sondern dieses ästhetische Verfahren ist erklärtermaßen schon das Weltmodell, die Form ist der Inhalt. Der metaphorische Prozeß, als besondere Art der Erkenntnismöglichkeit, wird von den Surrealisten in verschiedensten mikro- und makrostrukturellen Formen verabsolutiert: in der kühnen s surrealistischen Metapher, dem surrealistischen Bild, der Textcollage etc. Dieser metaphorische Prozeß, die Surrealisten nennen ihn Poesie, zeichnet sich aber dadurch aus, daß er neue Erkenntnisse über Wirklichkeit nur über den Ab- und Umbau schon 
bestehender sprachlicher oder bildlicher Weltmodelle und konventioneller Handlungsmodelle gewinnt. Er ist eine Art permanenter, imaginativer, vom Unbewußten, nicht von wissenschaftlicher Theorie ausgehender Ideologiekritik.

Die zerstörerische Seite des metaphorischen Prozesses hat dem Surrealismus (wie übrigens auch Rimbaud oder Lautréamont) den Vorwurf eingebracht, er bleibe auf der Stufe der bloßen Negativität stehen, er leiste nicht die dialektische Synthese, die zum Handeln und damit zu wirklichen Veränderungen der Realität führen könnte (Sartre [1]). Doch ist der Rezipient aufgerufen, die Synthese zu wagen: die Poesie unterscheidet sich eben darin von anderen, vorgedachten Systemen wie Philosophie oder Politökonomie, daß sie unabgeschlossen, offen und auf die Mitarbeit des Rezipienten angewiesen bleibt. Der Surrealismus liefert sozusagen nur das Rezept, höchstens Halbfabrikate, jedoch keine Fertigprodukte. Die folgenden Ausführungen sollen dazu beitragen, dem Leser das ,Verfertigen des Werks beim Lesen $z u$ erleichtern.

\section{Ziele des Surrealismus}

Das Surrealistische Manifest [2] von 1924 beginnt nicht etwa mit Überlegungen für und wider alte oder neue Kunst und Literatur, sondern mit einer Situationsbeschreibung des modernen Menschen. Breton setzt an der Realität des zeitgenössischen Lebens an und nicht an einer Kunsttheorie. In Abwandlung des Sprichwortes vom Krug, der nicht ewig zum Brunnen geht, stellt er fest: "Der Glaube [des Kindes an die unbegrenzten Möglichkeiten des Menschen] geht so lange zum Leben, zu dem, was das Leben an Vergänglichstem hat, nämlich das reale Leben, versteht sich, bis dieser Glaube verloren geht. “ (Manifestes, S. 11) Bis zum Eintritt in das Leben der Erwachsenen und des Gelderwerbs hat die Sozialisationsmaschinerie den Menschen zu einer "großen Bescheidenheit" erzogen, d.h. er hat seine Freiheit und seine Illusionen den angeblichen Zwängen eines willkürlichen Nützlichkeitsdenkens und dem sklavischen Streben nach sogenanntem Glück und Erfolg aufgeopfert. Gleichzeitig wird sein Leben immer sinnloser, die Fähigkeit zur Liebe erlischt; schließlich bleiben als Reste und Ahnungen eines reicheren, freieren Lebens nur noch die Erinnerung an den Zauber der Kindheit bzw. die Flucht in den Traum oder den Wahnsinn. Das Herzstück dieser bürgerlichen Sozialisation ist die Unterdrückung und Zähmung der Imagination zugunsten rationalistischer und utilitaristischer Logik. An diesem Punkt muß daher nach Breton auch der Versuch einer Veränderung ansetzen:

La seule imagination me rend compte de ce qui peut être, et c'est assez pour lever un peu le terrible interdit; assez pour que je m'abandonne à elle sans crainte de me tromper (comme si l'on pouvait se tromper d'avantage). (Manifestes, S. 13)

In den Augen Bretons stellt die realistische Literatur, als eine der angeblichen Domänen der Imagination, verglichen mit dieser im weitesten Sinne poetischen Fähigkeit des Menschen nur eine beschreibende Wiederholung dessen dar, was als Folge des herrschenden " Positivismus «, der " Mittelmäßigkeit ", des absoluten Ratio- 
nalismus und des "bon sens " bereits besteht.[3] Sie reduziert alles Unbekannte auf schon Bekanntes, indem sie "jede Art der Wahrheitssuche, die nicht der üblichen entspricht, ächtet " (Manifestes, S. 19). Daher bleiben neben der Poesie lediglich der Traum und der Wahnsinn als letzte Refugien der menschlichen Einbildungskraft. Breton erhofft sich bei der Auslotung der "Tiefen unseres Geistes ", in die sich die Imagination geflüchtet hat, und bei der Befreiung des menschlichen Denkens und Handelns Hilfe von der Psychoanalyse, die er als eine Art der Vernunftkontrolle unterworfenes Dichten begreift (Manifestes, S. 19). Dichten und Träumen können seiner Meinung nach einen wesentlichen Beitrag zur "Lösung der fundamentalen Fragen des Lebens « (Manifestes, S. 21/2) leisten. In der Versöhnung von Traum und Leben sieht Breton seine Lebensaufgabe; entsprechend formuliert er sein Glaubensbekenntnis:

Je crois à la résolution future de ces deux états, en apparence si contradictoires, que sont le rêve et la réalité, en une sorte de réalité absolue, de surréalité, si l'on pu .it ainsi dire. (Manifestes, S. 23/4)

Im Gegensatz zu Bergson und Valéry beruht aber die Erkenntnis und Gestaltung dieser zukünftigen Surrealität (Über-Wirklichkeit) nicht auf besonderer Begabung oder gar auf angestrengter Arbeit; im Gegenteil, jeder Mensch hat die Möglichkeit, wenn er nur dazu bereit ist, zu den in ihm liegenden, aber verschütteten Quellen des Unbewußten zurückzugehen. Es liegt an jedem einzelnen selbst, ob er dieses Ziel erreicht oder nicht, er braucht nur die neue Heilslehre, die Poesie, zu praktizieren:

L'homme propose et dispose [i. G. zu: Der Mensch denkt - Gott lenkt]. Il ne tient qu'à lui de s'appartenir tout entier, c'est-à-dire de maintenir à l'état anarchique la bande chaque jour plus redoutable de ses désirs. La poésie le lui enseigne. Elle porte en elle la compensation parfaite des misères que nous endurons. Elle peut être une ordonnatrice, aussi, pour peu que sous le coup d'une déception moins intime on s'avise de la prendre au tragique. Le temps vienne où elle décrète la fin de l'argent et rompe seule le pain du ciel pour la terre! Il y aura encore des assemblées sur les places publiques, et des mouvements auxquels vous n'avez pas espéré prendre part. Adieu les sélections absurdes, les rêves de gouffre, les rivalités, les longues patiences, la fuite des saisons, l'ordre artificiel des idées, la rampe du danger, le temps pour tout! Qu'on se donne seulement la peine de pratiquer la poésie. (Manifestes, S. 28)

Poesie ist also für Breton keine literarische Gattung, sondern eine umfassende menschliche Tätigkeit (Poiesis), die das ganze Leben umgestaltet; die Perspektive einer Veränderung des herrschenden Wirtschaftssystems erscheint dann nicht mehr ganz so weit hergeholt.

Diese Auffassung von Kunst erinnert teilweise an $\mathrm{H}$. Bergson, Breton radikalisiert und demokratisiert r aber seinen Ansatz. Für H. Bergson fallen Kunst und praktische Lebensbewältigung auseinander. Die Lebensbewältigung ist dadurch gekennzeichnet, daß der Mensch, um überhaupt existieren zu können, seine Wahrnehmungsund Denkweisen selektiv auf das für ihn Nützliche beschränken muß, so daß er alles nur wie durch einen Filter, nämlich den der rational-utilitaristischen Logik zu sehen vermag. Nur eine Laune der Natur ("par distraction") erlaubt es immer 
wieder einigen wenigen auserwählten Individuen, sich vom bloßen Leben so weit zu lösen, daß sie hinter diesen Schleier zu sehen vermögen und dort eine unendlich weitere, reichere Welt, die "Wirklichkeit selbst " erblicken.[4] A. Breton übernimmt die Überzeugung, daß es eine reale und erst zu erfindende höherwertige Realität gibt, die über die Zweckrationalität des Alltagslebens hinausgeht. Bei H. Bergson haben beide, Kunst und Leben, ihre Berechtigung, wobei Kunst das Umfassendere ist. Das beschränkte Leben ist die Existenzgrundlage der Kunst, die eine Veranstaltung für wenige, für eine Elite bleibt. Für Breton ist dieses reichere Leben keine Ausnahme, sondern das gemeinsame Erbe aller, die praktische Lebensbewältigung ist für ihn nicht die Grundlage, sondern der Tod der Poesie. Für ihn ist das aller Trennung von Kunst und Leben vorausgehende "wahre Leben " (Manifestes, S. 3), sozusagen das ursprüngliche, natürliche Lebenselement des Menschen, das es nur zu aktivieren gilt, um die Fehlentwicklung zu korrigieren, während Bergson mit seiner Sicht der Dinge im Gegenteil die Trennung der Kunst vom Leben als natürlich und notwendig darstellt.

\section{Surrealismus und ,Autonomie der Kunst}

Gerade dieser Autonomie-Status der bürgerlichen Kunst zeigt für H. Marcuse [5] zusammen mit ihrer gesellschaftlichen Wirkungslosigkeit nur die zwei Seiten der gleichen Medaille, denn die Herauslösung aus der zweckrational durchorganisierten bürgerlichen Gesellschaft ist die Voraussetzung für die Freiheit ihrer Welt des schönen Scheins. Doch ist dies die Freiheit einer gesellschaftlichen Randexistenz als elitäre Sonntags- und Feierabend-Veranstaltung zur Erholung vom sprosaischen alltäglichen Leben, das sie poetisch verklärt. Eine solche Funktionsbestimmung macht auf den ambivalenten ideologischen Charakter des Begriffs 'Autonomie der Kunst ‘ aufmerksam. Denn dadurch daß die Kunst "residuale Bedürfnisse « [6] nach einem humaneren Leben (schein-)befriedigt, die in der gesellschaftlichen Realität nicht zu ihrem Recht kommen, transzendiert sie die glücklose Gegenwart nicht nur kritisch, sondern sie stabilisiert und affirmiert auch das Bestehende. 'Tatsächlich erfüllt also diese rautonomer Kunst in der bürgerlichen Gesellschaft eine wichtige soziale und ordnungspolitische Funktion. Sie spiegelt den Kunstbeflissenen Reiche der Freiheit und Solidarität vor in einer Welt des Zwangs und der Konkurrenz, zweckloses Spiel in einer Welt durchrationalisierter Zweckmäßigkeit. Selbst wenn sie seit dem späteren 19. Jh. meist nicht mehr so weit geht, ihren Lesern eine Welt des Glücks und der Harmonie auszumalen, so flüchtet sie sich im Ästhetizismus in die Idealität der vollendeten Form. Will sie ihre affirmative Vereinnahmung mit einiger Aussicht auf Erfolg verhindern, so bleibt der modernen Kunst anscheinend nur die konsequente Negativität (Adorno). Kunst bewegt sich so in einem Teufelskreis: will sie zu einer glücklicheren Welt beitragen, so muß sie sich von den Zwecken, von den Wahrnehmungs- und Denkschemata, von der Sprache der herrschenden Zweckrationalität lösen; löst sie sich, so bürgert sie sich selbst aus und wird nicht mehr ernst genommen, ja sie befestigt als Ersatzbefriedigung ungestillter Bedürfnisse (un-)freiwillig deren 
Repression. Nach P. Bürger [7] ist es nun das Verdienst der "historischen Avantgardebewegungen ", diesen aporetischen [8] Zusammenhang zwischen Autonomie und Folgenlosigkeit wenn auch nicht überwunden, so doch offengelegt und damit die "Selbstkritik der Kunst « ermöglicht zu haben.

Versuchen die Surrealisten, die durch den Ästhetizismus aufgerissene Kluft zwischen Kunst und Leben zu überwinden und aus dem oben beschriebenen Teufelskreis auszubrechen, kurz: Poesie zu leben, dann muß ein solches Unterfangen aus der Perspektive der Heteronomie-Autonomie-Diskussion den leider nur bei Münchhausen von Erfolg gekrönten Anstrengungen im Sumpf gleichen ... Nicht nur weil Kunst sich in dieser Sicht notwendig selbst vom Leben scheidet, sondern auch weil Kunst in der bürgerlichen Gesellschaft nur noch unter der Annahme rezipiert wird, sie sei tatsächlich autonom. Wurde und wird so die reale gesellschaftliche Funktion der surrealistischen Werke auch von der bürgerlichen "Institution Kunst(Autonomie) " bestimmt, so braucht das jedoch nicht zu heißen, daß der Begriff der Institution Kunst als von der Lebenspraxis abgehobener auch noch heute, nach den Erfahrungen der Avantgarde, die zutreffendste wissenschaftliche Kategorie für eine Beschäftigung mit dem Phänomen des Surrealismus abgibt.

Konstatiert man nämlich das Scheitern des surrealistischen Versuchs, Kunst in Leben zu überführen [9], so tut man den Surrealisten Unrecht, da sie sich diese Aufgabe in dieser Form nie gestellt haben. Sie wollten dem Leben seinen ursprünglichen, immer noch vorhandenen, aber verdrängten Reichtum zurückgeben und griffen dabei unter anderem auf die Möglichkeiten der Kunst zurück, die aber nur einen Teil ihrer umfassenden Poesie ausmacht. Sie erkannten vor manchen ihrer Kritiker die Vergeblichkeit des Unterfangens, Kunst im traditionellen Sinn in Praxis zu überführen, und schnitten die Münchhausen'sche 'Aufstiegshilfe`, den salten Zopf, der Kunst, schlankweg ab. Darauf weist die Tatsache hin, daß sie ihre Vorbilder und Heiligen nicht nach künstlerisch-literarischen Kriterien aussuchten, sondern nach dem 'poetischen< Lebensstil [10]:

La poésie écrite perd de jour en jour sa raison d'être. Si des œuvres comme celles de Ducasse, de Rimbaud, de Nouveau, jouissent de ce prestige sur les jeunes, pour commencer c'est que ces auteurs n'ont pas fait profession d'écrire [...] C'est que leur attitude en tant qu'hommes laisse loin leurs mérites d'écrivains et que seule cette attitude donne son sens véritable à leur œuvre, telle que nous l'admirons.

Jegliche Theorie sollte, um ein Phänomen angemessen beurteilen zu können, in ihren Kategorien aus "Einsicht in den Zusammenhang zwischen der Entfaltung des Gegenstandes und der Kategorien einer Wissenschaft " [11] möglichst über den Stand der theoretischen Diskussion zur Zeit des Phänomens hinausgehen.[12] Der Begriff der Autonomie der Kunst stammt nun vornehmlich aus der theoretischen Diskussion des späten 18. Jh. (Kant, Schiller) und kam in der künstlerischen Praxis des Ästhetizismus zu seiner vollen Entfaltung. Er ist aber, wie P. Bürger mehrfach feststellt [13], ein historisch bedingter und ideologisch verzerrender Begriff, der zwar die Emanzipation der Künste von kultischen und höfisch-repräsentativen Funktionen richtig sieht, aber zweierlei verschweigt: 1) Er verschleiert, daß auch autonome Kunst nach wie 
vor von der bürgerlichen Gesellschaft in Dienst genommen bleibt. Das beweist die von ihr geleistete Befriedigung residualer Bedürfnisse; und die juristische und politische Verfolgung der Kunst, wenn sie zu autonom und vielleicht sogar wirkungsvoll wird; 2) er verkennt, daß auch die religiös und höfisch gebundene Kunst relativ autonom war. Um nur ein Beispiel zu nennen: Selbst als ’bloße Illustration ‘ biblischer Texte [14] oder christlicher Glaubenslehren war die bildliche Darstellung und auch die erbauliche Literatur bei der Darstellung des Irrealen und Überirdischen gezwungen, weit über die `Vorlage hinauszugehen.[15] (Außerdem hatte auch die religiöse Kunst Anteil am ambivalenten ideologischen Charakter der Religion selbst zwischen affirmativer Vertröstung und kritischem Vorschein.) Auch die höfische Kunst bot nicht nur Idealisierung, sondern außerdem Kontrast zur Wirklichkeit. Seit und trotz ihrer Emanzipation von der kultischen und repräsentativen Funktion übernimmt die Kunst die ideologische, ambivalente Funktion der inzwischen zurückgewiesenen Religion sozusagen in eigener, säkularisierter Regie. Ein Indiz dafür, die Anlehnung an religiöse Lebensformen und Ausdrucksweisen, läßt sich nicht nur bei den Surrealisten beobachten.[16]

Fassen wir kurz zusammen: Bei der Erklärung des Phänomens Surrealismus, der sich mit der Vorstellung von einer 'Autonomie der Kunst ' gar nicht auseinandersetzt, weil sie aus seiner Sicht der Dinge irrelevant ist, scheint ein solcher Begriff mindestens ebensoviel zu verbergen, wie er erklärt. Damit soll nicht geleugnet werden, daß tatsächlich erst der im Ästhetizismus konsequent bis auf die Spitze getriebene Versuch, die ,Autonomie der Kunst zu verwirklichen, die Möglichkeit eröffnete zu erkennen, daß auch die angeblich absoluteste und autonomste Kunst nicht völlig autonom sein kann und notwendig an die Wirklichkeit gebunden bleibt: "Die Freiheit der Kunstwerke, deren ihr Selbstbewußtsein sich rühmt und ohne die sie nicht wären, ist die List ihrer eigenen Vernunft. Alle ihre Elemente ketten sie an das, was zu überfliegen ihr Glück ausmacht und worein sie in jedem Augenblick abermals zu versinken drohen. «[17] Die von der Kunst erreichte Entwicklungsstufe ermöglicht aber eine neue Sicht des Verhältnisses von Kunst und Gesellschaft, in der der Gegensatz Heteronomie - Autonomie nicht mehr im Vordergrund steht. Sowohl der Begriff >Autonomie der Kunst ‘ als auch die Begriffe 'Affirmation und 'Kritik sind Versuche, produktive und rezeptive ästhetische Betätigung im Wandel der historischen Erscheinungsformen ihrer gesellschaftlichen Funktionen von außen zu erfassen. Sie bezeichnen eher die Forderungen, die die Gesellschaft nach dem Muster ihrer sonstigen unmittelbar zweckbestimmten Tätigkeiten je nach Entwicklungsstufe an die Kunst heranträgt, als den Beitrag, den die Kunst als ganz spezifische, nicht auf direkte Verwertbarkeit angelegte menschliche Tätigkeit von sich aus für die Gesellschaft zu leisten fähig ist. Es geht nun darum, Kategorien zu finden, die sowohl der Abhängigkeit der Kunst von der Wirklichkeit und von der Gesellschaft als auch ihrer relativen Unabhängigkeit Rechnung tragen. Statt von soziologischen Begriffen auszugehen, die auf das sich gegen ganz bestimmte historische, äußere gesellschaftliche Zwänge auflehnende Bewußtsein des Künstlers zurückgehen, bietet sich für die Literaturwissenschaft im Falle der modernen Poesie und speziell des Surrealismus der Weg an, von der künstlerischen Technik auszugehen, um von da aus die spezifische 
Leistungsfähigkeit von Kunst für die Gesellschaft in einem historischen Augenblick zu ermitteln.

Die notorische Unverständlichkeit moderner Poesie, darunter wären auch die surrealistischen Texte (nicht die diskursiven oder theoretischen Texte der Surrealisten) zu rechnen, gibt den entscheidenden Fingerzeig. Obwohl meist das einzelne Wort bekannt, die Syntax eingehalten ist, ergibt der Gesamttext keinen unmittelbar einsichtigen Sinn. Die Illusion einer Wirklichkeitsbeschreibung mit dem gewohnten Kausalzusammenhang, wie er seither auch für die fiktionale Wirklichkeit galt, wird zerstört. Dadurch wird zum einen der fiktive, nur auf einem konventionellen Betrachtungsmodus ruhende Charakter der seither gültigen, angeblich wirklichen Ereignisverkettung offenbar, zum anderen werden auf der Basis der desartikulierten Einheit von Wirklichkeit deren Elemente zu einem neuen Ganzen kombiniert und der Leser zu einer veränderten Bedeutungsfindung anhand dieser UmBeschreibung von Wirklichkeit angeregt. Eine solche Art Modellierung von Wirklichkeit war schon immer die spezifische Leistung von Kunst, das Avantgardistische des Surrealismus liegt nun darin, den Vorgang radikalisiert, ja verabsolutiert zu haben.[18]

Der bürgerliche Künstler des 19. Jh. konnte sich noch in der Illusion wiegen, mit der äußerlichen Emanzipation vom Kirchen- und Fürstendienst, mit einer konsequent subjektiven Wirklichkeitsmodellierung den entscheidenden Schritt zur kunstadäquaten Ausdrucksweise getan, den Zufall abgeschafft, die eigene, ohne Kaiser und ohne Gott auskommende Wirklichkeit eigenmächtig geschaffen zu haben. Flaubert, Mallarmé, Proust und Valéry versuchen als legitime Fortsetzer von Rationalismus und Positivismus, die bestehende Wirklichkeit distanziert darzustellen bzw. eine neue Wirklichkeit kraft ihres eigenen Intellekts und Kunstvermögens zu erzwingen. Allerdings um den Preis einer elitären Isolierung dieser ästhetischen Kunstwelt von der lebensweltlichen Wirklichkeit bzw. einer privaten Ästhetisierung ihres Lebens. Sie können ihre Kunst daher ohne weiteres mit einem mehr oder weniger konformistischen bürgerlichen Leben verbinden. Dagegen gibt es seit der Romantik Künstler, die das zukünftige Heil der Menschheit nicht von einer Steigerung des Rationalismus, einer dauernden Verfeinerung von Zivilisation und Kultur erhoffen, sondern von der Entfesselung der ungenutzten, unterdrückten und verdrängten irrationalen Kräfte, von der Rückverwandlung von Kultur in Natur.[19] Statt den Zufall abschaffen zu wollen, suchen ihn die Surrealisten mit Sinn zu erfüllen; statt nur von einer ästhetisch anders erfaßten Wirklichkeit zu schreiben, versucht Rimbaud anders zu leben; Lautréamont erhebt die Forderung nach einer Demokratisierung der Poesie statt elitärer Überhebung; an die Stelle idealistischer Vergöttlichung des Dichters tritt die Versenkung in die Materialität des Wirklichen. Im Gegensatz zum Äthetizismus erstrebt der Surrealismus nicht den subjektiven Gegenentwurf zur schlechten, unvollkommenen Wirklichkeit, sondern er versucht, die Totalität des Wirklichen zu erfassen und zu deuten, indem er die einseitig rationalistische Betrachtung und Wiedergabe von Wirklichkeit überwindet und sämtliche, auch die verschütteten Lebenskräfte reaktiviert. Die Rückwendung zum Irrationalen soll also keine Lösung von der Wirklichkeit, sondern eine stärkere Bindung an sie bewirken und zu einer verfeiner- 
ten Erkenntnis ihrer Beweggründe verhelfen; daher heißt die daraus entstehende Bewegung auch nicht Irrealismus, sondern Surrealismus.

Der Ästhetizismus ersetzt mit Hilfe metaphorischen Um-Denkens und UmBeschreibens eine Weltsicht durch eine andere, gehorcht aber im Grunde den gleichen rationalistischen Gesetzen, denn der metaphorische Prozeß wird sofort der bewußten, zielgerichteten künstlerischen Arbeit unterworfen. Mallarmé und Valéry machen den Mangel an konventioneller Kontiguität, der poetischen Texten auf Grund der Zerstörung traditioneller Begriffs- und Ereignisverkettung im metaphorischen Prozeß eigen ist, durch eine erhöhte formale, semantisierbare Strukturierung wett und schaffen geschlossene, runde Kunstwerke. Ihre Weltsicht distanziert sich dadurch kritisch vom Bestehenden, sie bietet ein komprimiertes, unendlich differenzierteres Bild von der Wirklichkeit, aber auch wieder ein relativ fertiges, vom Künstler entworfenes. Der Surrealismus befreit das poetische Prinzip auch von diesen letzten selbst und mit Bedacht gewählten Fesseln, dehnt das früher allein der Poesie vorbehaltene metaphorische Prinzip auf narrative Texte, ja auf die Lebensgestaltung aus und setzt es dadurch absolut, daß er die Strukturierung dem Unbewußten, dem "wahren Leben « überläßt. Denn ohne jegliche Struktur wäre auch keine Kommunikation möglich, ihre systematische Verweigerung wäre das Ende der Kunst. Nach Meinung Bretons braucht sie aber nicht künstlich erzeugt zu werden, sondern sie entsteht mit Hilfe der aus dem Unbewußten befreiten Imagination automatisch. Ihr Verständnis bedarf aber durchaus der rationalen Durchdringung, ähnlich der psychoanalytischen Traumdeutung.

Im folgenden werden wir uns weniger einer psychoanalytischen oder parapsychologischen [20] Erklärung der surrealistischen Metaphorik bedienen, als in Anlehnung an P. Ricœur [21] eine sprach- und literaturwissenschaftliche Perspektive einnehmen. Dabei wird sich zeigen, daß Bretons Theorie und Praxis nicht allgemein die Kunst ablehnt, sondern nur gegen bestimmte Kennzeichen bürgerlicher Kunst opponiert (Autonomie-Status, organisches Kunstwerk), von denen durchaus fraglich bleibt, ob sie wesentliche oder nur historisch akzidentielle Bestimmungen der Kunst betreffen. $\mathrm{Daß}$ sich Breton nicht grundsätzlich gegen die Kunst wendet, sondern im Gegenteil ihre Verfahren konsequent weiterentwickelt, macht der vorübergehend gemeinsame Weg und dann die Auseinandersetzung mit Dada deutlich.

\section{Surrealismus als Kunst}

Die geläufige Begriffsverbindung 'Dadaismus und Surrealismus nennt die zwei Bewegungen in einem Atemzug, so als handle es sich nur um zwei aufeinanderfolgende Phasen des gleichen Phänomens. Dabei bestehen trotz personaler Überschneidungen und der gemeinsamen Abneigung gegenüber dem konventionellen bürgerlichen Kunstbetrieb gravierende Unterschiede im angestrebten Ziel und folglich auch in der Wahl des Weges zu diesem Ziel. Für die unzulässige Vereinfachung ist schon bezeichnend, daß man an Dada - so lautet der richtige Name der 1916 von H. Ball, T. Tzara, M. Janco, H. Arp u.a. in Zürich gegründeten Bewegung - in 
dieser Begriffskoppelung ein zähmendes -ismus anzuhängen pflegt. Als mehr gelallter, denn artikulierter Kinderlaut wird 'dada‘, dieser Inbegriff des unernst Spielerischen, Anarchischen, dieser jeder Systematisierung und Katalogisierung bewußt widerstrebende Non-sens-Name durch unauffällige linguistische Suffixkosmetik auf die gleiche Ebene gestellt wie die Wortschöpfung Surrealismus, die sich mit ihrem bewußt quasi-wissenschaftlichen Duktus daneben wie das Produkt eines altväterlichen Präzeptors ausnimmt. In diesen beiden Namen ist die wesentliche Divergenz zwischen den beiden Bewegungen [22] schon sinnfällig ausgedrückt: hier spielerische, humorvolle bis bissige Zerstörungswut, die die Selbstaufhebung miteinbezieht und mit einem Salto mortale aus dem im Kunstbetrieb Gewohnten und Erwarteten herausspringt, dort der ernstgemeinte Anspruch auf eine Art Wissenschaftlichkeit, die, an literarische Traditionen anknüpfend, deren Überwindung in einer höheren Lebensform darstellen soll. Diese diametral entgegengesetzte Grundeinstellung gegenüber den (künstlerischen) Ausdrucksmitteln darf nicht aus den Augen verloren werden über dem zeitweilig gemeinsamen Weg und der vielfachen Personalunion zwischen den beiden Bewegungen, die immer wieder dazu führte, daßgrundsätzliche Divergenzen mit Kompromißformeln übertüncht wurden.

Auf das Skandalon des Ersten Weltkrieges, dieser anscheinend letzten Konsequenz des abendländischen Rationalismus und des technischen Fortschritts, die in der perfektionierten Organisation der gegenseitigen Massenvernichtung gipfelte [23], reagiert Dada mit anarchistischem Skandal. Nachdem alle Reform- und Verbesserungsversuche der bürgerlichen Gesellschaft im 19. Jh. als mehr oder minder gescheitert angesehen werden mußten , scheint den Dadaisten nur die vollständige Zerstörung dieser bürgerlichen Lebensform, einschließlich ihrer künstlerischen Äußerungen übrig zu bleiben. [24] Um die Zuschauer ihrer Manifestationen daran zu hindern, diese gleich wieder von ihrer Lebenswirklichkeit zu trennen und nur als interessante, unterhaltsame 'Kunst ‘ zu konsumieren, d. h. die dadaistische Kritik zur Wirkungslosigkeit zu verdammen, bleibt Dada nur die fortgesetzte Provokation.

Insofern haben die Dada-Aktionen über ihre in der Literatur- und Kunstgeschichtsschreibung beliebte anekdotische Auflockerungswirkung hinaus eine wesentliche Bedeutung innerhalb der Dada-Theorie. Diese "spectacles-provocations", die in Zürich, Berlin oder Paris etwa nach dem gleichen Schema abrollten, hatten den Vorteil, vergänglich, d. h. nicht als Kunstwerk fixiert zu sein. Auf Grund des unmittelbaren Kontaktes zwischen Zuschauer und ,Autoren , blieb der Akt der Rezeption kontrollierbar, konnte jede Tendenz zur affirmativen Vereinnahmung durch gezielte Provokation, Obszönitäten und Handgreiflichkeiten eingeschlossen, im Keim erstickt werden. Ein Beispiel soll kurz den Ablauf einer solchen Veranstaltung illustrieren [25]:

Réunis pour un spectacle d'art, pour une récitation de poèmes, les spectateurs, pleins de bonne volonté, étaient provoqués à toute force et poussés à éclater. Sur la scène on tapait sur des clés, des boîtes, pour faire de la musique, jusqu'à ce que le public protestât, devenu fou. Serner, au lieu de réciter ses poèmes, déposait un bouquet de fleurs au pied d'un mannequin de couturière. Une voix sous un immense chapeau en forme de pain de sucre disait des poèmes de Arp. Huelsenbeck hurlait ses poèmes, de plus en plus fort, pendant que Tzara frappait, en 
suivant le même rythme et le même crescendo, sur une grosse caisse. Huelsenbeck et Tzara dansaient avec des gloussements de jeunes ours, ou dans un sac, avec un tuyau sur la tête, se dandinaient en un exercice appelé noir cacadou. Tzara inventait des poèmes chimique et statique.

Der Unterschied zwischen Dada und Surrealismus zeigt sich auch in den theoretischen, "Manifest « genannten Äußerungen. Während Breton 1924 eine reine Buchausgabe vorlegte, ist Tzaras Manifest von 1916, das Anfang 1920 in Paris wiederaufgenommen wurde, ursprünglich eingebettet in eine öffentliche DadaAktion und umrahmt von Dada-Texten.[26] Durch diesen Kontext bekommt das Manifest einen ganz anderen Stellenwert. Dada wird nicht nur theoretisch abgehandelt, sondern praktisch vorgeführt. Einmal in der semantischen und grammatischen Struktur des Manifest-Textes selbst, zum anderen durch die enge Verbindung mit dem 'poetischen Kontext der das Manifest umgebenden Texte und zusätzlich noch durch die aktuelle Präsentation als "Theater " bzw. Cabaret im Kontrast zur Buchveröffentlichung.

In kontinuierlicher Selbstaufhebung wird im Manifest-Text als textstrukturierendes Grundprinzip jede Aussage sofort zurückgenommen und in ihr Gegenteil verkehrt: z.B. im Manifest Dada 1918:

J'écris ce manifeste pour montrer qu'on peut faire les actions opposées ensemble, dans une seule fraîche respiration; je suis contre l'action; pour la continuelle contradiction, pour l'affirmation aussi, je ne suis ni pour ni contre et je n'explique pas car je hais le bon sens.[27]

Die vergleichsweise logische und systematische Abhandlung der Surrealismustheorie im Surrealistischen Manifest, die sich selbst als neue Heilslehre sehr ernst nimmt, ist meilenweit entfernt von diesem nicht nur dargestellten, sondern noch zusätzlich szenisch vorgeführten Dada-Denken und Handeln. Der wesentliche Unterschied zu der in der literarischen Tradition stehenden Gruppe um Littérature (Breton, Aragon, Soupault) besteht darin, daß Dada Kunst und Literatur überhaupt abschaffen will, ohne deshalb aus dieser Destruktion wieder ein systematisch verfolgtes Ziel zu machen.[28]

\section{Manifeste du mouvement Dada}

Plus de peintres, plus de littérateurs, plus de musiciens, plus de sculpteurs, plus de religions, plus de républicains, plus de royalistes, plus d'impérialistes, plus d'anarchistes, plus de socialistes, plus de bolcheviques, plus de politiques, plus de prolétaires, plus de démocrates, plus de bourgeois, plus d'aristocrates, plus d'armées, plus de police, plus de patries, enfin assez de toutes ces imbécilités [sic], plus rien, plus rien, rien, rien, rien, rien.

De cette façon, nous espérons que la nouveauté qui sera la même chose que ce que nous ne voulons plus, s'imposera moins pourrie, moins égoïste, moins mercantile, moins obtuse, moins immensément grotesque.

Vivent les concubines et les concubistes. Tous les membres du Mouvement DADA sont présidents.[29]

Schon bevor Dada mit Tzara und dem ersten von der Zeitschrift Littérature veranstalteten Provokationsspektakel am 23. Jan. 1920 offiziell seinen Einzug in 
Paris hielt, war Breton mit J. Vaché befreundet, den er Anfang 1916 in Nantes kennengelernt hatte. J. Vaché, ein Dadaist avant la lettre, verkündete [30]: "L'art est une sottise." (9.5.18) oder

Donc nous n'aimons ni l'ART ni les artistes (à bas Apollinaire) [...] Nous ignorons MALLARMÉ, sans haine, mais il est mort - Nous ne connaissons plus Apollinaire - CAR - nous le soupçonnons de faire de l'art trop sciemment, de rafistoler du romantisme avec du fil téléphonique, et de ne pas savoir les dynamos. LES ASTRES encore décrochés! - c'est ennuyeux - et puis parfois ne parlent-ils pas sérieusement! - Un homme qui croit est curieux. MAIS PUISQUE QUELQUES-UNS SONT NÉS CABOTIN ... (18.8.1917)

In seinem Gefolge gibt sich auch Breton dada, behauptet, keinerlei literarischen Ehrgeiz zu besitzen und vor dem Dichtertum gerettet worden zu sein! ("Sans lui j'aurais peut-être été un poète ").[31]

Das einzige literarische Vorbild, das Vaché wirklich gelten ließ, war Jarry. Dieser faszinierte ihn jedoch weniger wegen seiner literarischen Produkte als deswegen, weil er sich halluzinatorisch mit seinen grotesken, humorvoll absurden Gestalten wie Ubu oder dem Doktor Faustroll bis zur Selbstaufgabe identifizierte. Statt wie ursprünglich geplant, Künstler zu werden, beschränkte sich Vaché darauf, provokativ als Dandy zu leben [32] (z. B. das Premierenpublikum von Apollinaires Mamelles de Tirésias, 1917, mit einer Pistole zu bedrohen) und mysteriös zu sterben: Laut Breton versuchte er aus ,Ulk ' zwei nichtsahnende Freunde mit in den Opium-Tod zu nehmen.

Dieser bis zur Selbstzerstörung kompromißlos dadaistischen Haltung konnte sich Breton, trotz aller Bewunderung für Vaché nie voll anschließen.

Je dois dire qu'il [Vaché] ne partageait pas mes enthousiasmes et que longtemps je suis resté pour lui le spohète،, quelqu'un à qui la leçon de l'époque n'a pas assez profité.[33]

Ähnlich geht es mit einem anderen großen Vorbild der Surrealisten, Marcel Duchamp. Dieser entschließt sich in den späten 20er Jahren, nachdem er auf dem Gebiet der bildenden Kunst und teilweise auch der Literatur [34] in kürzester Zeit und meist einige Jahre vor seinen Zeitgenossen die Entwicklung vom Kubismus bis zum Surrealismus durchlaufen hat, wobei er sie jeweils bis zu ihrem kritischen Punkt trieb, zur großen Enttäuschung Bretons [35] in Zukunft vornehmlich Schach zu spielen. Neben provokativen und kunst-destruktiven, schuf er auch äußerst sorgfältig konstruierte, die Assoziationstechnik Bretons vorwegnehmende Werke. Zu den ersten gehören sowohl die signierten industriellen Serienprodukte (Readymades: der Flaschenständer von 1914 und das als ,Fontaine bezeichnete Urinoir von 1917) als auch die inzwischen tausendfach wiederholte Verfremdung berühmter Gemälde (z. B. Leonardos Joconde mit Spitzbart und dem Untertitel L.H.O.O.Q. [Elle a chaud au cul]). Eine Art Summe der zweiten Gruppe bildet Duchamps unvollendetes Großes Glas (1915-1923) mit seinem surrealistischen Titel La mariée mise à nu par ses célibataires mêmes. Ohne hier auf eine detaillierte Deutung des Glasbildes eingehen zu können [36], soll die Verwandtschaft zur surrealistischen Assoziations- und Metapherntechnik kurz angedeutet werden.[37] Der eigenartige Titel spricht von einer 'Enthüllung, zwischen zwei in der Normalsprache unvereinbaren Begriffen "mariée « und "ses célibataires«. Jedoch auch im Bild erweisen sich inhaltlich 
anscheinend beziehungslos nebeneinander gesetzte Elemente, wie die Männischen Formen, die Schokoladenreibe als durch eine subtile Mechanik miteinander verbunden. Sie bilden mit den vielen einzelnen Vorstudien und den schriftlichen Äußerungen Duchamps zu diesem Werk eine konsequente Ikonographie, bewußt zueinander in Beziehung gesetzte Assoziationen, die Bezüge zur männlichen Sexualsphäre aufweisen und unüberbrückbar von der oberen Glashälfte mit ihren weiblichen Assoziationselementen getrennt bleiben. Die Bedeutung des Werkes liegt nicht auf einer vordergründigen 'realistischen ‘ abbildenden Ebene, sondern läßt sich erst auf dem Umweg über die Struktur und ihr kompliziertes Assoziationsgeflecht ermitteln: "A vrai dire, nous nous trouvons ici en présence d'une interprétation mécaniste, cynique, du phénomène amoureux. "[38] Mit seinem Entschluß, nur noch Schach zu spielen, bricht Duchamp eine über Dada hinausweisende Entwicklung schon ab, wie sie Breton erst für die Zukunft vorschwebte. Denn Breton zielte, mit einer kurzzeitigen Akzentverschiebung zur Dada-Zeit (ca. 1920-22) von Anfang an weiter als nur darauf, die abendländische Kultur im Gefolge des ersten Weltkrieges für bankrott zu erklären, die verlogene bürgerliche Moral mit ihren Idealen Vaterland, Familie und Religion zu entlarven und die schrankenlose Freiheit zu proklamieren. Er versucht Zeit seines Lebens einen schwierigen Kurs einzuhalten zwischen der Scylla bloßer Negation und auf die Dauer leerlaufender Provokation in der Art von Dada und der Charybdis eindeutig künstlerischer Aktivitäten, die Gefahr laufen, als autonome, vom Leben getrennte rezipiert zu werden. Trotz zeitweiliger Turbulenzen steuert er ein in groben Umrissen erkennbares, aber noch unbekanntes Ziel an, die Befreiung des Menschen von allen (unnötigen) Lebenszwängen, und auf diesem Weg sollten die Bemühungen nicht wirkungslos verpuffen.

Ce n'en serait pas moins une erreur de considérer l'art comme une fin. La doctrine de "l'art pour l'art " est aussi raisonnable qu'une doctrine de "la vie pour l'art " me semble insensée. On sait maintenant que la poésie doit mener quelque part.[39]

Il me semble que l'homologation d'une série d'actes "dada " les plus futiles est en train de compromettre, de façon grave, une des tentatives d'affranchissement auxquelles je demeure le plus attaché. Des idées, qui comptent parmi les meilleures, sont à la merci de leur trop prompte vulgarisation.[40]

Über zwei Unternehmungen Bretons, der Bewegung konstruktive Ziele zu setzen, kommt es zum Bruch mit Dada, d. h. mit Tzara und einigen Freunden. Breton meint es ernst mit dem fingierten Prozeß gegen den national-patriotischen Schriftsteller Barrès, während Tzara das Ganze ins Lächerliche zieht.[41] Ebenso ernst ist es Breton, so paradox es bei der pedantischen Formulierung des Themas auch scheinen mag, mit seinem 1922 geplanten Congrès pour la détermination des directives et la défense de l'esprit moderne, kurz Congrès de l'esprit moderne genannt. Der Kongreß scheitert unter dem Hohngelächter seiner ehemaligen Freunde.

Dernière heure. Les membres du Congrès du Modernisme, à la suite des menaces de quelques imposteurs perfides, ont décidé il y a quelques jours d'abandonner cette exellente idée de circuler comme les chiens en laisse entre les principes des célèbres théoriciens. Le Congrès meurt de nationalisme au chocolat, de vanité vanillée et de la bêtise presque suisse de quelques-uns de nos plus précis concitoyens.[42] 
Die Zeitschrift Littérature ist eine Art Chronik der frühen, einschließlich der dadaistischen Phase des Surrealismus.[43] Aus Dada-Perspektive erscheint der Titel post festum ironisch. Doch war die anfängliche Mitarbeit von anerkannten Größen des damaligen Literaturbetriebs wie Gide, Valéry oder Reverdy nicht nur ein Feigenblatt für literatur-subversive Tätigkeiten, sondern der Hang zum Seriös-Literarischen war echt, wenn er auch in der dadaistischen Phase immer wieder als von neuem einzudämmende Versuchung dargestellt wurde.[44] Nach dem Bruch mit Dada stellt Breton mit der Neuaufnahme von Littérature (Nouvelle Série) die Dada-Periode der Zeitschrift als eine Art Piratenakt Tzaras dar. [45] Um die Erfahrung der vorangegangenen Irrungen reicher, vermag er allerdings nun die Rolle der Literatur als Teil der von ihm angestrebten Lebenspoesie genauer zu definieren:

La littérature, dont plusieurs de mes amis et moi nous usons avec le mépris qu'on sait, n'est point traitée par nous comme une maladie (nous avons été obligés d'en passer par ces images grossières). J'écrirais, je ne ferais plus que cela, si, à la question: Pourquoi écrivez-vous? je pouvais répondre en toute certitude: J'écris, parce que c'est encore ce que je fais le mieux. Ce n'est pas le cas et je pense aussi que la poésie, qui est tout ce qui m'a jamais souri dans la littérature, émane davantage de la vie des hommes, écrivains ou non, que de ce qu'ils ont écrit ou de ce qu'on suppose qu'ils pouvaient écrire. Un grand malentendu nous guette ici, la vie, telle que je l'entends, n'étant pas même l'ensemble des actes finalement imputables à un individu, qu'il s'en soit ressenti pour l'échafaud ou le dictionnaire, mais la manière dont il semble avoir accepté l'inacceptable condition humaine. Cela ne va pas plus loin. C'est encore, je ne sais pourquoi, dans les domaines avoisinant la littérature et l'art que la vie, ainsi conçue, tend à son véritable accomplissement.[46]

Den Gründen, warum gerade das Poetische in Literatur und Kunst, d. h. ihre Bildlichkeit und die dieser zugrundeliegende Einbildungskraft der angestrebten Lebenspoesie am nächsten kommt, soll das nächste Kapitel gewidmet sein.

\section{Das surrealistische Bild und die automatische Schreibweise ("écriture automatique")}

Ursprung, Technik und erhoffte Wirkung des surrealistischen Bildes [47] nehmen eine zentrale Stellung in der surrealistischen Theorie ein. Das kann nicht verwundern, da sich ja nach ihr im Bild die Imagination, das poetisch schöpferische Vermögen des Menschen schlechthin, kristallisiert. Von ihr wird die Befreiung aus den Zwängen des bürgerlich zweckrationalen Denkens erwartet, nachdem die utopischen Hoffnungen, die das 19. Jh. in die auf dieses Denken gegründete Wissenschaft und Technik gesetzt hatte, enttäuscht worden waren. Diese hatten statt Fortschritt zur Freiheit die Versklavung in der Arbeit und den Massenmord des Krieges gebracht. In Aragons Paysan de Paris hält die Imagination eine großangelegte Propagandarede:

A la guerre comme à la guerre: vous tous avec votre façon de faire contre fortune bon cœur, vous aviez compté sans moi. D'une illusion à l'autre, vous retombez sans cesse à la merci de l'illusion Réalité. Je vous ai tout donné pourtant: la couleur bleue du ciel, les Pyramides, les automobiles. Qu'avez-vous à désespérer de ma lanterne magique? Je vous réserve une infinité de surprises infinies. [...] 
Aujourd'hui je vous apporte un stupéfiant venu des limites de la conscience, des frontières de l'abîme. Qu'avez-vous cherché jusqu'ici dans les drogues sinon un sentiment de puissance, une mégalomanie menteuse et le libre exercice de vos facultés dans le vide? Le produit que j'ai l'honneur de vous présenter procure tout cela, procure aussi d'immenses avantages inespérés, dépasse vos désirs, les suscite, vous fait accéder à des désirs nouveaux, insensés; n'en doutez pas, ce sont les ennemis de l'ordre qui mettent en circulation ce philtre d'absolu. Ils le passent secrètement sous les yeux des gardiens, sous la forme de livres, de poèmes. Le prétexte anodin de la littérature leur permet de vous donner à un prix défiant toute concurrence ce ferment mortel duquel il est grand temps de généraliser l'usage. C'est le génie en bouteille, la poésie en barre. Achetez, achetez la damnation de votre âme, vous allez enfin vous perdre, voici la machine à chavirer l'esprit. J'annonce au monde ce fait divers de première grandeur: un nouveau vice vient de naitre, un vertige de plus est donné à l'homme: le Surréalisme, fils de la frénésie et de l'ombre. Entrez entrez, c'est ici que commencent les royaumes de l'instantané.

$[\ldots]$

Le vice appelé Surréalisme est l'emploi déréglé et passionnel du stupéfiant image, ou plutôt de la provocation sans contrôle de l'image pour elle-même et pour ce qu'elle entraîne dans le domaine de la représentation de perturbations imprévisibles et de métamorphoses: car chaque image à chaque coup vous force à réviser tout l'Univers.[48]

Das surrealistische Lebenselixier, das Bild, ist also keine Frage des Willens oder der kunstvollen Verfertigung nach einem vorhergegebenen Plan, sondern eher einem Opiumrausch vergleichbar, der den Süchtigen mit Bildern überflutet. Doch braucht es für dieses "neue Laster " (Manifestes, S. 50) keine wirklichen Drogen, denn es ist allen kostenlos zugänglich, die sich nur dem ungefilterten Fluß ihrer Imagination überantworten. Im Gegensatz zum Kind, zum Wahnsinnigen, zum Träumer und unter Umständen auch dem Liebenden (allerdings nur, wenn er sich dem "Amour fou « überläßt) hat der durch die Sozialisation geschädigte normale bzw. wache Mensch, dessen Über-Ich nur noch nützliche Überlegungen und Handlungen zuläßt, jedoch Schwierigkeiten, diese Imagination, seine poetischen Fähigkeiten im weitesten Sinne, wieder zu beleben.

Zum Schlüsselerlebnis bei der Suche nach den verschütteten Quellen der Imagination wird für Breton ein Tagtraum, in dem sich ihm ein fertiger Satz geradezu aufdrängt und nach Art des ,Freien Assoziierens ‘ fortsetzt.[49] Das was Breton an dieser psychoanalytischen Technik besonders fasziniert, ist das Überlisten der zensierenden Vernunft, die als Handlanger des Über-Ich Sprache und Leben normiert. Das Ziel ist daher:

un monologue de débit aussi rapide que possible, sur lequel l'esprit critique du sujet ne fasse porter aucun jugement, qui ne s'embarrasse, par suite, d'aucune réticence, et qui soit aussi exactement que possible la pensée parlée. (Manifestes, S. 34)

Von einer solchen Technik des automatischen Schreibens ("écriture automatique") erhofft sich Breton wahre Wunderdinge. Der Automatismus dient nicht nur dazu, in der Art der Dadaisten das in Mißkredit geratene rationale Denken und die künstlerische Formung auszuschalten, sondern er soll über die bloße Befreiung von etwas hinaus auch noch eine positive Funktion erfüllen. Beide Momente der surrealistischen Tätigkeit, Zerstörung zweckrationaler und moralischer Zwänge und Zugang zu einem reicheren, freieren Leben, lassen sich deutlich in der berühmten Surrealismus-Definition unterscheiden: 
SuRRÉAliSme, n. m. Automatisme psychique pur par lequel on se propose d'exprimer, soit verbalement, soit par écrit, soit de toute autre manière, le fonctionnement réel de la pensée. Dictée de la pensée, en l'absence de tout contrôle exercé par la raison, en dehors de toute préoccupation esthétique ou morale.

ENCYCL. Philos. Le surréalisme repose sur la croyance à la réalité supérieure de certaines formes d'associations négligées jusqu'à lui, à la toute-puissance du rêve, au jeu désintéressé de la pensée. Il tend à ruiner définitivement tous les autres mécanismes psychiques et à se substituer à eux dans la résolution des principaux problèmes de la vie. (Manifestes, S. 37/8)

Obwohl sich Breton teilweise an die psychoanalytische Terminologie anlehnt und sich auf Freud beruft [50], sind die Unterschiede zwischen der automatischen Schreibweise und dem freien Assoziieren in der Analyse beträchtlich.[51] Das freie Assoziieren des Analysanden ist nur ein Mittel, das der Analytiker dazu verwendet, hinter dem manifesten Trauminhalt die latenten Traumgedanken interpretativ zu erschließen, keinesfalls der latente Traumgedanke oder das Unbewußte selbst ( fonctionnement réel de la pensée «). Es vermittelt ihm über den manifesten Trauminhalt hinaus zusätzliche Aufschlüsse über die unbewußten Abwehrmechanismen, die der Traumarbeit zugrundeliegen.[52] Die automatische Schreibweise erhebt dagegen in ihrer extremsten Ausprägung den manifesten Traum schon zum poetischen Endzweck.

Letztlich schwebte Breton wohl eine Art Selbstanalyse [53] mit Hilfe der automatischen Schreibweise vor, die nicht bei der bloßen Fixierung der Assoziationen stehenbliebe. Doch er sah schon im Second manifeste du surréalisme (1930), daß der wirklich praktizierte Automatismus sein Ziel kaum je erreichte und eher zur 'Mascher verkommen war.

[...] il faut avouer que leur [der automatischen Texte] intérêt a quelquefois peine à s'y soutenir ou qu'ils y font un peu trop l'effet de "morceaux de bravoure ". L'apparition d'un poncif indiscutable à l'intérieur de ces textes est aussi tout à fait préjudiciable à l'espèce de conversion que nous voulions opérer par eux. La faute en est à la très grande négligence de la plupart de leurs auteurs qui se satisfirent généralement de laisser courir la plume sur le papier sans observer le moins du monde ce qui se passait alors en eux - ce dédoublement étant pourtant plus facile à saisir et plus intéressant à considérer que celui de l'écriture réfléchie -, ou de rassembler d'une manière plus ou moins arbitraire des éléments oniriques destinés davantage à faire valoir leur pittoresque qu'à permettre d'apercevoir utilement leur jeu. (Manifestes, S. 115/6)

Doch bestand nicht nur die Gefahr, daß die automatische Schreibweise um die Möglichkeit einer eigentlich psychisch befreienden Wirkung gebracht wurde. Die noch vor der Selbstbeobachtung liegende Klippe, daß es zu gar keinem echten Automatismus, zu keinem wirklich freien Assoziieren kam, war bei Schriftstellern, die ihre Assoziationen nicht nur auf der Couch von sich gaben, sondern selbst schriftlich fixierten, mindestens ebensogroß. Breton erhob zwar gegenüber den Dichter-Ahnen des Surrealismus, die als "zu stolze Instrumente" zuviel literarischen Ehrgeiz entwickelten, den Anspruch, keinerlei rationale Filtrierung zuzulassen und rein maschinelles "Aufnahmegerät " für das "Echo" des Unbewußten zu sein [54], doch schon bei der Produktion der ersten automatischen Texte zusammen mit 
Soupault, den Champs magnétiques, zeigt sich das "Laster des Konstruierens" (Manifestes, S. 34). Starobinski spricht daher von einem "simulierten " Automatismus:

Man darf im automatischen Schreiben der Surrealisten ohne Zweifel einen aufrichtigen Versuch der Annäherung an die Spontaneität erkennen; aber im Verlauf dieser Suche griffen immer wieder eine wache Kontrolle und eine bewußte Überwachung ein, um jede zu starke Unterordnung unter die Regeln der gewöhnlichen Mitteilung zu verhüten. Eine Filtrierung war im Namen der dichterischen Qualität immer wirksam.[55]

Breton selbst hatte das Problem klar erkannt, als er im Message automatique (1953) feststellte:

Cette attitude [surrealistische Texte qualitativ zu beurteilen], instinctive de la part d'hommes exercés à l'appréciation de la valeur poétique, a eu pour conséquence fâcheuse de donner au sujet enregistreur prise immédiate sur chacune des parties du message enregistré. «[56]

Doch selbst wenn ein wirklicher Automatismus hätte gelingen können, bliebe immer noch zweifelhaft, ob er den Zugang zu einer » réalité supérieure «, einer ÜberRealität, eröffnet hätte. Unter teilweiser Anlehnung an parapsychologische Theorien stellt sich Breton unter dem Unterbewußten eine Art "Gnadenstand « eines von Rationalismus und Utilitarismus noch nicht verstümmelten Lebens, ein wertvolles "gemeinsames Erbe « [58] aller Menschen vor, das es nur wieder von den es verdekkenden Verkrustungen zu befreien gelte.

Geht man vom angestrebten Ziel - ob es je verwirklicht wurde, ist eine andere Frage - einer Fixierung freier Assoziationen und damit verbundener Selbstbeobachtung aus, so kann man ein solches Zurückgehen aufs Unbewußte nicht als bloße Regression einstufen und die davon erhoffte Bewußtseinserweiterung als parapsychologisches Erbe abtun. [59] Auch nach Freud führt der (allerdings durchgearbeitete analysierte) Traum zu einer Erweiterung des Bewußtseins (und damit eventuell zur Heilung einer neurotischen Störung). Nicht die ins Bewußtsein gehobenen Triebregungen selbst sind regressiv, sondern höchstens die Art ihrer Befriedigung. Außerdem enthält das Unbewußte nach Freud früher bewußte oder vorbewußte Elemente, die unter dem Einfluß des Über-Ich und/oder der Realität - allerdings nicht nur in den Augen der Surrealisten zu Unrecht - verdrängt wurden; so etwa die in der Kindheit noch aufleuchtenden "Möglichkeiten mehrerer Leben «, die von der Sozialisation abgewürgt und ins Unbewußte abgedrängt wurden. Schließlich umfaßt das Unbewußte auch nach Freud noch die an Jungs Archetypen erinnernde "archaische Erbschaft «.[60]

Zusammenfassend läßt sich feststellen, daß zu Anfang der automatischen Schreibweise sicher die "Reduktionsversuche" (Manifestes, S. 38), die Zerstörung konventioneller Bilder und des logischen, realistischen Diskurses im Vordergrund standen. Sie vertraute auf eine eher zufällige "Produktion der schönsten Bilder ", die den Schreiber einfach "überkamen" (Manifestes, S. 52). Bevor Breton noch den Anspruch auf Selbstanalyse richtig stellen konnte, der ihm wohl erst bei der eingehenderen Lektüre von Freud klar wurde, und bevor er das teilweise Scheitern eines solch 
hohen Anspruchs konstatierte, hatte das von ihm sonst eher beiläufig erwähnte Bedürfnis nach ästhetischer Qualität der Bilder eine Art Ersatz für die Selbstanalyse geschaffen. Schaut man sich nämlich Bretons surrealistische Texte an, so scheint die bloße Ansammlung mehr oder minder überraschender Bilder nur einen geringen Teil seines Schaffens darzustellen. Stattdessen läßt sich beobachten, daß selbst surrealistische Gedichte wie Rideaux oder Vigilance oder der Theater-Sketch S'il vous plait, von Nadja ganz zu schweigen, eine gewisse (Bild-)Struktur aufweisen. Diese später noch anhand einer Metapherntheorie zu explizierende Struktur gibt dem Leser die Möglichkeit, eine ähnliche synthetisierende und interpretative Leistung zu vollbringen wie der Analytiker, wenn er die ihm vom Analysanden gelieferten Elemente des Unbewußten (manifester Trauminhalt, freie Assoziationen, Fehlleistungen etc.) in einen sinnvollen Bezug setzt bzw. dem Patienten bei der Arbeit an der eigenen Bewußtseinserweiterung hilft. Eine solche ästhetisch-künstlerische Struktur - sei sie nun aus theoretischen Erwägungen von Breton erwünscht oder nicht - bietet den Schlüssel zu einer (dem Medium Kunst) adäquateren Bewußtseinserweiterung als nachträglich angehängte, 'wissenschaftliche، Analysen in Form von Postscripta.[61]

Bevor wir diese entwickelte surrealistische Bildtechnik untersuchen, soll kurz ein Beispiel für die frühe Phase der eher mechanisch als automatisch zu nennenden Assoziationstechnik vorgestellt werden.[62] Die beabsichtigte Störung der logischen Gedankengänge wird in den Champs magnétiques (1919) [63] durch die dialogische oder besser: doppelt monologische [64] Konstruktion gefördert, die die Assoziationsströme zweier Personen, A. Bretons und $\mathrm{Ph}$. Soupaults, wie zwei sich überlagernde »Magnetfelder « kombiniert.

Im Gegensatz zu anderen Texten aus der gleichen Sammlung verschmelzen in Barrières die Magnetfelder aber nicht zu einem einzigen, kommt es nicht zu einer Überwindung der "Schranken ", etwa mit Hilfe eines durchgehaltenen Themas, sondern von Abschnitt zu Abschnitt werden nur einzelne Stichwörter (von mir im Text kursiv hervorgehoben) [65], als "Sprungbrett " zu einem anderen Kontext wieder aufgenommen.

"Les histoires de brigands que vous avez recueillies pour notre plus grande joie ont cessé de nous intéresser. La chanson télégraphique que je viens d'entendre au bureau de poste charme les plus obscurs citoyens. Je passe mes journées devant ce buvard maculé et je lis les confidences des correspondants.

- L'équation de la pudeur des femmes est autrement difficile. J'ai rencontré une jeune fille qui portait $x^{2}+2$ ax sur son cœur. Cela lui allait à ravir.

- Vous m'en direz tant. Les animaux du Jardin des Plantes sucent plusieurs heures par jour du pain bis. J'ai eu la faiblesse d'aller les écouter. Sur les quais j'ai failli pleurer en saluant un remorqueur. La cheminée était rouge.

- Les rivières sont taries sur terre et dans les cieux. Les anciens naufrageurs ont la partie belle et vous voilà devant une cheminée endurcie qui n'apprivoise plus même les étincelles des forges!

- La fumée que le ciel abandonne tombe lentement vers quatre heures du soir en hiver: c'est la nuit. Mais toutes les étincelles des forges villageoises se perchent sur les réverbères.

- J'ai été souvent victime d'agressions nocturnes. Pour qu'on ne me retînt pas, je devenais pâle et balbutiais de petites étoiles dont on se contentait. Ceux qui prirent part tout l'hiver à des expéditions sans profit n'ont pas trouvé les jours si courts que vous le dites. 
- Les grandes avenues sont tristes en cette saison. Nous avions froid, quand brusquement la lumière d'une boutique de bijouterie nous enchaînait.

- De très bonne heure, nous avons été préparés à cette dure vie d'inaction et aujourd'hui les femmes pas plus que les bijoux ne nous endorment.

[...] [66]

(Breton hat am Rande notiert: "Porter au plus haut point le malentendu de la conversation. Voir ce qui en résulte. L'un des interlocuteurs écrit très vite quelques phrases. L'autre les lit très vite sans en prendre véritable connaissance. Il continue, de même. «[67])

Bis auf "l'équation de la pudeur des femmes " gibt es innerhalb der einzelnen, auch syntaktisch einwandfreien Sätze kaum schwerwiegende semantische Unvereinbarkeiten. Dagegen sind die einzelnen Sätze bzw. Abschnitte trotz zum Teil gleichlaufender wiederkehrender Wörter, die eine lose Kette von Reizwörtern bilden, weitgehend selbst ohne Zusammenhang. Ob hierbei das "Wunderbare " entsteht, das »immer schön ist " (Manifestes, S. 24) kann bezweifelt werden.

Ganz anders funktionalisiert wird die Dialogform in S'il vous plaît. [68] Dort dient der Dialog nicht mehr wie in dem angeführten Stück von Barrières nur zur willentlichen Zerstörung des semantischen Zusammenhangs, sondern die Interaktion von banalem Alltagsdialog und surrealistischen Antworten bzw. Einwürfen und Aufforderungen wird zum wesentlichen Handlungselement. Der Zuschauer des Stücks bekommt die Initiation der Sekretärin in surrealistische Denk-, Rede- und Verhaltensweise durch ihren Chef Letoile auf der Bühne vorexerziert. Sie lernt schnell, da sie sich in der "außergewöhnlichen Situation" (Manifestes, S. 12) der Verliebtheit befindet. Der Zusammenhang der Rede wird nur an der Oberfläche der Alltagssprache zerstört, nicht jedoch auf einer metaphorischen Ebene. Auf dieser erhalten auch die lose aneinandergereihten Szenen insgesamt eine Struktur und eine bestimmbare Bedeutung.[69]

Auch in La glace sans tain [70] läßt sich trotz kühner Metaphorik und unerwarteter Gedankensprünge ein einheitliches Thema ("atmosphère, voulue, communicative, du désespoir ") [71] ausmachen, das in etwa dem Beginn des Surrealistischen Manifestes entspricht: ein trostloser, toter und menschenunwürdiger Jetztzustand ("vie limitée", S. 30; "ce doît être à présent ce qu'il est convenu d'appeler l'âge d'homme ", S. 31) wird mit einem verlorenen und vergangenen verglichen, der durch Leben, Freude und Begeisterung gekennzeichnet war ("désirs d'enfant ", S. 31). (Die den Jetztzustand kennzeichnenden Passagen sind von mir kursiv, diejenigen, die sich auf das verlorene Paradies beziehen, in Kapitälchen gesetzt.)

\section{LA GLACE SANS TAIN}

Prisonniers des gouttes d'eau, nous ne sommes que des animaux perpétuels. Nous courons dans les villes sans bruits et les AFFICHES ENCHANTEEs ne nous touchent plus. A quoi bon ces GRANDS ENTHOUSIASMES FRAGILES, ces SAUTS DE JOIE desséchés? Nous ne savons plus rien que les ASTRES morts; nous regardons les visages; et nous soupirons de plaisir. Notre bouche est plus sèche que les plages perdues; nos yeux tournent sans but, sans espoir. Il n'y a plus que ces cafés où nous nous réunissons pour boire ces boissons fraîches, ces alcools délayés et les tables sont plus poisseuses que ces trottoirs où sont tombées nos ombres mortes de la veille.

QUELQUEFOIS, LE VENT nous entoure de ses grandes mains froides et nous attache aux arbres découpés par le soleil. Tous, NOUS RIONS, NOUS CHANTONS, mais personne ne sent plus son cour battre. LA FIÈVRE nOus abandonne. 
LES GARES MERVEILLEUSES ne nous abritent plus jamais: les longs couloirs nous effraient. Il faut donc étouffer encore pour vivre ces minutes plates, ces siècles en lambeaux. Nous AIMIONS AUTREFOIS LES SOLEILS DE FIN D'ANNEE, LES PLAINES ÉTROITES OÙ NOS REGARDS COULAIENT COMME CES FLEUVES IMPÉTUEUX DE NOTRE ENFANCE. Il $n^{\prime} y$ a plus que des reflets dans ces bois repeuplés d'animaux absurdes, de plantes connues.

Les villes que nous ne voulons plus aimer sont mortes. Regardez autour de vous: il n'y a plus que le ciel et ces grands terrains vagues que nous finirons bien par détester. Nous touchons du doigt CES ÉTOILES TENDRES QUI PEUPLAIENT NOS RÊVES. Là-bas, ON NOUS A DIT QU'IL Y AVAIT DES VALLEEES PRODIGIEUSES: chevauchées perdues pour toujours dans ce Far West aussi ennuyeux qu'un musée. [...] [72]

Auch in den >Gedichten ‘ [73] Bretons aus den Champs magnétiques sind diejenigen mit nachvollziehbaren Assoziationsketten eher häufiger (z. B. die gescheiterte Traum-Flucht aus der Enge des abendlichen Zimmers in Rideaux [74] oder die unkonventionellen Gedanken eines Kommunionskindes über die Fortpflanzung in Detour par le ciel) als diejenigen (z. B. J'ai beaucoup connu), denen eine mechanische Zufälligkeit zugrundezuliegen scheint, wie sie Tzaras Rezept Pour faire un poème dadaiste vorführt [75]:

Prenez un journal.

Prenez des ciseaux.

Choisissez dans ce journal un article ayant la longueur que vous comptez donner à votre poème. Découpez l'article.

Découpez ensuite avec soin chacun des mots qui forment cet article et mettez-les dans un sac. Agitez doucement.

Sortez ensuite chaque coupure l'une après l'autre dans l'ordre où elles ont quitté le sac.

Copiez consciencieusement.

Le poème vous ressemblera.

Et vous voilà "un écrivain infiniment original et d'une sensibilité charmante, encore qu'incomprise du vulgaire".

Die Champs magnétiques sind also durch eine ästhetische Strukturierung gekennzeichnet, die auch der indirekte Einfluß von Dada [76] nie ganz zurückgedrängt hat. Trotz aller Aktionsgemeinschaft unterscheidet sich Breton mit diesem konstruktiven Zug von Dada, erst recht allerdings nach der Überwindung dieser gemeinsamen Zwischenphase. Bretons variierende Wiederaufnahme des Zeitungs-Collage-Verfahrens im Surrealistischen Manifest enthüllt die signifikanten Unterschiede gegenüber Tzara:

Il est même permis d'intituler POEME ce qu'on obtient par l'assemblage aussi gratuit que possible (observons, si vous voulez, la syntaxe) de titres et de fragments de titres découpés dans les journaux. (Manifestes, S. 56; Herv. d. Vf., H.H.W.)

Das ist schon etwas anderes, als Zeitungsschnipsel in einem Sack blind zu mischen, wie es Tzara vorschlägt. Tatsächlich bleibt nämlich die Syntax, in Wirklichkeit das Sprach-Korsett der verhaßten Logik [77] (Trennung von Subjekt und Objekt, Aktiv und Passiv etc.) fast ohne Abstriche erhalten. Auch trifft Breton offensichtlich eine gezielte Auswahl dessen, was ausgeschnitten wird, so daß nicht nur syntaktisch richtige, sondern durchaus sinnvolle Sätze entstehen. [78] Ein Satz 
wie "Une voie carrossable vous conduit au bord de l'inconnu " (Manifestes, S. 57) eignet sich wohl kaum als Beleg für eine "möglichst willkürliche Zusammenstellung ".

Eine mehr oder weniger ausgeprägte Textstruktur bleibt also erhalten, selbst wenn Breton zunächst die Tendenz, die Imagination schranken- und unterschiedslos zu befreien, überbetonte. Doch neben der »löblichen Verachtung für die literarischen Folgen « [79] der solcherart provozierten poetischen Aktivität und der Begeisterung über ihre "gratuité " und "absurdité immédiate " fällt Breton über das Produzierte eindeutig ästhetische Urteile: er spricht von »eigenartig malerischen « Qualitäten, "außerordentlichem Schwung ", ja sogar von einem "organischen Charakter " (Manifestes, S. 32-35 pass.).

Neben dem theoretischen Anspruch einer Demokratisierung der Poesie gemäß der Lautréamont'schen Devise "La poésie doit être faite par tous. Non par un. " und der Destruktion traditioneller moralischer und ästhetischer Normen, steht ein elitärer und konstruktiver Anspruch, der den "pohète "Breton verrät. Im Gegensatz zu den Dadaisten glaubt er nicht, daß es mit dem Zerstörungswerk allein getan ist, das allzu schnell im poetischen Leerlauf versandet. Aragon drückt sich dazu mit der notwendigen Klarheit aus:

Tout au contraire la légende règne qu'il suffit d'apprendre le truc, et qu'aussitôt des textes d'un grand intérêt poétique s'échappent de la plume de n'importe qui comme une diarrhée inépuisable. Sous prétexte qu'il s'agit de surréalisme, le premier chien venu se croit autorisé à égaler ses petites cochonneries à la poésie véritable, ce qui est d'une commodité merveilleuse pour l'amour-propre et la sottise.[80]

Eine genauere Analyse der surrealistischen Bildtheorie im allgemeinen Zusammenhang einer Metapherntheorie soll die spezifische Leistung der "wahren Poesie « bei der Befreiung der versklavten imaginativen Fähigkeiten und der allgemeinen Veränderung der Welt verdeutlichen.

\section{Die surrealistische Metapher}

Bretons eigener Weg zur Erkenntnis des surrealistischen Prinzips der Imagination führte über die verschiedenen Etappen seiner Einsichten in das Wesen des dichterischen Bildes. Seine ersten epigonalen Versuche, in der Art Rimbauds und Mallarmés zu dichten, machten ihm klar, daß die Kraft des dichterischen Bildes nicht im Weglassen, in der Ellipse und in der bewußten Verrätselung liegt, sondern in etwas anderem. Er geht dabei von einer Definition P. Reverdys [81] aus:

L'image est une création pure de l'esprit.

Elle ne peut naître d'une comparaison mais du rapprochement de deux réalités plus ou moins éloignées.

Plus les rapports des deux réalités rapprochées seront lointains et justes, plus l'image sera forte - plus elle aura de puissance émotive et de réalité poétique ... 
Reverdy hat damit wesentliche Elemente des metaphorischen Prozesses erkannt [82]: Semantisch inkompatible, d. h. im Kontext der normalen, kodifizierten Sprache üblicherweise nicht kombinierbare Wörter werden trotzdem kombiniert. Das berühmteste Beispiel dürfte der von den Surrealisten besonders geschätzte [83] Satz Lautréamonts sein: "Beau comme la rencontre fortuite sur une table de dissection d'une machine à coudre et d'un parapluie. "[84] Der Schock einer solchen Wortkombination kann Selbstzweck bleiben, er kann aber auch auf Seiten des Lesers einen komplizierten Semioseprozeß ingangsetzen, der die Kluft ("écart «) zwischen den angeblich unvereinbaren Satzelementen zu überwinden trachtet.

Je vois les arêtes du soleil

A travers l'aubépine de la pluie (aus: Vigilance). [85]

Die Aufmerksamkeit des Lesers wird zunächst auf bestimmte Wörter gelenkt (hier fokalisiert auf "arêtes " und "aubépines"), deren seigentliche`, übliche Bedeutung (Gräte, Weißdorn) in dem vorliegenden Kontext fraglich geworden ist. Daraufhin beginnt die sinnschöpferische Suche des Lesers danach, was die nun im 'Brennpunkt des Interesses stehenden Wörter innerhalb des Kontext->Rahmens، [86] ("Je vois le soleil à travers la pluie «) 'uneigentlich, im sübertragenen، Sinne, bedeuten könnten. Diese Suche ist aber nur möglich, weil der Leser einerseits darauf eingestellt ist, daß er nicht alles 'wörtlich ' nehmen darf (weder in der alltäglichen Rede noch viel weniger aber in der Literatur), d. h. daß die normalsprachliche Referenz eines Begriffs momentan ausgesetzt ist, - andererseits der Leser aber fest damit rechnet, daß das Gelesene grundsätzlich Sinn hat. Mit Metapher bezeichnet daher P. Ricœur nicht die prädikative Impertinenz (»écart") selbst, sondern »das Verfahren, mit dem der Sprecher die Kluft überbrückt, indem er den Sinn der Worte ändert «.[87]

Bei der Suche nach dem Sinn des Satzes zeigt es sich, daß »arêtes « und » aubépines « nicht ohne Verlust durch andere, nur etwa weniger ’dekorative`, ,eigentlich ‘ passende Wörter ersetzt werden können (Substitution), etwa durch "rayons " und "gouttes ". Durch die Überlagerung des Bildfelds [88] ,Weißdorn ("rapprochement de deux réalités éloignées ") wird nämlich ein dynamischer Interaktionsprozeß inganggesetzt, der etwas Neues, seither Ungesagtes und mit der üblichen Sprache so nicht Sagbares konstituiert. Weißdorn bringt unter anderem die Vorstellung von Frühling, von weißer, zartester Blüte auf dornigem, blattlosem und trist schwarzem Holz, phonetische Qualitäten, etymologische Anklänge mit sich, eventuell auch literarische Reminiszenzen (Proust); der Regen dagegen Trauer, aber auch Leben, Reinigung und vieles andere mehr. Das Entscheidende am metaphorischen Prozeß ist es nun nicht, durch Reduktion den gemeinsamen Nenner zweier Systeme von " common places " [89], d. h. das gemeinsame Sem zweier zugrundeliegender Wortfelder zu finden, sondern im Gegenteil, diese klischierte Vorstellungswelt der »idées reçues " durch die Eröffnung neuer Perspektiven zu sprengen, oder wie Aragon es ausdrückt: "chaque image à chaque coup vous force à réviser tout l'Univers. «[90] Diese auf den ersten Blick etwas übertrieben anmutende Behauptung hat insofern eine gewisse Berechtigung, als jeder Begriff in ein Netz von anderen Begriffen, Wertvorstellungen und Handlungsmustern eingebunden ist. Erfährt ein solches 
System oder ein solches Weltmodell an einer signifikanten Stelle eine Änderung, so ist tatsächlich eine Revision des gesamten Systems fällig.

Stellte man den Satz "Je vois les arêtes du soleil à travers l'aubépine de la pluie " in den Kontext einer alltäglichen Kommunikationssituation, d. h. sagte jemand diesen Satz auf einem Spaziergang angesichts einer durch den Regen brechenden Sonne, so würde trotz der poetischen Ausdrucksweise niemand an dem Bezug des Satzes auf die Wirklichkeit zweifeln, auch wenn weder Fischgräten noch Weißdornbüsche zu sehen sind. Die Referenz wird in der Metapher verdoppelt [91], d. h. die normalsprachliche Referenz eines Wortes, seine Bezeichnungsfunktion (Skeletteile eines Fisches, Unterart der Rosazeen) wird momentan ausgesetzt, um sie auf einer komplexeren Ebene, nämlich als Ergebnis des gesamten metaphorischen Prozesses wiederzuerhalten. Die Referenz ist nicht in direkter Bezeichnung oder Beschreibung fertig gegeben, sondern sie muß vom Empfänger auf dem 'Umweg, über den schöpferischen Prozeß der Metapher, über die "réalité poétique " (Reverdy), erschlossen werden. Die Metapher hat dabei nicht nur dekorative Funktion, sondern sie läßt als Erkenntnisgewinn den Empfänger vielleicht dieses von ihm hundertmal so oder ähnlich schon beobachtete Naturphänomen aus einer neuen, seither unbekannten, aber treffend und einleuchtend erscheinenden Perspektive sehen.

Nach dem gleichen metaphorischen Prinzip der zunächst ausgesetzten, verdoppelten Referenz funktioniert das literarische Werk, etwa das Gedicht, als Ganzes. Es verweist mit seinen einzelnen Wortkomponenten nicht direkt auf die Wirklichkeit, sondern gestaltet als Ganzes modellhaft Wirklichkeit. Die darin genannten einzelnen Dinge, Eindrücke, Sachverhalte, Vorgänge etc. werden dadurch, daß sie in einem fiktionalen Text stehen, aus ihrer gewöhnlichen referentiellen Funktion teilweise entlassen. Ihr Sinn muß im Kontext der gesamten Struktur des Textes erst hergestellt werden, d. h. der Leser muß das Modell erst einmal in seinem Zusammenhang selbst konstituieren. Das ist relativ einfach etwa in der romantischen Poesie, wo das einmal gewählte Bild (die Groß-Metapher, das poetische Modell) in sich metonymisch als Reihenmetapher weitergeführt wird. Ausgehend von der Primärmetapher erschlieBen sich zwei parallele Bedeutungssysteme, wobei die reziproke Selektion [92] dafür sorgt, daß nur diejenigen Elemente im bildspendenden Bereich aktualisiert werden, für die es im bildempfangenden Bereich eine referentielle Entsprechung gibt. Zur Erleichterung der Übertragung sind die Systeme weitgehend traditionell und verlassen nur punktuell die »lieux communs «. Solche Gedichte, etwa Baudelaires Albatros, schildern metonymisch [93], den allgemein akzeptierten Vorstellungen von einem Albatros weitgehend entsprechend, und liefern die metaphorische Bedeutung, die verdoppelte Referenz gleich mit ("Le poète est semblable au prince des nuées «). Doch selbst wenn das nicht der Fall ist, wenn das Modell absolut steht, aber in sich geschlossen, auf einen Bildbereich beschränkt bleibt (z. B. Victor Hugos Le rouet d'Omphale), läßt sich die Referenz, wenn auch schon nicht mehr so eindeutig wie im Vergleich, angeben (etwa: die Zähmung des Männlichen durch das Weibliche, der wilden Natur durch die Kultur etc.). Denn im Vergleich (" est semblable «) bleiben die beiden Systeme sauber getrennt, während in der Metapher beide miteinander unauflösbar verschmolzen werden.[94] 
Schwieriger wird die Konstitution des Modells, d. h. der Struktur des literarischen Textes in der modernen Poesie, in der das Schöpferische der Sprache, ihr die Weltsicht revolutionierendes Element, d. h. der metaphorische Prozeß, immer weiter ausgedehnt wird und auch noch den früheren, inneren metonymischen Zusammenhalt des poetischen Modells angreift. Das Gedicht als modellhaftes Ganzes bietet nicht sozusagen nur eine neue in sich geschlossene Perspektive auf die Welt, sondern auch innerhalb des Modells wechseln die Perspektiven mehrfach. Das bedeutet, daß nicht mehr nur eine Reihenmetapher von einer Primärmetapher her zu analysieren ist, sondern davon fortgesetzt immer neue metaphorische Bereiche abgeleitet werden. So ensteht der Eindruck, die Sprache habe sich verselbständigt - ohne je wieder zu einer Referenz zurückfinden zu können.

Nehmen wir als Beispiel das vollständige Gedicht Vigilance, dem schon die beiden weiter oben zitierten Zeilen entnommen waren.

\section{VIGILANCE}

A Paris la tour Saint-Jacques chancelante

Pareille à un tournesol

$\mathrm{Du}$ front vient quelquefois heurter la Seine et son ombre glisse imperceptiblement parmi les remorqueurs

A ce moment sur la pointe des pieds dans mon sommeil

$5 \mathrm{Je}$ me dirige vers la chambre où je suis étendu

Et j'y mets le feu

Pour que rien ne subsiste de ce consentement qu'on m'a arraché

Les meubles font alors place à des animaux de même taille qui me regardent fraternellement Lions dans les crinières desquels achèvent de se consumer les chaises

10 Squales dont le ventre blanc s'incorpore le dernier frisson des draps

A l'heure de l'amour et des paupières bleues

Je me vois brûler à mon tour je vois cette cachette solennelle de riens

Qui fut mon corps

Fouillée par les becs patients des ibis du feu

15 Lorsque tout est fini j'entre invisible dans l'arche

Sans prendre garde aux passants de la vie qui font sonner très loin leurs pas trainnants

Je vois les arêtes du soleil

A travers l'aubépine de la pluie

J'entends se déchirer le linge humain comme une grande feuille

20 Sous l'ongle de l'absence et de la présence qui sont de connivence

Tous les métiers se fanent il ne reste d'eux qu'une dentelle parfumée

Une coquille de dentelle qui a la forme parfaite d'un sein

Je ne touche plus que le cœur des choses je tiens le fil

Die Grundlage des Verstehens von metaphorischen Aussagen wie auch von ganzen poetischen Modellen ist die Normalsprache und ihre Referenz, von der sich das metaphorisch Gemeinte abhebt. In dem vorliegenden Text lassen sich verständliche, den Gesetzen der allgemein akzeptierten Logik und Erfahrung unterworfene Sätze, und unverständlichere unterscheiden.

Im allgemeinen schwankt ein Turm nicht und er stößt auch nicht mit der Stirn aufs Wasser - es sei denn, es handelt sich um ein Spiegelbild im Wasser oder um seinen Schatten. Dagegen ist es üblich, davon zu sprechen, daß die Schlepper auf dem 
Wasser gleiten und der Schatten relativ still steht. Denkt man aber an den Zeitraffereffekt, so gleitet auch der Schatten. Oder man fixiert mit dem Blick die sich in Wirklichkeit bewegenden Schlepper und das Wasser, dann scheint es, als ob sich der Schatten bewegte. Auch der Vergleich eines Turmes mit einer Sonnenblume ist ungewöhnlich, zumal der Vergleichspunkt gar kein direkter ist. Die Sonnenblume dreht sich mit ihrer Blüte nach der Sonne ("tourne-sol «), die Sonne aber dreht sich um den Turm und wirft einen sich bewegenden Schatten. Die Äquivalenz besteht erst auf einer höheren Ebene des Bewegungsablaufs, wenn auch mit vertauschten Rollen.[95] Schon in diesen einleitenden, Ort und Zeit des gesamten modellhaften Bildes umreiBenden Zeilen bringt Breton durch seine Metaphorik die gewöhnliche Zeit- und Raum-Perspektive sowie die Wirklichkeitserfahrung ins Wanken ("la tour chancelante «).

Die Zeilen 4 und 5 beschreiben zwei aller Logik hohnsprechende Vorgänge. Man geht im Schlaf nicht auf Zehenspitzen und ebensowenig kann man sich zu einem Zimmer aufmachen, in dem man schon liegt. Bevor der Leser einen metaphorischen Sinn sucht, schöpft er jedoch alle Möglichkeiten einer wörtlichen primärreferentiellen Erklärung aus. In Verbindung mit Schlaf‘ und /liegen ‘ bietet sich die srealistische، Erklärung des Schlafwandlers, des Träumers an. Der Traum ist, wie wir schon gesehen haben, ja eine der wenigen gesellschaftlich zugelassenen Möglichkeiten, den Naturgesetzen und den Gesetzen der herrschenden Logik Widersprechendes, Unwirkliches, als Wirkliches zu erleben.

Wäre nicht dieser vorausgehende Kontext, so könnte man geneigt sein, die 6. und 7. Zeile ("Et j'y mets le feu Pour que rien ne subsiste de ce consentement qu'on m'a arraché «) , wörtlich zu nehmen. So geschieht jedoch die vom Subjekt beobachtete und gleichzeitig verursachte Metamorphose seiner Umgebung wie auch seiner selbst durch das Feuer, die Rettung auf die Arche, die veränderte Sinneswahrnehmung im Traum. Im Traum gelingt die Verweigerung des durch die Sozialisation erzwungenen Konsenses, in einem Stuhl nur einen Stuhl und nicht eine Löwenmähne, in einem Bettuch nur ein Bettuch und nicht den weißen Bauch eines Hais zu sehen; im Traum gelingt die Überwindung des künstlichen (Schein- und Lügen-) "Gewebes « und das Vordringen zum "Herz der Dinge «. Diese letzten Zeilen sind ein schönes Beispiel dafür, wie im surrealistischen Gedicht scheinbar völlig vom roten Faden` abgekommene Metaphern, innerhalb des Gesamtmodells doch noch Sinn und eine sekundäre Referenz erhalten. Die im Brennen zu Asche verwelkenden Stickrahmen ("Tous les métiers se fanent ") lassen sich noch ohne größere Schwierigkeiten metonymisch in die Feuermetamorphose einordnen. Dagegen scheint sich die Reihe ("métier " "dentelle" - "coquille de dentelle" - "forme d'un sein « - "cœur « - "fil«) zu verselbständigen. Doch wird hier zum Abschluß des Gedichts noch einmal der modellhafte Prozeß der Metamorphose und der Reduktion, den das Gedicht im Ganzen ausdrückt, im kleinen an einem einzigen in sich geschlossenen Bild nachgezeichnet. Der Dichter dringt mit Hilfe des Feuers der poetischen Einbildungskraft von dem kunstvollen Stickmuster, der Art von Wirklichkeitsbild, wie es durch den stabilen Stickrahmen der normalen Logik und Wirklichkeitserfassung zusammengehalten und begrenzt wird, über die herzförmige Spitze zum Herz 
der Dinge, zur Erkenntnis ihres wesentlichen Kerns (Stickfaden) vor ("je tiens le fil «).[96]

Der surrealistische Dichter benützt wie schon frühere Dichter, wenn auch in einem seither ungewohnten Umfang, den Prozeß der Metaphorisierung nicht etwa dazu, die Wirklichkeit zu beschreiben, noch auch wie Mallarmé eine eigene Wirklichkeit ex nihilo mit Hilfe der Sprache zu erschaffen, sondern dazu, die Wirklichkeit umzubeschreiben, so wie sie sich ihm vorstellt. $\mathrm{Daß}$ bei einer solchen neuen Modellbildung die Bedeutung einzelner Worte, ja eines ganzen Weltbildes geändert, im Extremfall ins Gegenteil verkehrt werden kann, zeigt die Überschrift des eben analysierten Textes.

"Vigilance " heißt im gängigen Französisch soviel wie ,Wachsamkeit`, Wach-Sein im Gegensatz zu 'Schlafen`, "Surveillance attentive, sans défaillance ". Dem eigentlichen Wortsinn nach ist aber im Gedicht gerade vom Gegenteil die Rede. Das Ich schläft ("dans mon sommeil «). Und wenn man zudem davon ausgeht, daß die Wächter auf den Türmen der Städte (»tour Saint-Jacques «) in früheren Zeiten ihre ganze Wachsamkeit darauf richteten, Feuersbrünste rechtzeitig zu entdecken und damit zu verhindern, so ist der Titel über einem 'Brandstifter - Gedicht auf den ersten, auf eine umgangssprachliche Referenz zielenden Blick, doppelt widersinnig.

Das Gedicht verhilft uns aber modellhaft zu der Erkenntnis, daß die wahre Wachsamkeit (also nicht die seither definierte) in den Augen eines Breton der (Halb-)Schlaf bzw. der Traum ist und die eigentliche Aufgabe eines raufgeweckten', wenn auch nicht 'wachen', zum Kern der Dinge vorstoßenden Menschen nicht das Bewahren der Dinge vor Veränderung in einer ein für alle Mal fixierten Bedeutung, sondern der dauernde Wechsel der Perspektive, ihre fortgesetzte imaginäre Metamorphose.

Das Gedicht Vigilance wurde auf dem Hintergrund und im Kontrast zur alltäglichen Sprache und dem dazugehörigen logischen, rationalistischen Weltbild gesehen.[97] Die interpretative Leistung des Lesers besteht in der Erschließung und Konstitution der poetischen Referenz auf den Trümmern der primär-referentiellen Bedeutung der Wörter und Sätze. Der Schlüssel, der sich beim Bemühen, alle die semantischen Unvereinbarkeiten zu lösen, ergab, war die Vorstellungswelt des Traums. Dieser Begriff bot sich zur Synthese besonders auch deshalb an, weil er im surrealistischen Weltmodell eine zentrale Rolle spielt. Betrachtet man die Verwendung der Metapher und der Modellierung in Vigilance, so unterscheidet sich die surrealistische Poesie nicht grundsätzlich von früherer. Von wenigen Ausnahmen wie Rimbaud und Lautréamont einmal abgesehen, zeichnet sich ihre Metaphorik allerdings durch größere Absolutheit und Kühnheit aus.

Worin besteht nun diese Kühnheit? Reverdy gibt für die Beurteilung der Qualität von Bildern (Metaphern) folgende Kriterien an:

Plus les rapports des deux réalités rapprochées seront lointains et justes, plus l'image sera forte - plus elle aura de puissance émotive et de réalité poétique [...].[98]

In den Qualitätskriterien stimmt Breton weitgehend mit Reverdy überein, der einzige Einwand richtet sich gegen den Bewußtheitsgrad der Metaphernfindung: 
Il est faux, selon moi, de prétendre que "l'esprit a saisi les rapports " des deux réalités en présence. Il n'a, pour commencer, rien saisi consciemment. C'est du rapprochement en quelque sorte fortuit des deux termes qu'a jailli une lumière particulière, lumière de l'image, à laquelle nous nous montrons infiniment sensibles. La valeur de l'image dépend de la beauté de l'étincelle obtenue; elle est, par conséquent, fonction de la différence de potentiel entre les deux conducteurs. Lorsque cette différence existe à peine comme dans la comparaison, l'étincelle ne se produit pas. Or, il n'est pas, à mon sens, au pouvoir de l'homme de concerter le rapprochement de deux réalités si distantes. Le principe d'association des idées, tel qu'il nous apparaît, s'y oppose. Ou bien faudrait-il en revenir à un art elliptique, que Reverdy condamne comme moi. Force est donc bien d'admettre que les deux termes de l'image ne sont pas déduits l'un de l'autre par l'esprit en vue de l'étincelle à produire, qu'ils sont les produits simultanés de l'activité que j'appelle surréaliste, la raison se bornant à constater, et à apprécier le phénomène lumineux. (Manifestes, S. 51)

Die Kühnheit der Metaphorik, wenn man darunter lediglich die Distanz der beiden Metapherngliedern versteht, ist also nicht das einzige Wertkriterium der Surrealisten.[99] Sie müssen auch Leuchtkraft haben, d. h. einleuchtend, "wunderbar ", d. h. Verwunderung erregend, kurz "schön " sein ("il n'y a même que le merveilleux qui soit beau ", Manifestes, S. 24).

Die konsequente Ausweitung des metaphorischen Verfahrens durch die Surrealisten hat bestimmte Konsequenzen. Riffaterre konnte bei der Analyse eines HugoGedichtes noch einigermaßen glaubhaft davon ausgehen, daß der Leser die fiktive Wirklichkeit im Text nicht mit seiner empirischen Lebenswelt, sondern lediglich mit dem in seiner Sprache fixierten Wirklichkeitsmodell vergleiche. "[le texte] est reconnu, comparé aux phrases stéréotypées qu'il reproduit ou transforme; la mimesis est donc toute entière perçue non par rapport à des référents ou des signifiés, mais par rapport à des formes verbales, à des mots déjà arrangés en texte. "[100] Wenn die Surrealisten aber den Bezug zu diesem "système descriptif « einer Sprachgemeinschaft willkürlich zerstören, wenn sie das Gebot der "acceptabilité « [101] der Metaphern souverän mißachten, so bleibt dem Leser zunächst nichts anderes übrig, als die Inkongruenz dieses neuen Weltmodells mit seinem seitherigen festzustellen. Er muß sich daran machen, die Sprache des Textes wie eine ihm fremde Sprache zu entziffern, indem er zunächst ihre Strukturen, ihre ,Grammatik ‘ herauspräpariert.[102]

Verfügt der Text allerdings über keine Struktur mehr, und sei sie dem Autor noch so unbewußt, so ist auch keine Kommunikation mit dem Leser mehr möglich. Die 'Grammatik، ist allerdings nur die eine Bedingung dafür, daß der vielberedete "Funke" überspringen und die Verständigungsschwierigkeit deblockiert werden kann. Soll die Metapher nämlich reinleuchten ‘ [103], so muß sie auch eine referentielle Entsprechung in den Sachverhalten der Wirklichkeit bzw. den Erfahrungen haben, die der Leser mit ihr gemacht hat oder den utopischen Hoffnungen, die er mit ihr verbindet. Es genügt nämlich nicht, auch wenn manche Äußerungen Bretons in der ersten Begeisterung über die automatische Schreibweise es so darstellen, die Trümmer der zugrundeliegenden zumeist sprachlich artikulierten Weltmodelle willkürlich, sirgendwie zu kombinieren, sondern sie müssen sinnvoll interagieren, sie müssen sich zu einem neuen, im Idealfall "wahreren ", den Erfahrungen des Lesers besser als die seitherigen entsprechenden Weltmodell fügen, damit es zum beschrie- 
benen Überspringen des Funkens kommt. Je unvereinbarer und ferner diese im neuen Weltmodell nebeneinander eingefügten Elemente im zugrundeliegenden Weltmodell und Sprachsystem waren, desto überraschender und erkenntnisfördernder ist ihre Neukombination. Sie erfordert nicht nur Retuschen oder leichte Umstellungen am vorhandenen Weltmodell, sondern grundlegende Umbauten.

Gelingt die Verständigung nicht, bleibt der Text nur geschwärztes Papier ohne Information und Erkenntniswert - von den enttäuschten Erwartungen des Lesers auf das ästhetische Vergnügen bei der Entzifferung der sneuen Sprache‘ ganz zu schweigen. Das kann an der Unfähigkeit des Lesers zu ungewöhnlicher Semiose liegen, aber auch am Text. Was für den einen ein unverständliches Kauderwelsch in einer fremden Sprache bleibt, ist für einen anderen, der die Sprache (mühsam) gelernt hat, sinnvoll und verständlich, vorausgesetzt natürlich, es ist überhaupt ein Sinn in der Text-Partitur angelegt. "Si vous écrivez, suivant une méthode surréaliste, de tristes imbécillités, ce sont de tristes imbécillités. Sans excuses. «[104] Das poetische Bild ist übrigens nicht der einzige sprachliche Ort an dem der metaphorische Prozeß zur Wirkung kommt. Grundsätzlich gehört jede Art von Parallelismus hierher, der paradigmatisch Getrenntes syntagmatisch verbindet.[105] Daher die Vorliebe der Surrealisten für sogenannte Sprachspiele, von denen hier nur einige kurz erwähnt werden sollen. So bildet das Homonym eine Art Metapher in einem Wort.

L'identité des mots [...] est elle-même une expérience à double versant: elle révèle dans le mot le lieu d'une rencontre imprévue entre les figures du monde les plus éloignées (il est la distance abolie, le point de choc des êtres, la différence ramassée sur elle-même en une forme unique, duelle, ambiguë, minotaurine).[106]

Ähnliches gilt von Kalauern ("on est diamants " / "on est dit amants"), der Contrepèterie ("Chants de guerre" - "gants de chair ") oder leichten vokalischen Veränderungen (» rideaux « - »radeau «).

Ein privilegiertes Experimentierfeld sind in dieser Hinsicht die Sprichwörter als Inbegriff verknöcherter, unorigineller und beschränkter Lebensweisheit. Bei völliger syntaktischer und weitgehender phonetischer Äquivalenz zum Ursprungssprichwort, das als "Rahmen « präsent bleibt, lassen sich durch winzige Veränderungen ( Brennpunkte ") die vorgefertigten Gedankenzusammenhänge, die zum poetischen Gemeinplatz geronnenen ideologischen Formeln von innen her in Frage stellen. Paul Eluard gründete gar eine Zeitschrift mit dem Titel Proverbe (1920) und zusammen mit Benjamin Péret gab er eine ganze Sammlung verballhornter Sprichwörter heraus.[107] Daraus ein Beispiel, das zeigt, wie verkrustete Denkstrukturen provokativ aufgebrochen werden können:

Statt

Il faut battre le fer pendant qu'il est chaud.

steht bei Eluard/Péret

Il faut battre sa mère pendant qu'elle est jeune. 
Hier wird eine Handlungsanweisung aus dem mechanischen Bereich, die in der Umgangssprache metaphorisch gemeint ist, wörtlich angewendet; vorher jedoch auf einen anderen Bereich übertragen, wodurch alle Regeln bürgerlichen Anstands (man schlägt seine Mutter nicht; "jeune " verweist zurück auf »chaud[e] ") und biographischer Logik durcheinander geraten.

Bevor wir das Prinzip des »rapprochement de deux réalités plus ou moins éloignées" in seinen Auswirkungen, nicht nur auf die poetische Wirklichkeitserfassung und die Kritik des üblichen, in der Sprache fixierten Wirklichkeitsbildes, sondern auch auf die Handlungs- und Lebensweise der Surrealisten ("trouvailles ", "hasard objectif ") anhand von Nadja untersuchen, kurz noch ein Blick auf das analoge Verfahren in der Bildenden Kunst.

Eine Verbindung zwischen Poesie und Bildcollage wurde zum ersten $\mathrm{Mal}$ in Bretons Katalogvorwort zur ersten Ausstellung Max Ernsts in Paris (eröffnet am 2. Mai 1921) hergestellt. Breton erkannte "in der ihr [der Collage] zugrundeliegenden Auseinandersetzung mit einer in Reproduktionen verfügbaren sichtbaren Welt als erster eine völlig neue ästhetische Praxis. "[108] Der Begriff Collage wird von W. Spies, ähnlich wie wir oben in Anlehnung an P. Ricœur den Begriff des metaphorischen Prozesses verwenden, im weiten Sinne als Koppelung und Verschmelzung verschiedener ursprünglich unzusammenhängender Bilder und Bedeutungen genommen und als die Verfahrensweise Max Ernsts schlechthin bestimmt, ob nun mit Leim und Schere gearbeitet wurde oder nicht. Abgesehen von "technischen Eigengesetzlichkeiten " gibt es verschiedene Verfahren, in denen die Analogie zwischen Metapher und der Collage auf das bloße Nebeneinanderstellen von Unerwartetem beschränkt ist. Unerwartet ist der Schnurrbart im Gesicht der Mona Lisa bzw. das Readymade im Museum auch, beides ist jedoch ein Akt der Kontext-Collage oder der parodistischen Verfremdung, dessen Bedeutung auf der Metaebene der Kritik institutionalisierter Kunst überhaupt liegt. Es werden nicht Bild mit Bild, sondern industrielles Serienprodukt mit dem Markenzeichen des Künstlers (Nicht-Kunst verbunden mit dem Zeichen für Kunst) bzw. ein anerkanntes Kunstwerk mit Gassenjungen-Schmierereien (Kunst verbunden mit einem Zeichen für Nicht-Kunst) kombiniert. Dagegen bezieht sich die überraschende Koppelung von Bildern untereinander auf eine Veränderung der Sicht auf die Welt, nicht nur eine metaästhetische Problematisierung in der Bewertung des allgemeinen Phänomens Kunst, das ja nur einen kleinen Ausschnitt von Welt ausmacht.[109]

Max Ernsts Beschränkung auf nicht-ästhetisches "visuelles Informationsmaterial “ aus Katalogen, Zeitschriften etc., also auf bereits unter Waren-Gesichtspunkten reproduzierte, zu seiner Zeit schon veraltete Wirklichkeit, macht dagegen eine ganz spezifische Komponente des metaphorischen Prozesses augenfällig, die in dieser Deutlichkeit im sprachlichen Medium nicht immer zu erkennen, aber geradeso vorhanden ist. Auch die Metapher benutzt ja ,Klischees` von Wortbedeutungen (Max Ernst arbeitet teilweise nach Klischeevorlagen für Druckereien), abgegriffene WortMünzen (vgl. Max Ernsts Ausschnitte aus veralteten Warenhauskatalogen und Reklamen), die in ihrem ideologisch verfestigten Gehalt hinter der Entwicklung um Jahre und Jahrzehnte herhinken. Durch eine analoge Kombination solchen ver- 
knöcherten Wortmaterials und der damit verbundenen Weltmodelle versucht der Poet eine neue, adäquate Sicht auf die gegenwärtige Wirklichkeit zu eröffnen. Die Verwendung von veraltetem visuellem Material hat also nichts mit Nostalgie zu tun, sondern sie gleicht nur einen Unterschied im Medium zwischen Sprache und Bild aus. Die Bildreproduktionen von Wirklichkeit (Photographie, Film, Farbfilm) sind nämlich technisch gesehen zur Zeit Max Ernsts wie auch heute auf dem neuesten Stand, nicht aber die `Begriffs-Reproduktionen ‘ von Wirklichkeit. Daß Max Ernst für seine Collagen kaum künstlerisches Material verwendet, zeigt, daß er sich nicht mit einer Kunstwelt, mit der Sicht früherer oder zeitgenössischer Künstler auf ihre Welt auseinandersetzen will (etwa so wie Rimbaud die Bibel, Banville und Coppée parodiert), sondern mit der alltäglichen, wenn auch ideologisch veralteten Welt der Waren und der trivialen und ideologisch ebenso veralteten Welt der Colportageromane. Die Ablehnung direkten Malens oder Zeichnens und das Ausgehen von vorgefundenen Bildelementen machen sichtbar, daß die Welt immer nur durch Neukombination bereits vorhandener Weltmodelle erkannt werden kann und daß zur Erstellung eines erkenntnisfördernden neuen Modells die alten Materialien verwendet werden müssen. Auch bei der Interpretation von Max Ernst'schen Collagen ergeben sich aufschlußreiche Parallelen zu der oben vorgeschlagenen Verfahrensweise nach Metaphernketten und großräumigen Strukturen. So wie die einzelne Metapher kaum deutbar ist, jedoch eine Bedeutung erkennen läßt, sobald sie in den Kontext eines ganzen Gedichts oder gar eines ganzen Werks gestellt wird, so ist auch die einzelne Collage nur im Kontext des Zyklus (Collage-Romane) bzw. des gesamten Werks verständlich. Damit stellt sich das Problem des (organischen) Kunstwerks, dessen Zerstörung eines der wesentlichen Kennzeichen der Avantgarde zu sein scheint. Dieses Problem soll an Bretons Nadja [110] exemplifiziert werden.

\section{7. ,Organisches und surrealistisches Kunstwerk (Nadja)}

Ausgehend von Theodor W. Adornos paradoxem Diktum: "Die einzigen Werke heute, die zählen, sind die, welche keine Werke mehr sind. " [111], stellt Peter Bürger fest, daß die Avantgarde - selbst wenn sie es wie Dada beabsichtigt haben sollte nicht das Kunstwerk als Einheit schlechthin, sondern nur die bestimmte historische Ausformung des "organischen Kunstwerks " zerstört habe.[112] Den Hauptunterschied zwischen surrealistischem und organischem Kunstwerk sieht Bürger folgendermaßen: "Während im organischen Kunstwerk jedes Element unentbehrlich, weil unmittelbar sinnstiftend ist, würde hier [im avantgardistischen Kunstwerk Nadja] die ,Aussage durch Streichung einer Begebenheit keineswegs verändert. «[113] Ganz offensichtlich geht diese Unterscheidung von dem Begriff des organischen Kunstwerks aus, das mit positiven Prädikaten versehen ist. Eine solche Perspektive erlaubt nur eine negative (nicht negativ wertende!) Bestimmung des Neuen, des avantgardistischen Kunstwerks. Wir wollen nun gerade umgekehrt verfahren und die spezifische Einheit und die darin begründete spezifische Sinnkonstitution beim surrealistischen Kunstwerk als Ausgangspunkt der Überlegungen nehmen. Aus dieser Per- 
spektive nämlich gibt es im sorganischen Kunstwerk Redundanzen, d. h. streng genommen teilweise entbehrliche Elemente; ja es wird häufig geradezu durch eine solche Redundanz definiert ('die Form entspricht dem Inhalt/). Die sogenannten formalen Elemente unterstützen, ja verdoppeln und verdreifachen kookkurrent das, was im sogenannten Inhalt erzählt wird: so auf der mikrostrukturellen Ebene zum Beispiel die Lautgestalt die herbstliche Trauer ("Les sanglots longs des violons de l'automne ... «) oder in der makrostrukturellen Handlungsführung die Rückkehr des Helden an den Ausgangspunkt den Abschluß seines von Irrungen und Wirrungen gekennzeichneten und der konventionellen Sozialisation dienenden Läuterungsweges.

Mit aus diesem Grunde können auch im "organischen Kunstwerk " einzelne Elemente in ihrer Funktion durch andere ersetzt werden, länger oder kürzer ausfallen, ohne daß die >Aussage` entscheidend verändert würde. Charles Bovarys Mütze ist dafür eines der berühmtesten Beispiele aus einem Roman, dem man wohl kaum vorwerfen kann, er sei nicht organisch durchkonstruiert. Auch ist es eine soptischer Täuschung zu glauben, im klassischen organischen Kunstwerk seien die Elemente "unmittelbar sinnstiftend ". Die Bedeutung der "Comices agricoles ", um bei der Madame Bovary zu bleiben, oder auch der Schlacht von Waterloo in der Chartreuse de Parme ist auch erst innerhalb des Kontextes des gesamten Weltmodells des Romans zu ermitteln. Der "organische "Charakter dieser Kunstwerke besteht eher darin, daß alle Elemente mehr oder minder ausdrücklich psychologisch motiviert, in eine "affabulation romanesque (Nadja, S. 17) eingebettet sind und der implizite ideologische Gehalt der formalen Gestaltung mit dem explizit geäußerten Tenor des Werks übereinstimmt. Schon im Surrealistischen Manifest (Manifestes, S. $14 \mathrm{ff}$.) wendet sich Breton gegen die realistische Romanliteratur, deren formaler Verknüpfungsmodus in etwa unserer eigenen normalen positivistisch genormten Erfahrung bzw. den herrschenden Urteilen über Kausalität entspricht.[114] Die Verknüpfungstechnik bewegt sich innerhalb eines geltenden "Systems von Gemeinplätzen “ oder eines konventionellen "système descriptif “ [115], wie wir es schon bei der Analyse der Metapher kennengelernt haben. Die vorherrschende Sprachtätigkeit ist die metonymische Kombination auf der syntagmatischen Achse.[116] Entsprechend der Zerstörung konventioneller Sprache und ihrem Neuaufbau im metaphorischen Prozeß der Poesie bedarf es bei der Übertragung der gleichen Ziele auf die umfassende Lebensgestaltung (auch der fiktiven in narrativen Texten) einer Zerstörung der traditionellen biographischen Muster und Rollen und der damit verbundenen realistischen Romantechnik.

Im Hinblick auf deren Art von Faktenverkettung spricht Breton selbst von "gleitenden " ("faits-glissades"), im Gegensatz zu den "abgründigen Fakten " ("faitsprécipices «) (Nadja, S. 20). Beim traditionellen "Gleiten « von einem Vorkommnis zum nächsten sei der weitere Geschehnisablauf ('von der Wiege bis zum Grabe) in etwa abzusehen, ihr "Text " entspreche einem reiflich überlegten Satz, einem teleologischen Lebensplan.

Dagegen nimmt sich Breton für Nadja eine Ereignisdarstellung vor, die gerade auf einen solchen "organischen [117] Lebensplan « (Nadja, S. 18) ohne Sprünge und 
Überraschungen verzichtet, dafür die Lebensepisoden dem Zufall ausgeliefert sein läßt und nur von plötzlichen, unvorhergesehenen Begegnungen mit Personen und Koinzidenzen von Ereignissen erzählt - eben von jenen "abgründigen Fakten «, vor denen der sie erlebende Zeuge verstört, überrascht und fasziniert verharrt, ohne einen rationalen oder kausalen Zusammenhang entdecken zu können. Breton vergleicht diese Art von Darstellung einem " automatischen Text " (Nadja, S. 21) [118] nach der Art der freien Assoziation:

j'en parlerai sans ordre préétabli, et selon le caprice de l'heure qui laisse surnager ce qui surnage. (Nadja, S. 22)

Auch andere Begriffe wie "plötzliche Annäherungen ", "Ideenassoziationen ", "Blitze, die sichtbar machen " (Nadja, S. 19) und die Ablehnung der Verantwortlichkeit für solche Taten (Nadja, S. 21) stellen die "abgründigen Fakten « auf eine Stufe mit den surrealistischen Bildern. Sie werden in einer Art Reihenmetapher als Ereignisund Fakten-Reihe zur Wiedergabe eines Lebensabschnittes verwendet.

Wie in einem surrealistischen Bild im metaphorischen Prozeß zwei durch eine semantische Kluft (vgl. die »abgründigen Fakten «) getrennte Wörter und ihre Bedeutungen in einen überraschenden, den normalen Sprachgebrauch und das normale Wahrnehmungsvermögen sprengenden, dynamischen Zusammenhang gebracht werden, so bleiben auf der makrostrukturellen Ebene eines ganzen Lebens-Modells zwei im realen Leben ohne Kausalverbindung [119] aufeinander folgende Ereignisse oder Fakten einfach ohne künstliche zweckrationale Verbindung zusammengestellt. Es ist nun wie bei der Metapher die Aufgabe des Lesers, den Zusammenhang eigenschöpferisch herzustellen; der Lebenssinn wird nicht gleich noch als Inhalt ausformuliert mitgeliefert. Die Ereignisse selbst haben nur allgemeinen Signalcharakter (Nadja, S. 19/20). Ihre Bedeutsamkeit steht allerdings außer Zweifel, und Breton warnt den Leser davor, die Ereignisse nur als zusammenhang- und belanglose »Faits divers " zu betrachten.[120]

Nun ist es in Nadja aber durchaus nicht so, daß eine durchgehende, z. B. chronologische Ordnung fehlte. Doch selbst wenn Breton konsequent in der Ich-Form schreibt und sich zum Teil sogar äußerst exakt an die chronologische Ereignisabfolge hält, so läßt er es an Zusammenhang bewußt fehlen und verfolgt nach Meinung von $M$. Beaujour » eine Strategie der Unterbrechung und der scheinbaren Unordnung «.[121] Die einzelnen Teile werden zwar in der Art von Dokumenten bzw. Tagebucheintragungen datiert [122], jedoch nicht in einen kontinuierlichen und motivierten biographischen Zusammenhang gebracht, sondern lediglich aneinandergereiht. Das Vorwort von 1962 stellt jedoch nachträglich klar, daß die Abfolge der Ereignisse alles andere als willkürlich und beliebig vertauschbar ist. [123] Der Wunsch Bretons nach "offenen " Büchern (»battant comme une porte ", Nadja, S. 149) und die Ergänzungen von 1962 (Vorwort, Photos und einzelne Anmerkungen) dürften kaum so gedeutet werden, als ob beliebige Ergänzungen und Umstellungen denkbar wären.[124]

Die makrostrukturelle Gliederung des Werkes in drei Abschnitte, die vom Autor drucktechnisch abgesetzt sind, sieht folgendermaßen aus: 
1. Eine Art theoretische ("Qui suis-je?") und praktische Exposition, die mit einer Reihe von Ereignissen und Begegnungen in den folgenden Abschnitt einstimmt. (Nadja, S. 2-55)

2. Das 'Tagebuch der Begegnungen bis zum Abbruch der Beziehungen und die Bewertung dieser Erfahrungen (bis hin zur Internierung Nadjas) für die Identitätsfindung des Autors ("Qui vive? est-ce moi seul? est-ce moi-même? "). (Nadja, S. 57-138)

3. Rückblick auf Nadja, die nachträglich nur als Präfiguration der erfüllten Liebe und der nun endlich geschauten "konvulsivischen Schönheit " erscheint. (Nadja, S. 139-155)

Das Fehlen einer traditionellen syntagmatischen Verknüpfung veranlaßt G. Steinwachs dazu, für Nadja "paradigmatisches Lesen « zu fordern:

Denn, darüber kann auch die konventionelle Form der Drucklegung nicht hinwegtäuschen, in der "Nadja" dominieren die paradigmatischen die syntagmatischen Einheiten. Das hängt damit zusammen, daß Bretons Prosa sich wesentlich am Merkmal des Poetischen überhaupt, an der Metapher, orientiert, die bekanntlich zur paradigmatischen Ebene im gleichen engen Verhältnis steht wie nur die Metonymie zur syntagmatischen Ebene.[125]

Dabei beachtet Steinwachs jedoch nicht genügend, daß die Ereignisse durch Breton selbst schon doppelt syntagmatisch geordnet sind und diese Ordnung es ihr erst ermöglicht, von einer Paradigmen-»Reihe " bzw. von der "Deklination " eines einzigen Paradigmas [126] zu sprechen. Die Einzelepisoden bestehen meist (nicht immer) aus zwei Komponenten, die vom Autor ausdrücklich in Beziehung zueinander gesetzt werden: etwa daß Eluard Breton im Theater zuerst mit jemand anderem verwechselt, ihn dann aber später doch kennenlernt (Nadja, S. 24/5). Außerdem stehen die Einzelepisoden untereinander in einem syntagmatischen Zusammenhang, dadurch daß Breton sie als "die markantesten Episoden meines Lebens", im Zentrum die Begegnung mit Nadja, unter dem Generalthema der Identitätssuche ("Qui suis-je? «) vergleichbar einer Reihenmetapher zusammenfaßt. Die Episoden sind keine beliebig substituierbaren Paradigmata, d. h. auch nicht beliebig austauschbar, sondern sie bringen vermittels eines strukturierten Modells einen metaphorischen Erkenntnisprozeß in Gang. Die Begegnung mit Nadja ist zweifellos der entscheidende Gipfelund Wendepunkt des ganzen Textes, dem die ersten berichteten Ereignisse nur präludieren. Die Erfahrung mit Nadja dient dann wiederum nur als Hintergrund für die neueste Begegnung, die die Erfüllung von Bretons Hoffnungen im letzten Teil bringt.

Statt von paradigmatischer Lektüre müßte man wohl von einer metaphorischen sprechen; metaphorisch allerdings in dem von uns schon expliziten Sinne von P. Ricœur, der anders als Jakobson [127] (und G. Steinwachs) die Metapher, im Gegensatz zu der der syntagmatischen Achse zugeordneten Metonymie, nicht der paradigmatischen Achse allein zuordnet (Metapher als Substitution), sondern in der Metapher (als widersprüchlicher Prädikation) eine Synthese der beiden Sprachtätigkeiten der Selektion und der Kombination erkennt [128] und so die Metapher in den Rahmen der poetischen Verfahren nach dem sog. Äquivalenzprinzip stellt. Damit rückt der Roman, seither eine Domäne weitgehend metonymischer (realistischer) Darstellung, in den Bereich der poetischen (metaphorischen) ein. Ein Prozeß, der der Romantechnik eine Vielzahl von poetischen Verfahren zur zusätzlichen Semiose 
eröffnet (vgl. den Nouveau Roman) und dem Leser durch die Zerstörung klischierter Erwartungen an die Ereignisabfolge und Ereignisverknüpfung eine erhöhte schöpferische Eigeninitiative bei der Sinnkonstitution zumutet.

Im Gegensatz zu den sog. automatischen, dominant poetischen Texten lenkt Breton den metaphorischen Prozeß, d. h. die schöpferische Überbrückung der "Abgründe " zwischen den "Fakten «, entsprechend der Reduktion der Kluft zwischen den beiden Gliedern einer Metapher, durch eingeschobene Überlegungen und Deutungsversuche; was um so leichter geschieht, als er ja das Material mit einer zeitlichen Distanz von einem guten halben Jahr ordnete. Das Thema von Nadja ist nicht nur wie bei den meisten "automatischen " Texten implizit durch die Metaphernstruktur (oder vielleicht noch andeutungsweise durch eine Überschrift) auf der sekundären referentiellen Ebene gegeben, sondern das Thema des Buches, die Identitätsfindung des surrealistischen Ich des Autors verbunden mit seiner Begegnungsund Liebesfähigkeit, wird ausdrücklich gestellt.

Nadja ist ein Dokument der Fremd- und Selbstbeobachtung. Breton ist gleichzeitig (frei) assoziierender Patient und registrierender, teilweise analysierender Beobachter seiner selbst und Nadjas sowie der beide begleitenden Umstände. So kommt es zu einer eigenartigen Mischung aus Dokumenten, theoretischer Deutung dieser Dokumente (z. B. der Bilder Nadjas) und eigentlich surrealistischen poetischen Texten.[129] Diese dritte poetische Komponente äußert sich allerdings mehr auf der schon erwähnten makrostrukturellen Ebene metaphorischer Ereignisverknüpfung als auf der Ebene sprachlicher Gestaltung einzelner Textstellen. Lediglich an besonders exponierten Stellen oder solchen eigener Betroffenheit (z. B. beim Übergang von Teil 1 zu Teil 2 - Begegnung mit Nadja), in den Äußerungen (bes. den bildlichen) Nadjas und im dritten Teil verdrängt der surrealistische Diskurs momentan den "Ton eines Arztberichts", von dem Breton im Vorwort von 1962 spricht.

Im Zusammenhang mit diesem dokumentarischen, wissenschaftlichen Stil sind die Photos zu sehen. Sie sind überraschend kunstlos und langweilig und nach eigenen Erklärungen im Avant dire dazu da, die im Surrealistischen Manifest getadelte realistische Beschreibung überflüssig zu machen.[130]

Daß das nicht die einzige Funktion der Photos sein kann und ist, geht aus verschiedenen Beobachtungen hervor:

1. Tatsächlich gibt es Beschreibungen im Text, denen gegenüber die Photos keine zusätzliche Information hinsichtlich ihrer äußeren Eigenschaften bringen (z. B. die Fassade einer Kohlenhandlung, S. 25; das Objekt "unregelmäßiger HalbZylinder «, S. 49; außerdem fast alle der Zeichnungen Nadjas S. 118 ff.).[131]

2. Um Beschreibungen zu ersetzen, müßten die Photos besonders sscharf und reich an aussagekräftigen Details sein. Es sind aber fast ausnahmslos ausgesprochen nichtssagende Frontalaufnahmen von Personen und Gebäuden, wie sie von phantasielosen Amateuren ohne jeden künstlerischen und technischen Anspruch gemacht werden. Es besteht kein Zweifel, daß Breton damit seiner Absicht Ausdruck verleiht, lediglich die Faktizität und Existenz eines Orts bzw. einer Person zu dokumentieren, ohne deren Deutung zu präjudizieren. 
3. Die Photos sind nicht immer an den entsprechenden Textstellen eingefügt und zwar nicht nur aus druck- und bindetechnischen Gründen. Sie haben also nicht nur die oben benannte Hilfsfunktion in einem Ereignisablauf, sondern die Anordnung erfolgte offensichtlich teilweise nach ästhetischen Gesichtspunkten: Von der Abfolge der Seitenzahl her gesehen sind die Zeichnungen Nadjas irregulär angeordnet, so daß z. B. die Photos zu den Seiten 143 ("Au musée Grevin ") und S. 111 ("Ses yeux de fougère ... «) oder diejenigen der beiden Springbrunnen (zu S. 85/86) nebeneinander zu stehen kommen.

Die Photos haben also einerseits eine dokumentarische Funktion, sozusagen als Anlage zum Arztbericht, gleichzeitig sind sie gerade auf Grund ihrer fehlenden eigenen Aussagekraft offen für das Entstehen des Geheimnisvollen und Wunderbaren mit Hilfe des metaphorischen Prozesses, der durch die Gegenüberstellung von Photo zu Photo und von Photo zu Text in Gang gesetzt wird. Der triviale, die eigene künstlerische Aussage verweigernde Charakter der Photos verlagert die Suche nach der Bedeutung der Dinge in ihre syntagmatische Kombination mit Text und anderen Photos. Insofern fügen sich die Photos in die Metaphern- und Collagetechnik des übrigen Textes ein und eröffnen dem metaphorischen Prozeß eine zusätzliche, visuelle Dimension.

\subsection{Auf der Suche nach dem surrealistischen Leben}

Vordergründig, d. h. auf der primär referentiellen, dokumentarischen Ebene geht es in Nadja um ein zufälliges Zusammentreffen des Autors mit Menschen und Gegenständen. Der Zufall wird aber zur inneren Notwendigkeit erklärt und damit zur sinnvollen, bedeutenden Begegnung. Das metaphorische Prinzip wird in Nadja vom sprachlichen auf den lebensweltichen Bereich ausgedehnt. Breton tritt mit Menschen und Dingen in Kontakt, die zunächst im normalen metonymisch-biographischen Verlauf eines rollenfixierten bürgerlichen Lebens eigentlich nichts mit ihm zu tun haben, läßt sich seine Lebensgestaltung von ihnen prägen und versucht auf diese Weise aus dem berechneten, nützlichen, bloß vernünftigen Leben auszusteigen - kurz, er versucht die Poesie praktisch zu leben, metaphorisch [132], surrealistisch zu leben. Durch die nicht vorprogrammierte Begegnung und Entwicklung, eine Art automatische Lebensweise, soll das Ich wirklich zu sich selbst kommen, so wie die Gedanken in der automatischen Schreibweise.

Die zentrale Frage "Qui suis-je? « leitet den ersten Teil ein und beschließt den Bericht der Begegnung mit Nadja, die offensichtlich noch keine Antwort auf diese Frage gebracht hat: "Qui vive? Est-ce vous, Nadja? Est-il vrai que l'au-delà, tout l'audelà soit dans cette vie? Je ne vous entend pas. Qui vive? Est-ce moi seul? Est-ce moimême? " (Nadja, S. 138). Die "vollkommene und unwahrscheinliche Verwirklichung " seiner Hoffnungen (Nadja, S. 141) auf eine Begegnung und Liebe, die zur Selbstfindung führt, haben sich erst erfüllt, als er nochmals einige Monate später (Dezember '27) den dritten Teil anfügt.

Nur eines weiß Breton von Anfang an: Der Lebenssinn läßt sich weder in noch durch Arbeit finden, Arbeit, die sich allerhöchstens als nackter Broterwerb rechtferti- 
gen läßt, noch in einem geplanten, verplanten Leben [133], sondern er läßt sich erst finden durch Offensein gegenüber dem Zufall [134], den Begegnungen mit Menschen und Dingen. Dazu gehört aber eine gewisse »Voreinstellung «:

En ce qui me concerne, plus importantes encore que pour l'esprit la rencontre de certaines dispositions de choses m'apparaissent les dispositions d'un esprit à l'égard de certaines choses, ces deux sortes de dispositions régissant à elles seules toutes les formes de la sensibilité. (Nadja, S. $14 / 15$ )

Breton bezieht zwar diese Voreinstellung nur auf die "sensibilité " und weist einen Zusammenhang zwischen Ereignissen und eigener Initiative weit von sich ("ne répondant à aucune démarche de ma part ", "m'arrivant par des voies insoupçonnables ", Nadja, S. 22), in Wahrheit betrifft sie schon die bewußte Auswahl des Ortes, an dem das Wunderbare, die bedeutsame Begegnung erwartet wird. Den äußersten Rahmen bietet die Wahl des Wohnortes Paris, der, was Überraschungen und unverhoffte Begegnungen angeht, jeder französischen Provinzstadt, in der jeder jeden kennt, alles übersichtlich ist und in traditionellen Bahnen verläuft, den Rang ablaufen dürfte.[135]

Dort angekommen wählte der 22jährige Breton in schöner Bescheidenheit das Hôtel des Grands Hommes, place du Panthéon, als angemessenes Quartier. Nicht genug, daß er damit seine Zukunft als großer Mann suggestiv vorprogrammiert, sorgt die Adresse (place du Panthéon) gleich noch für seine kommende Vergöttlichung. Unter diesen (selbstgesetzten) Vorzeichen erhält das Zusammentreffen mit den Größen des Surrealismus nicht den Charakter des Zufälligen, sondern eher den des Selbstverständlichen und Notwendigen: Die kurzen Szenen zeigen Breton nacheinander mit Eluard, Soupault, Péret und Desnos. Zwischen Péret und Desnos ist bei der Erwähnung von Nantes eine unausgesprochene Erinnerung an sein Vorbild Jacques Vaché eingeflochten, an den später ein anekdotischer Bericht über gemeinsame provokative Kinobesuche erinnert (Nadja, S. 31/32).

Der "Zufall « der Begegnungen, besonders aber ihre Reihung in Nadja, hat ganz offensichtlich System. Das zeigt sich noch besser als an der eben verfolgten Reihe von Begegnungen mit Surrealisten an der nun folgenden, die durch angeblich ziellose, aber regelmäßige Spaziergänge auf dem Boulevard Bonne-Nouvelle (der Name soll Breton nicht verführt haben!?) [136] eingeleitet wird. Alle die nun berichteten Ereignisse und Begegnungen haben einen mehr oder minder offensichtlichen sexuellen Hintergrund und bereiten den "Auftritt Nadjas « vor (Nadja, S. 55).

Der Titel des zunächst erwähnten Films, L'Étreinte de la Pieuvre, liefert gleichsam die Primärmetapher für die nun folgende Kette, die vom Kino über das Theater zum Flohmarkt typische Orte schrankenloser Phantasie aneinanderreiht. Bretons zensierendes Über-Ich ist dafür verantwortlich, daß der erzählte Inhaltsausschnitt aus dem Film (Vervielfältigung der Chinesen, S. 30) mit dem ganz zuletzt erst genannten Titel (S. 31) nichts zu tun zu haben scheint. Eigenartigerweise erscheint die photographische Reproduktion einer informationsreicheren Inhaltsangabe des Films (Verfolgung des jungen Paares, Raub der Frau durch Bösewichter etc.) erst fünfzehn Seiten später, obwohl zwischen die Seiten 30 und 31 ohnehin schon Fotos eingefügt sind. 
Das Théâtre Moderne ist der Beschreibung nach ein schon nicht mehr zweifelhaftes Etablissement; es folgt der Tag-Wunsch-Traum nach der Begegnung mit einer nackten schönen Frau nachts im Wald, der ergänzt wird durch die tatsächliche Beobachtung einer Exhibitionistin am Electric-Palace. In einer Art Chiasmus koppeln auch die beiden nächsten Abschnitte, nur in umgekehrter Reihenfolge, das reale Erlebnis einer Theateraufführung mit einem anschließenden und damit verbundenen Traum. Sowohl die ausführlich wiedergegebene Sex-and-Crime-Atmosphäre des Stücks Les Détraquées (Nadja, S. 35-44) als auch der Traum vom moosfarbenen Insekt (Nadja, S. 45-48) führen das sexuelle Thema fort. In einer Anmerkung von 1962 zu der mit einem Photo verewigten Hauptdarstellerin des Theaterstücks, Blanche Derval, wirft er sich sogar vor, keine Beziehung zu ihr angeknüpft zu haben.[137]

Die nächsten beiden Szenen sind wieder gekoppelt, obwohl sie anscheinend zeitlich nicht beieinander liegen. Breton begegnet zweimal jungen Rimbaudverehrerinnen, die erste spricht Breton zu seiner Überraschung an, um ihm Rimbaudgedichte zu rezitieren, die zweite dichtet selbst und kennt gar schon Aragons Paysan de Paris. Die "attraction passionnelle " ist offensichtlich. Zwischen die beiden Begegnungen schiebt sich in Klammern der Fund des ebenfalls abgebildeten (Nadja, zwischen S. 46/ 47) eigenartigen Halb-Zylinders im Schrein. Die Bildunterschrift ("Pervers enfin comme cette sorte de demi-cylindre blanc irrégulier ... «) verkürzt den Text von S. 49 ("en quête de ces objets qu'on ne trouve nulle part ailleurs, démodés, fragmentés, inutilisables, presque incompréhensibles, pervers enfin au sens où je l'entends et où je l'aime, comme par exemple cette sorte de demi-cylindre blanc irrégulier, verni «) und rückt das bei einem Leser psychoanalytischer Literatur wohl nicht zufällige Adjektiv "pervers" ein in die Reihe der Exhibitionistin, Les Détraquées und des in der nächsten Szene auftauchenden Handschuh-Fetischs. Das Objekt im Schrein verweist auf Gliedmaßen von Heiligen wie sie in Reliquienschreinen aufbewahrt werden.

Mit der Dame au gant in Verbindung gebracht werden zwei Vexierbilder [138]: das erste ein Schild, das je nach Perspektive MAISON ROUGE oder POLICE zu lesen ist, das zweite im Besitz der oben genannten Frau, das Tiger, Gefäß [139] und Engel gleichzeitig darstellt. Trotz fehlender »rationaler Korrelation« war Breton eine "Annäherung « dieser beiden Vexierbilder " unvermeidlich «. Im Kontext der gesamten Reihe gehört das erste Vexierbild in den Assoziationsbereich verbotener ("Police") Liebe ("Maison rouge"), das zweite zeigt gleichsam drei Gesichter, drei Inkarnationen der Frau; der Frau, die als Nadja nun in das Leben des ordentlich und bürgerlich verheirateten Breton eintritt. Die Ungewöhnlichkeiten der Begegnungen und die Perversität (im Sinne von: die herrschende Moral mißachtend) der in den besprochenen Einzelepisoden vorgeführten Liebe präfigurieren den Versuch, surreal zu leben und zu lieben.

\subsection{Die Begegnung mit Nadja}

Der in sich formal geschlossenste Teil des Buches ist, schon auf Grund der einzigen Zentralgestalt, der Bericht über Bretons Verhältnis zu Nadja. Ein streng chronologischer, tagebuchartiger Abschnitt (S. 57-108) wird ergänzt durch einen, der die 
Begegnungen resümiert und bewertet (S. 109-125). Die Nachricht von Nadjas Internierung löst eine Attacke gegen die Irrenanstalten aus, und veranlaßt Breton zu einer Rechtfertigung seines eigenen Verhaltens gegenüber Nadja (S. 125-138).

Noch vor dem Eintritt in die Nadja-Episode, am Ende des ersten Teils (S. 55), steht ein kurzer Textabschnitt, der in surrealistischer Sprache ein Bild entwirft, das in Nadjas gelebten Surrealismus einstimmen soll, aber auch gleich schon das Ergebnis der Begegnung vorwegnimmt:

Enfin voici que la tour du Manoir d'Ango saute, et que toute une neige de plumes, qui tombe de ses colombes, fond en touchant le sol de la grande cour naguère empierrée de débris de tuiles et maintenant couverte de vrai sang!

Zum Verständnis kurz ein paar Informationen zum Kontext: Das einzige dem Text beigegebene Photo des in einen Gutshof verwandelten Renaissance-Landschlosses Manoir d'Ango zeigt eine Art reich verzierten, massigen Turm, ein großes, stabiles Taubenhaus, wie es früher auf landwirtschaftlichen Anwesen hauptsächlich zur Gewinnung von Dünger aus Taubenmist errichtet wurde. Breton besucht den Landsitz, um in Ruhe zu schreiben; er pflegt dies in einer Art Jägerstand zu tun ("une cahute masquée artificiellement de broussailles ", Nadja, S. 22), der in eigenartigem Kontrast zum abgebildeten Gebäude steht: hier das Manoir und sein Taubenhaus als Inbegriff des Stabilen, Zivilisierten und Nützlichen - dort eine primitive Hütte aus der Entwicklungsstufe eines Jägers am Rande der Wildnis (des Waldes) und der Nacht ( chasse au grand-duc ", Nadja, S. 23). Breton stellt sich bewußt außerhalb der Zivilisation bei seinem Versuch, seine Erfahrungen mit einem reicheren, umfassenderen Leben als dem normalen von der modernen Zivilisation verstümmelten niederzuschreiben. Der Auftritt Nadjas auf der Bühne des normalen, gesicherten Lebens wird mit Hilfe einer absoluten Metapher in eins gesetzt mit der visionären Explosion des ebenso stabilen Taubenturms. Diese Explosion fordert allerdings das Leben der unschuldigen Tauben ("neige de plumes «), sprich das Leben Nadjas, ein Opfer, das sich durch sein Blutzeugnis abhebt vom normalen, bloß zeitbedingten AbnützungsTod, dessen Spuren sich als Ziegelscherben auf dem Boden des Hofes finden. Bezeichnenderweise aber beobachtet Breton diesen Vorgang nur als etwas, das außerhalb von ihm vor sich geht, ihn zwar berührt, aber nicht selbst in den Untergang mitreißt.

Denkt man an die Analogie zwischen dem metaphorischen Prozeß, der im surrealistischen Bild durch die Annäherung von seither Unvereinbarem, Nicht-Zusammengehörigem plötzlich einen erleuchtenden Funken überspringen läßt, und dem »objektiven Zufall«, der Ähnliches im Bereich des Zusammentreffens von Mensch und Ereignis oder auch von Mensch und Ding ("trouvaille ") bewirkt, so wäre die für einen Surrealisten adäquate Begegnungsart zwischen Mensch und Mensch die Liebe als " coup de foudre".[140]

So wie aber im metaphorischen Prozeß beide Metaphernelemente erst dann zu einer neuen Einheit verschmelzen, wenn sie ihre seitherige konventionelle Bedeutung (teilweise) aufgeben - Breton: "les mots font l'amour " [141] - so ist der " amour fou " zwischen zwei Menschen erst dann möglich, wenn jeder einen Teil seiner seitherigen Identität aufgibt. Geschieht das bei einem Teil nicht, wird der andere zum Objekt, zur 
bloßen "trouvaille «. Breton spürte diesen Mangel in seinem Verhältnis zu Nadja und er nennt auch die Indizien: die Nadja umgebenden Dinge sind ihm näher als sie selbst (Nadja, S. 88); er liest ihre Briefe nicht als ihn direkt existentiell betreffend, sondern er beurteilt sie ästhetisch, unter dem Gesichtspunkt ihrer poetischen Qualität [142]; ebenso beschreibt er einige der Zeichnungen im "Ton des Arztberichts ", obwohl er persönlich darin involviert ist.

Ganz offensichtlich beobachtet er sie mehr, als daß er sie liebt [143], obwohl die erste Begegnung der beiden, ein typisch herbeigeführter surrealistischer 'Zufall,, einiges versprach:

Le 4 octobre dernier, à la fin d'un de ces après-midi tout à fait désœuvrés et très mornes, comme j'ai le secret d'en passer, je me trouvais rue Lafayette [...] sans but je poursuivais ma route [...] Tout à coup, alors qu'elle est peut-être encore à dix pas de moi, venant en sens inverse, je vois une jeune femme, très pauvrement vêtue, qui, elle aussi, me voit ou m'a vu. Elle va la tête haute, contrairement à tous les autres passants. Si frêle qu'elle se pose à peine en marchant. Un sourire imperceptible erre peut-être sur son visage. [...] Je n'avais jamais vu de tels yeux. Sans hésitation j'adresse la parole à l'inconnue, tout en m'attendant, j'en conviens du reste, au pire. Elle sourit, mais très mystérieusement, et, dirai-je, comme en connaissance de cause, bien qu'alors je n'en puisse rien croire. Elle se rend, prétend-elle chez un coiffeur du boulevard Magenta (je dis: prétend-elle, parce que sur l'instant j'en doute et qu'elle devait reconnaittre par la suite qu'elle allait sans but aucun). (Nadja, S. 57-59)

Für Breton ist Nadja eine Inkarnation der surrealistischen Lebensweise. Sie bezeichnet sich selbst als "âme errante " (Nadja, S. 69), die ziemlich ziel- und planlos in unbestimmter Erwartung durch die Straßen irrt (S. 113) und ihr Leben in der Art eines Spiels einrichtet, in dem auf ein beliebiges Stichwort hin eine beliebige Geschichte erzählt wird (S. 73/74). Breton ist fasziniert von ihrer Leichtigkeit (S. 93, 115), ihrer scheinbaren Freiheit von allen irdischen Fesseln (S. 88), die sie über die "einfachen Dinge der Existenz", die sog. Erfordernisse des Alltags hinweggehen läßt, als existierten sie für sie nicht (S. 125). Dieses Schweben über der Wirklichkeit nach der Art eines "génie libre" (S. 110) ist die Grundlage ihrer bedingungslosen Liebe zum vergötterten (S. 110) Breton. Während sie sich ihm rückhaltlos ausliefert, ihm zuliebe auf ihren sonstigen Gelderwerb [144] verzichtet, zieht er sich instinktiv, aus Selbsterhaltungstrieb, wie er es nennt (S. 20,136), allmählich von ihr zurück.

Für diejenigen, die sich in Nadja ver-^narren`, wie der Gerichtspräsident G..., verschiedene Betrunkene, der ungeschickte Kellner, die Schwarzen (!) (S. 97/98), oder denen sie im wahrsten Sinn des Wortes den Kopf verdreht (S. 106-108), hat Breton nur Verachtung bzw. Erstaunen übrig. Ihre Berichte über Erlebnisse mit anderen Männern langweilen und ärgern ihn als etwas, was ihn an ihre reale ärmliche und hilflose Situation erinnert (S. 113-115) und sein Idealbild eines vollkommenen surrealistischen Lebens (zer)stört.

Seine andauernde reservatio mentalis im Verhalten ihr gegenüber wird von ihm selbst als Verrat und Sakrileg empfunden. Jedenfalls legt das "zufällige " Zusammentreffen zweier Ereignisse diese Bedeutung nahe: ein Kuß wird von Nadja mit dem Satz kommentiert "la communion se passe en silence", wobei sie die Zähne 
mit der Hostie vergleicht. - Am darauffolgenden Morgen findet Breton eine Postkarte Aragons vor, die einen Ausschnitt aus Paolo Uccellos La profanazione dell'ostia (S. 93/94) zeigt.

Diese Ereignisse sind eingebettet in eine Bitte Nadjas um Geld und die durch einige Mißverständnisse verzögerte Erfüllung dieser Bitte. In der Erwähnung, daß er ihr das Dreifache der erbetenen Summe gegeben habe, zeigt sich das schlechte Gewissen Bretons über diese "mit allen Kunstgriffen geistiger Verführung d durchgeführte "Verfolgung" (S. 109). Selbstkritisch gesteht er sich ein, daß es vielleicht an ihm, an seinem die Liebesprobe nicht bestehenden Realitätssinn gelegen haben könnte, daß sich das Wunder einer echten Beziehung zu Nadja und damit vielleicht ihrer Rettung nicht ereignete.[145]

Quelque envie que j'en ai eue, quelque illusion peut-être aussi, je n'ai peut-être pas été à la hauteur de ce qu'elle me proposait. Mais que me proposait-elle? N'importe. Seul l'amour au sens où je l'entends - mais alors le mystérieux, l'improbable, l'unique, le confondant et l'indubitable amour - tel enfin qu'il ne peut être qu'à toute épreuve, eût pu permettre ici l'accomplissement du miracle. (Nadja, S. 127)

Daneben nehmen sich die Verteidigungsversuche, die sich an die Nachricht von Nadjas Internierung in einer Irrenanstalt anschließen, ziemlich kläglich aus. Nach der Devise 'Angriff ist die beste Verteidigung, attackiert er (gewiß zu recht) die Psychiatrie und ihre Verwahrungs- und Behandlungsmethoden. Doch sein eigenes Verhältnis zum Wahnsinn ist eigenartig gespalten. Einerseits behauptet er im Einklang mit den Theorien aus dem Surrealistischen Manifest, daß die Grenze zwischen Wahn und Nicht-Wahn nicht existiere (Nadja, S. 137), ja er versteigt sich sogar zu der Behauptung, für Nadja komme es fast auf das Gleiche heraus, ob sie in oder außerhalb der Anstalt sei [146], andererseits scheinen er und seine Freunde diese Grenze sehr genau zu kennen und auch zu respektieren, sonst könnte er sich nicht darüber wundern, daß Nadja sie überschritten hat.

Or, je n'ai jamais supposé qu'elle pût perdre ou eût déjà perdu la faveur de cet instinct de conservation - auquel je me suis déjà référé - et qui fait qu'après tout mes amis et moi, par exemple, nous nous tenons bien - nous bornant à détourner la tête - sur le passage d'un drapeau, qu'en toute occasion nous ne prenons pas à partie qui bon nous semblerait, que nous ne nous donnons pas la joie sans pareille de commettre quelque beau "sacrilège ", etc. (Nadja, S. 136).[147]

Nadja war im Gegensatz zu Breton offensichtlich nicht fähig, ihre "Eigenmittel " [148] bei der von ihm so geförderten, von "jeglicher pragmatischen Überlegung unabhängigen schrankenlosen Befreiung " richtig einzuschätzen.

Das Fazit der Begegnung mit Nadja scheint nicht gerade optimistisch. Ein bedingungslos surrealistisches Leben, wie er es in Nadja sieht und fördert, ist nur um den Preis der körperlichen Selbstzerstörung oder zumindest des seelischen Todes, verbunden mit dem Verlust jeglicher Freiheit, zu verwirklichen. Das Buch endet daher (vorläufig) auf die gleiche Frage, mit der es begonnen hat, mit der Frage nach dem Ich. Der einzige Fortschritt in der Selbsterkenntnis dürfte für Breton nach der Begegnung 
mit Nadja darin liegen, daß er die Grenze klarer sieht, bis zu der er in seinem Streben nach surrealistischer Freiheit und Selbstverwirklichung zu gehen bereit ist.

Breton balanciert auf dem schmalen Grat [149] zwischen Anpassen und Ausflippen, ein Drahtseilakt, bei dem einige seiner Weggefährten abstürzten: Vaché, Rigaut und Crével begingen Selbstmord, Nadja und Artaud endeten in der Irrenanstalt.

\subsection{Die Erfüllung surrealistischer Liebe - »Les Aubes"}

Wie wenn ihm diese Zukunftsperspektive für den noch jugendlichen Surrealismus nun doch etwas zu trübe erschiene, findet Breton doch noch eine (weibliche) Hand [150], die ihm den Weg zur himmelblauen Morgenröte weist [151] und ihn so, durch neue (bessere) Erfahrungen gestärkt, die Feder nochmals zur Hand nehmen läßt.

Nun ist alles anders, plötzlich gelten die Wenn und Aber, die Breton an seine Liebe zu Nadja knüpfte, nicht mehr. Er entschuldigt sich ausdrücklich (Nadja, S. 149) für seinen Satz, daß die surrealistische Liebe, wie er sie sich vorstellte und wie sie Nadja vielleicht hätte retten können, nicht jeder Belastung gewachsen sein könnte (Nadja, S. 127). Jetzt, wo weniger sein Geist (wie bei Nadja) als sein Herz (S. 141) betroffen ist, jetzt kann er alle Abstriche, alles Zögern bei der Verwirklichung surrealistischen Lebens und surrealistischer Liebe über Bord werfen.[152] Seine Leidenschaft läßt ihn nun in die von ihr gestellte Bedingung "Alles oder nichts" (S. 152) einwilligen, das was bei Nadja als Unvernunft ("déraison «) galt, werden nun "strahlende Vernunftgründe" (Nadja, S. 149). Das nicht namentlich genannte Du, das Breton nun »die unwahrscheinliche Verwirklichung aller seiner Hoffnungen " (Nadja, S. 141) bringt, der Endpunkt einer Kette, für die die anderen Frauen nur vorläufige Substitute waren (S. 151), wird nach Art einer Marien-Litanei mit allen Superlativen ausgestattet (S. 149/150) und dennoch - oder gerade deswegen? - bleibt dieses Du und seine Surrealität im Gegensatz zu Nadja seltsam abstrakt, unwirklich und farblos.

Auch der pointenlose Irrenwitz von $M$. Delouit, diese "so dumme, so verworrene und so rührende Geschichte « ( $S$. 147), die zum ersten gehört, was er seiner neuen Liebe erzählt, ist nicht gerade geeignet, surrealistische Lebensart erstrebenswert erscheinen zu lassen. M. Delouit ist im Sinne praktischen, vernünftigen Handelns lebensuntüchtig (kann sich die Zimmernummer im Hotel nicht merken), wählt dafür aber eine recht unkonventionelle, surrealistische Art, das Treppensteigen zu vermeiden: er springt einfach im 3. Stock aus dem Fenster.

Dieser dritte Teil von Nadja ist von Breton ganz offensichtlich als positive Korrektur des Nadja-Erlebnisses gedacht, als Beweis für die Möglichkeit surrealistischer Liebe. Doch den Lesern Nadjas - auch den professionellen [153] - bleibt eher das Scheitern des Surrealisten Breton an der Liebe Nadjas haften als die schließlich doch noch geschaute "konvulsivische Schönheit « (Nadja, S. 155), die das Thema des 1937 erschienenen Amour Fou bildet.

Die Formulierung vom »Roman, der wie ein Türflügel schlägt « (Nadja, S. 149) bezieht sich also nicht nur auf die formale Offenheit, sondern bedeutet im Gegensatz zur verriegelten Tür eines Gefängnisses oder Irrenhauses auch die Öffnung auf eine hoffnungsvolle surrealistische Zukunft. 
Bei der Analyse von Nadja hat sich gezeigt, daß der Eindruck des Unzusammenhängenden, Zusammengestoppelten, beliebig Ergänzbaren und Umstellbaren nur oberflächlich ist. Breton zerstört nicht mutwillig eine einheitliche in sich geschlossene Wirklichkeit [154], sondern er versucht im Gegenteil, ihre immanent verborgene, aus dem eigenen Unbewußten, nicht aus der Transzendenz stammende Einheit abzulauschen. Eine Einheit, die nichts mit dem zu tun hat, was man sich unter einem normalen, gut bürgerlichen Lebenslauf eines unproblematischen oder auch eines "problematischen " Helden vorstellt, und dessen einzelne Etappen in ihrer Bedeutung innerhalb eines solchen erreichten oder verfehlten Lebensplanes festliegen. Die Bedeutung der Wirklichkeitsfragmente in Nadja läßt sich durchaus interpretativ erschließen, allerdings nicht nach einem vorgängigen »festen Bezugssystem allegorischer Deutung " [155], sondern nach einem aus der Struktur des Werks selbst gewonnenen 'Schlüsselı. Dieser Schlüssel ist die Suche nach dem surrealistischen Ich und seiner Begegnung mit sich selbst im Anderen, über das Scheitern an Nadja bis zur schließlichen Selbstverwirklichung im "amour fou «.

L'œuvre d'art, au même titre d'ailleurs que tel fragment de la vie humaine considérée dans sa signification la plus grave, me paraît dénuée de valeur si elle ne présente pas la dureté, la rigidité, la régularité, le lustre sur toutes ses faces extérieures, intérieures, du cristal. Qu'on entende bien que cette affirmation s'oppose pour moi, de la manière la plus catégorique, la plus constante, à tout ce qui tente, esthétiquement comme moralement, de fonder la beauté formelle sur un travail de perfectionnement volontaire auquel il appartiendrait à l'homme de se livrer. Je ne cesse pas, au contraire, d'être porté à l'apologie de la création, de l'action spontanée et cela dans la mesure même où le cristal, par définition non améliorable, en est l'expression parfaite. La maison que j'habite, ma vie, ce que j'écris: je rêve que cela apparaisse de loin comme apparaissent de près ces cubes de sel gemme. (Amour fou, S. 14)

\section{Surrealismus und Politik [156]}

Die seitherigen Beobachtungen haben ergeben, daß der metaphorische Prozeß, der durch das surrealistische Bild im Sprach- und Bewußtseinsbereich in Gang gesetzt wird, sich im "poetischen Leben " eines Surrealisten in einem Lebensstil äußert, der der zufälligen Begegnung, dem überraschenden Fund und dem dadurch gestifteten poetischen Zusammenhang den Vorrang vor der Arbeit und dem planvollen ,Aufbau einer Existenz، gibt.

Welchen Gefahren ein solcher Lebensstil in einer zweckrationalen Gesellschaft ausgesetzt ist, zeigt sich an Nadja. Sie ist der Spannung zwischen surrealistischem Leben und den Anforderungen der Wirklichkeit nicht gewachsen, sie bringt es nicht fertig, den nun einmal herrschenden Normen soviel zu opfern, daß sie von der sie umgebenden Gesellschaft ertragen würde - sie endet ausgeschlossen aus der Gesellschaft in der psychiatrischen Anstalt.

Der Gedanke liegt nahe, ein Programm zur Befreiung des Menschen nicht nur mit Hilfe der Poesie, sondern handfester mit Hilfe der Politik verwirklichen zu wollen. Da es sich um eine Befreiung von einer ganz bestimmten Sklaverei, nämlich der bürgerlichen von Familie, Vaterland, Moral und Religion geht, scheint auch der politische 
Verbündete schon bereit zu stehen, dem man nur zu folgen brauchte, nämlich die erst 1921 gegründete KPF. Es ist für Breton aber nicht von Anfang an selbstverständlich, daß ein Surrealist in seinem Bemühen, das Leben des Menschen in allen Bereichen von Grund auf zu verändern, auch politisch darum kämpfen muß, daß die ihn umgebende Gesellschaft seine freie Entfaltung nicht durch repressive Maßnahmen verhindert. Noch im Surrealistischen Manifest (1924) wird das Problem der Aktion nur ganz zum Schluß, wie um sich noch schnell einer eher lästigen Pflicht zu entledigen, angesprochen und mit dem bezeichnenden Satz beendet: "L'existence est ailleurs.«

In der im gleichen Jahr einsetzenden Zeitschrift La Révolution surréaliste stehen Poesie und Traum im Vordergrund, außerdem Umfragen und Untersuchungen zu Selbstmord (No. 2), Sexualität (No. 11) und Liebe (No. 12); erst in zweiter Linie und eng mit dem Poetischen verbunden kommen die vehementen Frontalangriffe gegen die Stützen der bürgerlichen Gesellschaft, als da sind: Vaterland, Familie, Religion, Militär und die Universitäten. Ausgesprochen politisch aktuelle Themen werden kaum angesprochen, polit-theoretische Artikel fehlen fast ganz.[157] Die erste Sorge der Surrealisten ist nach wie vor die Verunsicherung und Veränderung des eigenen Bewußtseins, nicht die praktische Umgestaltung des gesellschaftlichen Lebens. So lautet der 5. Punkt der ganz im Zeichen der "totalen Befreiung des Geistes « stehenden Déclaration du 27 Janvier 1925:

Nous ne prétendons rien changer aux mœurs des hommes, mais nous pensons bien leur démontrer la fragilité de leurs pensées, et sur quelles assises mouvantes, sur quelles caves, ils ont fixé leurs tremblantes maisons.

Trotz Bretons konstruktivem Geist, der sich schon bei der Auseinandersetzung mit Dada durchgesetzt hatte, wagen sich die Surrealisten nur zögernd an ein politisches Engagement. Das liegt weniger daran, daß sie nicht etwa von der Notwendigkeit überzeugt wären, daß der Kampf um die "totale Befreiung des Geistes « nicht auch politisch geführt werden muß, als daran, daß sie mit den Repräsentanten der einzigen politischen Richtung, die für sie von ihren Zielen her überhaupt in Frage kam, nämlich mit der UdSSR und der KPF nicht so recht glücklich waren. Berühmt wurde die abwertende Äußerung Aragons über die Sowjetunion in einem pamphletären Nachruf für A. France [158], wo er von "Moscou la gâteuse" spricht. Noch deutlicher wird er in seiner Antwort auf Attacken der Zeitschrift Clarté wegen eben dieser Äußerung. Da heißt es [159]:

Si vous me trouvez fermé à l'esprit politique et mieux: violemment hostile à cette déshonorante attitude pragmatique, qui me permet d'accuser au moins de modérantisme idéal ceux qui à la fin se résignent, c'est, vous n'en pouvez douter, que j'ai toujours placé, que je place l'esprit de révolte bien au delà de toute politique. [...] La révolution russe, vous ne m'empêcherez pas de hausser les épaules. A l'échelle des idées, c'est au plus une vague crise ministérielle [...] les problèmes posés par l'existence humaine ne relèvent pas de la misérable petite activité révolutionnaire qui s'est produite à notre orient au cours de ces dernières années.

Unter dem Eindruck des von den Franzosen und Spaniern (unter Franco) geführten Kolonialkrieges gegen die Rif-Kabylen stellten sich die Surrealisten jedoch an die 
Seite dieser der KPF nahestehenden Zeitschrift. In der No. 5 von La Révolution surréaliste erschien ein gemeinsamer Aufruf La Révolution d'abord et toujours (S. 31/2), der neben den allgemeineren Parolen zur geistigen Revolte, wie sie die Surrealisten pflegten, deutlich marxistisches Gedankengut enthält und den Auftakt zu einer engen Zusammenarbeit der beiden Zeitschriften bildete. Der Plan, gemeinsam die Zeitschrift La Guerre civile herauszugeben, scheiterte allerdings. Trotz dieser engen, allerdings indirekten Beziehungen zur KPF, zögerten Breton und seine Freunde, in die Partei einzutreten, obwohl sie immer wieder die Richtigkeit der Marx'schen Analysen und die Notwendigkeit einer politischen Revolution betonten.

Noch 1926 lehnte Breton in Légitime Défense [160] ein solches Parteiengagement ab, nachdem die Surrealisten von einem der ihren, der kurz zuvor in die KPF eingetreten war, Pierre Naville, fast ultimativ aufgefordert worden waren, endlich den Schritt vom Anarchismus zum disziplinierten Klassenkampf zu wagen. Breton weist die von Naville in Que peuvent faire les Surréalistes? [161] gestellte alternative Frage zurück:

"Oui ou non, cette révolution souhaitée est-elle celle de l'esprit a priori, ou celle du monde des faits? Est-elle liée au marxisme, ou aux théories contemplatives, à l'épuration de la vie intérieure? " Cette question est d'un tour beaucoup plus subtil qu'elle n'en a l'air, quoique sa principale malignité me paraisse résider dans l'opposition de la réalité intérieure au monde des faits, opposition toute artificielle qui cède aussitôt à l'examen. Dans le domaine des faits, de notre part aucune équivoque n'est possible: il n'est personne de nous qui ne souhaite le passage du pouvoir des mains de la bourgeoisie à celles du prolétariat. En attendant, il n'en est pas moins nécessaire, selon nous, que les expériences de la vie intérieure se poursuivent et cela, bien entendu, sans contrôle extérieur, même marxiste. Le surréalisme ne tend-il pas, du reste, à la limite ces deux états pour un seul [...].[162]

Obwohl Breton die Meinung vertritt, die KPF sei tatsächlich die » einzige Kraft, auf die man zählen kann ", dreht er gegenüber Naville gewissermaßen den Spieß um und stellt fest, daß es nicht an ihnen, den Surrealisten liege, wenn die Zusammenarbeit mit der KPF nicht funktioniere:

Si notre contribution à l'action révolutionnaire, dans ce sens, était agréée, nous serions les premiers à ne pas vouloir outrepasser les limites qu'elle comporte et qui sont en rapport avec nos moyens.[163]

Das Programm der KPF sei, gemessen an dem der Surrealisten, nur ein Minimalprogramm, und besonders der für den literarisch-kulturellen Teil der Humanité zuständige $\mathrm{H}$. Barbusse habe noch gar nicht verstanden, worum es bei der Revolution gehe und welche Rolle die Literatur dabei zu spielen habe.

Überraschenderweise entschlossen sich Aragon, Breton, Eluard, Péret und Unik 1927 doch in die KPF einzutreten, in dem Jahr, in dem P. Naville, der sie zum Eintritt gedrängt hatte, seinerseits schon wieder ausgeschlossen wurde. Offensichtlich schien ihnen das gemeinsame Ziel wesentlicher als die Unterschiede, die darüber bestanden, wie dieses Ziel zu erreichen sei.[164] Da Breton dennoch nicht bereit war, den Surrealismus völlig in der KPF aufgehen zu lassen, und an einer gewissen Eigenständigkeit festhielt, kam es immer wieder zu Reibereien mit der Partei. 
Im Second manifeste du surréalisme [165], das einerseits deutliche Spuren der radikalen Säuberung der surrealistischen Bewegung von politisch unzuverlässigen Elementen zeigt, wird andererseits eben diese Eigenständigkeit des Surrealismus unterstrichen. Breton nimmt Motive aus der Légitime défense wieder auf, wie die Vorwürfe gegen die Kulturpolitik der KPF und das mißtrauische Verhalten der Partei gegenüber der Loyalität der Surrealisten, die Bretons Meinung nach nicht sinnvoll, d.h. ihren Fähigkeiten entsprechend für die Partei eingesetzt werden.[166]

Kommunismus und Surrealismus sind gleichberechtigt, ja der Surrealismus ist eher die weitergehende Bewegung, an der die praktische Tätigkeit der KPF und auch der Sowjetunion zu messen ist.

Comment admettre que la méthode dialectique ne puisse s'appliquer valablement qu'à la résolution des problèmes sociaux? Toute l'ambition du surréalisme est de lui fournir des possibilités d'application nullement concurrentes dans le domaine conscient le plus immédiat. Je ne vois vraiment pas, n'en déplaise à quelques révolutionnaires d'esprit borné, pourquoi nous nous abstiendrions de soulever, pourvu que nous les envisagions sous le même angle que celui sous lequel ils envisagent - et nous aussi - la Révolution: les problèmes de l'amour, du rêve, de la folie, de l'art et de la religion. Or, je ne crains pas de dire qu'avant le surréalisme, rien de systématique n'avait été fait dans ce sens, et qu'au point où nous l'avons trouvée, pour nous aussi, sous sa forme hégélienne la méthode dialectique était inapplicable. (Manifestes, S. 95/96)

Le problème de l'action sociale n'est, je tiens à y revenir et j'y insiste, qu'une des formes d'un problème plus général que le surréalisme s'est mis en devoir de soulever et qui est celui de l'expression bumaine sous toutes ses formes. Qui dit expression dit, pour commencer, langage. Il ne faut donc pas s'étonner de voir le surréalisme se situer tout d'abord presque uniquement sur le plan du langage [...] (Manifestes, S. 108/9)

Die eigentliche Domäne des Surrealismus ist und bleibt also zunächst die künstlerische Sphäre (Manifestes, S. 138).

Zum offenen Bruch mit der KPF kam es dann im Gefolge der "Affäre Aragon «.[167] Aragon war zusammen mit Sadoul Ende 1930 zum Schriftstellerkongreß nach Charkow gefahren, hatte sich dort der Parteilinie unterworfen und dem "Idealismus « und "Freudianismus ", wie er in Bretons Zweitem surrealistischen Manifest zutage trat, abgeschworen. Nach seiner Rückkunft versuchte er noch einmal in einem größeren, äußerst gewundenen Artikel, Le Surréalisme et le devenir révolutionnaire [168], die Identität der Sichtweisen zu demonstrieren, die Bewegung auf Parteilinie zu bringen und gleichzeitig, ohne seine surrealistischen Freunde zu verprellen, die spezifische Erkenntnisrolle des Surrealismus innerhalb des historischen Materialismus und seine praktische Rolle im Klassenkampf zu unterstreichen. Als jedoch Aragon wegen seines Propagandagedichts für die UdSSR Front rouge der Anstiftung zum Mord angeklagt worden war und ihn Breton und andere Linksintellektuelle mit Hilfe des Kunstvorbehalts vor juristischer Verfolgung zu bewahren versuchten, gleichzeitig Breton aber poetische Regression feststellte, distanzierte Aragon sich von ihrer Schützenhilfe öffentlich und traktierte Breton als Konterrevolutionär. Im Jahr darauf besiegelte schließlich ein abfälliges Urteil über die Sowjetunion in der Zeitschrift Le Surréalisme au Service de la Révolution den endgültigen Bruch Bretons mit der KPF. 
Der französisch-sowjetische Beistandspakt (1935) und die Entwicklung in der Sowjetunion raubten den Surrealisten die letzten Illusionen:

Bornons-nous à enregistrer le processus de régression rapide qui veut qu'après la patrie ce soit la famille qui, de la Révolution russe agonisante, sorte indemne (qu'en pense André Gide?). Il ne reste plus là-bas qu'à rétablir la religion - pourquoi pas? - la propriété privée, pour que c'en soit fait des plus belles conquêtes du socialisme. Quitte à provoquer la fureur de leurs thuriféraires, nous demandons s'il est besoin d'un autre bilan pour juger à leurs œuvres un régime, en l'espèce le régime actuel de la Russie soviétique et le chef tout-puissant sous lequel ce régime tourne à la négation même de ce qu'il devrait être et de ce qu'il a été.

Ce régime, ce chef, nous ne pouvons que leur signifier formellement notre défiance.[169]

Bretons Scheitern, oder vorsichtiger formuliert, die Unmöglichkeit einer Zusammenarbeit mit der KPF, hat vor allem zwei Gründe. Der erste zog sich wie ein roter Faden durch die schon besprochenen Äußerungen Bretons vor dem Eintritt in die $\mathrm{KPF}$, und erst recht nach dem Bruch mit ihr, und ist historischer Natur, d. h. er hängt mit der Verfassung der KPF bzw. der Entwicklung der Sowjetunion zur damaligen Zeit zusammen. Der zweite Grund ist eng mit dem ersten verbunden und prinzipieller Art; er bezieht sich auf das Verhältnis von Poesie und Staatsräson, Freiheit und Engagement. Der Selbstmord Majakowskijs (1930), der Ablauf des Schriftstellerkongresses in Charkow und des Congrès International des Ecrivains pour la défense de la Culture (Paris 1935), der vom Selbstmord Crévels überschattet wurde und auf dem die Surrealisten ganz offensichtlich ausgebootet werden sollten, zeigten die Schwierigkeiten der Dichtung im Verhältnis zu einem stalinistischen Staat bzw. zu einer stalinistischen Partei, die auf bedingungsloser Unterordnung bestand und die hohen Ziele der Revolution in Bretons Augen schnödem Pragmatismus opferte.

Doch wäre es Breton über kurz oder lang wohl mit jeder (bis jetzt existierenden) politischen Partei so ergangen, denn es besteht ein grundsätzlicher Widerspruch zwischen einem Parteiprogramm und einem Programm wie dem Surrealistischen Manifest, auch wenn es einen politisch klingenden Titel hat. Das Prinzip des Traums und des Zufalls ist für die Arbeit einer Partei wohl kaum praktikabel, der es nicht in erster Linie um die Veränderung des Bewußtseins geht, sondern um eindeutige Aussagen und fertige Weltmodelle, die ihr helfen, ihre Wähler zu überzeugen und die Macht zu gewinnen, um mit ihr ihre Programmpunkte durchzusetzen. Dagegen ist es gerade ein Kennzeichen revolutionärer Kunst, daß sie auf solche vorgefertigten Modelle verzichtet und ihre Modelle permanent revolutioniert:

L'art véritable, c'est-à-dire celui qui ne se contente pas de variations sur des modèles tout-faits [...] ne peut pas ne pas être révolutionnaire, c'est-à-dire ne pas aspirer à une reconstruction complète et radicale de la société.[170]

Der Streit und der schließliche Bruch mit Aragon spitzt sich auf die Frage zu, auf welche Weise denn die Revolution, die soziale und die geistige, am entschiedensten vorangetrieben werden könne. Breton plädiert im Zweiten Surrealistischen Manifest dafür, die Kunst dem allgemeinen Verständnis zu entziehen ("Je demande l'occultation profonde, véritable du surréalisme ", Manifestes, S. 139), da alles, was "unmittelbar und allgemein verstanden wird ", der "Geistesverachtung " und »konterrevolu- 
tionärem« Geist entspringe (Manifestes, S. 115), gemäß seiner Einschätzung des Realismus als bloßer Verdoppelung des (schlechten) Bestehenden. Aragon sieht in diesem elitären Zug die Gefahr der bloßen Selbstbespiegelung und der faktischen Folgenlosigkeit. Er steckt sein Ziel der geistigen Revolution zunächst bescheidener zurück, um erst einmal an der Verbesserung der gesellschaftlichen Bedingungen des Lebens mitzuarbeiten, während Breton die soziale Revolution nur als eine Etappe zum Fernziel einer Änderung der gesamten conditio humana ansieht. Außerdem müssen sich die konkreten Schritte in dieser Richtung immer an diesem hohen Anspruch messen und bewerten lassen.

Nicht nur der zum Realismus bekehrte Aragon, auch Breton bemüht sich, allerdings mit Hilfe einer anderen, der surrealistischen Methode, die Realität besser zu erkennen und damit ihre Veränderung zu ermöglichen. Das "wahre Leben ", "das wirkliche Denken " soll aus seiner Versklavung befreit werden. Aragon weist selbst auf diese realistische Komponente im Surrealismus hin:

[...] je n'ai jamais cessé de penser [...], que dans surréalisme, il y a réalisme. Ce qui n'est pas une boutade. En tout cas, c'est par ce chemin là que j’ai accédé au réalisme [...] [171]

Der Streit zwischen Realismus und Surrealismus läuft darauf hinaus, wieviel Poesie dem potentiellen Leser und Bürger zugemutet werden kann, um eine im Sinne der Revolution optimale Wirkung zu erzielen. Denn daß die poetische Imagination auch im realistischen Roman die treibende Kraft sein muß, steht auch für Aragon seit seinem Paysan de Paris außer Diskussion, selbst wenn dieser Gesichtspunkt zwischenzeitlich etwas in den Hintergrund getreten sein sollte, bevor sich Aragon in seinen späten Romanen dem »experimentellen Realismus « zuwandte.[172]

\section{Zusammenfassung}

Der Vorwurf an den Surrealismus, er habe letztlich doch nur Kunst produziert statt das Leben zu verändern, ist in Wirklichkeit kein Vorwurf und zudem ein wenig voreilig.

Es ist sicher richtig, daß die unmittelbare politische Wirkung des Surrealismus in Frankreich, erst recht in der übrigen Welt, unbedeutend war und eventuell vorhandene bescheidene Ansätze zu einer solchen Wirksamkeit durch den Zweiten Weltkrieg und die folgende Restaurationsphase abgewürgt wurden. Doch lassen sich geistige Strömungen und ihre politischen Auswirkungen nur in größeren Zeiträumen messen. Die Rückverwandlung von Kultur in Natur ist ein Jahrhundertwerk. Erst die Geschichte bis zum Ende des Jahrhunderts wird zeigen, ob die Ansätze surrealistischer politischer Praxis, wie sie H. Marcuse in den weltweiten Studentenrevolten der $60 \mathrm{er}$ Jahre zu erkennen glaubte oder wie sie sich teilweise heute in der AlternativBewegung zu organisieren versuchen, sich weiterentwickeln und fähig sind, Bewußtsein und Leben allgemein und nachhaltig zu verändern.

Andererseits ist es unzweifelhaft, daß der Surrealismus das Leben seiner Anhänger umgemodelt hat und wenig von der Norm ihrer meist gutbürgerlichen Herkunft 
übrig ließ; bei dem Vorwurf, er sei letztlich nur Kunst geblieben, denkt man daher auch weniger an die Produzenten als an die Rezipienten surrealistischer Werke. Breton selbst ist der Versuchung erlegen, Autoren nach dem Gebrauch zu beurteilen, den ihre Rezipienten von ihren Werken machen; der Mythos des bekehrten, gut katholischen Rimbaud hat ihm sein früheres Idol verleidet. Das Beispiel Rimbaud konnte ihn aber auch lehren, daß die vollkommenste "occultation " nicht vor dem Mißbrauch und der Falschinterpretation schützt.

Von der Rezeption hängt es auch letztlich ab, ob Kunst nur Kunst oder auch Leben ist; die Frage wird nicht nur von der Kunst bzw. den Kunstwerken entschieden. Wenn der avantgardistische Schriftsteller keine Menschen als Publikum findet oder sich zu schaffen fähig ist, "die bereit sind, durch die geschriebenen Worte sich ihrer eigenen ,Weltanschauung [einer "neuen «, "zweifellos chaotischen Welt "] bewußt zu werden « [173], dann wird die aus dem 18./19. Jh. ererbte Vorstellung einer Autonomie der Kunst und ihre damit verquickte Unverbindlichkeit und Wirkungslosigkeit auch nicht überwunden werden können. Die Trennung von Kunst und Leben, die Möglichkeit, sie unverbindlich, bloß genießend zu rezipieren und zu konsumieren, hat zwei Quellen: erstens die besondere historische Lage, die der Kunst in der zweckrationalen bürgerlichen Gesellschaft nur noch die Befriedigung residualer Bedürfnisse überläßt; zweitens das besondere Verhältnis der Kunst aller Zeiten zur Wirklichkeit mit seiner Mischung aus Abhängigkeit und Unabhängigkeit.

Um den ersten 'Rezeptionsmangel zu beseitigen, versuchen es die Surrealisten mit der Provokation, mit der Enttäuschung der Erwartungen, die an die Kunst gestellt werden. Diese Seite der Negativität genügt aber nicht zum Aufbau eines neuen Bewußtseins - und selbst wenn die Bewußtseinsänderung gelungen sein sollte, sind da immer noch die sehr realen Zwänge der bestehenden Gesellschaft, wie die zum Gesetz erhobene Moral, die Religion, Familie und Vaterland mit ihren Korrekturbzw. Unterdrückungsinstrumenten Gefängnis und Irrenhaus, die eine Umsetzung des neuen Bewußtseins in reales Sein zu verhindern wissen. Dennoch wird man festhalten können, ohne hier den Primat ökonomischer und sozialer Veränderungen gegenüber solchen des Bewußtseins diskutieren zu wollen, daß sie einander gegenseitig bedingen, daß die soziale Revolution allein die Änderung des Bewußtseins nicht schafft und auch politisch regrediert. Diese Erfahrung gewannen die Surrealisten schon in den 30er Jahren an der KPF und der Sowjetunion unter Stalin.

Das Verhältnis von Kunst und Wirklichkeit wird wesentlich von zwei Faktoren bestimmt. Einmal von der Einstellung, die der Autor selbst zur Wirklichkeit hat, zum anderen von der Einschätzung des Wirklichkeitsverständnisses des Publikums durch den Autor. Zum ersten: an der Auseinandersetzung zwischen Dada und Surrealismus und dann in einer weiteren Stufe zwischen dem Surrealismus und der Bekehrung Aragons zum Realismus, spiegeln sich die ideologischen Überzeugungen der Autoren wider. Die Strömung absoluter Negativität, die sich angesichts der allgemeinen Vernichtungswut im Ersten Weltkrieg kein sinnvolles Weltmodell mehr vorstellen kann, weicht im Surrealismus einer Wirklichkeitserfahrung, die zwar die bestehende Gesellschaftsordnung und ihren rational-utilitaristischen Umgang mit der Wirklichkeit ablehnt, dafür aber seither verdrängte Wirklichkeitsbereiche entdeckt (Traum, 
Unbewußtes etc.), an deren positive, menschliche und zukunftsträchtige Perspektiven sie glaubt. Sie kann es daher unternehmen, die sprachliche und bildliche Wahrnehmungs- und Begriffsstruktur im metaphorischen Prozeß zu zerstören, aber nur zu Gunsten einer neuen, den Mechanismen der Sinnkonstitution im Unbewußten entsprechenden Struktur, deren Bedeutung sich nach den Methoden der Psychoanalyse interpretieren läßt.[174] In dieser fideistischen Überschätzung des Unbewußten und der Bindung an eine parapsychologisch verfälschte Psychoanalyse liegt die historische und ideologische Bedingtheit des Surrealismus.[175]

Als Aragon der festen Überzeugung ist, daß er den gültigen Schlüssel zur Welterkenntnis und Wirklichkeitsgestaltung im Marxismus-Leninismus gefunden hat, ist es nur konsequent, wenn er den metaphorischen Prozeß, der die Begriffe fortgesetzt verunsichert, die Welt dauernd ummodelliert und ihre Deutung in der Schwebe läßt, reduziert und statt dessen seiner Meinung nach eindeutig definierte Begriffe und ein festes Weltmodell literarisch gestaltet. So kann Aragon mit durchaus gutem ästhetischen Gewissen, ohne daß es ihm die Schamröte auf die Stirn zu treiben braucht, ein Gedicht wie das von der Staatsanwaltschaft wegen seines Inhalts und von Breton wegen seiner Form inkriminierte Front rouge schreiben.

Was in den Augen Bretons ästhetische Regression ist, ist aus Aragons Perspektive ideologische Progression. Tatsächlich kann man ein solches ästhetisches Urteil kaum fällen, ohne sich auf den jeweiligen ideologischen Standpunkt der Autoren zu stellen. Die ästhetische Weiterentwicklung und Verabsolutierung des metaphorischen Prozesses ist ja auch in den Augen Bretons kein Selbstzweck, die Poesie muß auch nach ihm "irgendwo hinführen ". Gerade aber von diesem "irgendwo " hängt auch die ästhetische Form ab. Je genauer ein Autor zu wissen meint, "wohin " seine Poesie "führen " soll, desto metonymischer, d. h. realistischer kann er sich innerhalb seines relativ stabilen Weltmodells bewegen. Je weniger er es weiß, desto metaphorischer, destabilisierender wird er reden und schreiben. Daß das nicht in erster Linie etwas mit den poetischen Fähigkeiten bzw. der Entwicklungsstufe der literarischen Reihe zu tun hat, sondern mit der gewandelten Wirklichkeitssicht der Autoren, beweisen viele moderne Lyriker, die neben hermetischsten Gedichten sogenannte reine Propagandaoder Gelegenheits-Lyrik geschrieben haben: man denke an Rimbaud, Majakowski, Neruda und einen Großteil der Résistance-Lyrik.

Der Surrealismus bleibt hier knapp an der Grenze der völligen Destabilisierung, der Auflösung von Kunst und ihrer Kommunikabilität, wie sie Dada proklamierte. $\mathrm{Da}$ Breton diesen Balanceakt zwischen reiner Negativität, die notwendig in Nihilismus und Selbstmord endet, und dem bedingungslosen Glauben an die Richtigkeit einer einmal gewonnenen Überzeugung für den eines Intellektuellen und Künstlers einzig angemessenen Weg hält, benimmt er sich auch in dieser Beziehung so intransigent gegenüber allen Abweichlern von der surrealistischen Linie.[176]

Die eben aufgezeigte Verknüpfung zwischen Weltbild und ästhetischer Form wirkt sich nicht nur auf die Produktion, sondern auch auf die Rezeption aus. Alle Kunst ist engagiert in dem Sinne, daß sie sich notwendig auf die Wirklichkeit »einlassen " muß, indem sie aus den sprachlichen, bildlichen und materiellen Elementen der Wirklichkeit ihre eigene Welt aufbaut. Bleibt sie verständlich, in der Hoffnung von vielen 
gelesen zu werden und so zu wirken, so nur um den Preis, daß sie ihre eigentliche Domäne, den metaphorischen Prozeß, zähmt, sich weitgehend metonymisch in den Bahnen des Gewohnten und der allgemein verständlichen Sprache bewegt und all dessen, was sie an ideologischer Fracht mit sich schleppt. Außerdem bleibt sie als realistische Literatur der Gefahr ausgesetzt, daß ihr Modellcharakter, ihre spezifische Differenz zur Lebenswelt gar nicht erkannt und sie als bloße Widerspiegelung, Verdoppelung der Wirklichkeit, nicht als Antwort und kritische Reaktion auf sie rezipiert wird.

Verweigert sie die Kompromisse mit dem Bestehenden, löst sie sich radikal von ihm, zerstört sie die üblichen Wortbedeutungen und schreibt sie die bestehenden Weltmodelle von Grund auf um, so ist sie zur Entfaltung ihrer Wirkung auf die ernsthafte und mühsame Mitarbeit des Lesers angewiesen. Ja, diese Mitarbeit ist schon die Wirkung. Eine Arbeit, zu der nur wenige die Zeit haben, nur wenige bereit, ausgebildet und fähig sind.

Der elitäre Charakter solcher Kunst auf dem Grat zwischen Dada und sozialistischem oder auch (heutigem) bürgerlichen Realismus ist also so unvermeidlich wie der elitäre Charakter von Philosophie und von jeglicher Art des (Um-)Denkens. Das Entscheidende ist die Dosierung des Neuen, sowohl was den Selbsterhaltungstrieb des Autors als auch die Wirkung auf das Publikum angeht.

$\mathrm{Da}$ es immer Aufgabe des Denkens und der Kunst sein wird, die bestehenden Weltmodelle und Ideologien so umzumodellieren, daß sie den Entwicklungen der Wirklichkeit Rechnung tragen, ist der Vorwurf Enzensbergers an die Neo-Avantgarde ("Jede heutige Avantgarde ist Wiederholung, Betrug oder Selbstbetrug «) [177] absurd. Künstlerische Techniken mögen sich formal gleichen, ja man könnte so weit gehen und sie letztlich alle auf den metaphorischen Prozeß reduzieren. Damit wäre allerdings über die Inhalte, die der Metaphorik unterworfen werden, nichts gesagt. Natürlich gibt es künstlerischen Leerlauf, Wiederholung von Klischees, doch so lange das Um-Denken und dauernde Umgestalten der Wirklichkeit, der ökonomischen, sozialen und politischen, nicht eine von allen Menschen geübte Praxis ist, d. h. so lange die Poesie nicht von allen gelebt wird, wird es auch immer neue Avantgarden geben müssen.

\section{Anmerkungen}

1 J.-P. Sartre, Qu'est-ce que la littérature?, Paris 1972 (Coll. Idées, 58), S. 219-234; $360-370$.

2 A. Breton, Manifeste du surréalisme, in: ders., Manifestes du surréalisme, Paris 1970 (Coll.Idées, 23), S. 11-64; diese Ausgabe, aus der auch noch andere Werke zitiert werden, wird im folgenden abgekürzt als Manifestes.

$3 \mathrm{Vgl}$. die Charakterisierung der realistischen Literatur als metonymisch, d. h. als in der Wirklichkeit verankert, aber weitgehend konventioneller Kontiguität folgend, im Gegensatz zum dominant metaphorischen Charakter der Poesie bei R. Jakobson (Der Doppelcharakter der Sprache. Die Polarität zwischen Metaphorik und Metonymik, in: J. Ihwe, Hrsg., Literaturwissenschaft und Linguistik, Frankf./M. 1971, Bd. 1, S. 323-333; hier: S. 333). 
4 H. Bergson, Le Rire. Essai sur la signification du comique, Paris ${ }^{273} 1969$, S. $115-121$; S. 120: "Ainsi, qu'il soit peinture, sculpture, poésie ou musique, l'art n'a d'autre objet que d'écarter les symboles pratiquement utiles, les généralités conventionellement et socialement acceptées, enfin tout ce qui nous masque la réalité, pour nous mettre face à face avec la réalité même."

5 H. Marcuse, Über den affirmativen Charakter der Kultur (1937), in: ders., Kultur und Gesellschaft Bd. 1, Frankf./M. 1965, S. 56-101.

6 J. Habermas, Bewußtmachende oder rettende Kritik - die Aktualität des Walter Benjamin, in: S. Unseld, Hrsg., Zur Aktualität Walter Benjamins, Frankf./M. 1972, S. 173-225; hier S. $192 \mathrm{ff}$.

7 P. Bürger, Theorie der Avantgarde, Frankf./M. 1974.

$8 \mathrm{Im}$ Gegensatz zu Bürger geht es H. M. Enzensberger (Die Aporien der Avantgarde, in: ders., Einzelheiten II, Poesie und Politik, Frankf. ${ }^{3} 1970$, S. 50-80) weniger um die Bestimmung der Leistung der historischen Avantgarde, als um den Aufweis, daß die Auswüchse heutigen angeblichen Kunstbetriebs im Begriff der Avantgarde bereits angelegt seien. "Der Surrealismus ist das Paradigma, das vollkommene Modell aller avantgardistischer Bewegungen. Er hat deren Möglichkeiten und Begrenzungen ein für allemal zu Ende formuliert und alle Aporien entfaltet, die solchen Bewegungen innewohnen. " (S. 78). So schlage die propagierte absolute Freiheit notwendig in doktrinären Fanatismus, sektenhafte Bindung an das Kollektiv, Irrationalismus und blinden Aktionismus um. Der avantgardistische Anspruch, "Zukunft im Gegenwärtigen " zu verwirklichen, "dem Gang der Geschichte vor [zu]greifen" (S. 59), sieht Enzensberger vornehmlich im ökonomischen Bereich verwirklicht, die Antizipation wird zur Spekulation, zum Modetrend, zum Bluff: "Der Satz von der Ungleichzeitigkeit des Gleichzeitigen wird verwirklicht, indem man die Kundschaft zur Vorhut ausbildet, die mit dem Neuesten bedient werden will und Zukunft gleichsam als Konsumgut verlangt. " (S. 60/61)

9 P. Bürger, Theorie der Avantgarde, S. 78.

10 A. Breton, Réponse à une enquête, in: ders., Les Pas perdus, Paris 1969, S. 109. In diesem Sinne aufschlußreich sind auch die Attribute in der 'Heiligenlitanei des Surrealistischen Manifestes (S. 38-39).

11 P. Bürger, Theorie der Avantgarde, S. 21; vgl. auch S. 9: Kritische Literaturwissenschaft untersucht »die Kategorien der traditionellen Wissenschaft daraufhin, welche Fragen mit ihnen gestellt werden können und welche anderen Fragen bereits auf der Ebene der Theorie (eben durch die Wahl der Kategorien) ausgeschlossen sind. "

12 Gemäß seinem eher poetischen Sprachduktus verzichtet Breton auch in seinen theoretischen Äußerungen auf kunst- und literatur-wissenschaftliches Fachvokabular. Er begründet den Surrealismus nicht innerliterarisch oder als Reaktion auf die Autonomie oder die Wirkungslosigkeit von bürgerlicher Kunst, sondern historisch und gesellschaftspsychologisch als Reaktion auf die Verkümmerung und Entfremdung des modernen Menschen in der zweckrationalen bürgerlichen Gesellschaft. In der Wahl seiner Kategorien lehnt er sich teilweise an die damals neueste Wissenschaft, die Psychoanalyse, an bzw. in der Zeit seines politischen Engagements an die marxistische Terminologie.

13 Das wird von P. Bürger (Theorie der Avantgarde, S. 49 ff.) ganz deutlich herausgearbeitet. Sieht man jedoch bürgerliche Kunst unter dem Blickwinkel fortschreitender Arbeitsteilung, so wird auch von daher der Begriff "Autonomie" relativiert. Denn Arbeitsteilung ist ja ein Mittel zur Steigerung der Produktivität und bedeutet nicht, daß sich eine Teilproduktion verselbständigt; im Gegenteil, der Künstler bekommt eine Spezialaufgabe zugewiesen, die ihn im Interesse der Leistungssteigerung sinnvoll in den gesamten Produktionsprozeß (re-)integriert.

14 Bekanntlich sind diese Texte selbst oft durchaus sautonom', man denke nur an das Hohe Lied.

15 Schöne Beispiele aus der mittelalterlichen Literatur bei R. R. Grimm, Paradisus coelestis paradisus terrestris. Zur Auslegungsgeschichte des Paradieses im Abendland bis um 1200, München 1977, bes. Kap. VIII und XI. 
16 Es wimmelt im Surrealistischen Manifest von Anspielungen an christliche Symbole und Texte; ich erinnere nur an schon zitierte Stellen: "rompre le pain du ciel pour la terre ", "je crois à la résolution future..."; die Vorstellung eines paradiesischen Gnadenstandes der noch nicht der Nützlichkeit unterworfenen Imagination etc.

17 Th. W. Adorno, Ästhetische Theorie, (Ges. Schriften, 7), Frankf./M. 1970, S. 16.

$18 \mathrm{Vgl}$. H. R. Jauss. Ästhetische Erfahrung und literarische Hermeneutik, Bd. 1: Versuche im Feld der ästhetischen Erfahrung, München 1977; bes. Kap. A.5. Poiesis: die produktive Seite der ästhetischen Erfahrung (construire et connaître), S. 77-96.

19 So lautet der Untertitel von G. Steinwachs, Mythologie des Surrealismus, Neuwied/Berlin 1971.

20 J. Starobinski, Surrealismus und Parapsychologie, in: Schweizer Monatshefte 45, 1966, S. $1155-1164$.

21 P. Ricœur, La métaphore vive, Paris 1975; s. u. S. 92 ff.

22 Vgl. dazu M. Nadeau, Histoire du surréalisme, suivie de Documents surréalistes, Paris 1964; M. Sanouillet, Dada à Paris, Paris 1965.

23 A. Breton (*1896), L. Aragon (* 1897) und Ph. Soupault (*1897) waren 'Kriegsjahrgänge،. Die Verluste an Menschenleben haben im Ersten Weltkrieg ein seither unvorstellbares Ausmaß angenommen. Von 8400000 französischen Soldaten starben 1350000, und die Zahl der Verletzten lag um ein Vielfaches höher. (Zum Vergleich: im Zweiten Weltkrieg hatte Frankreich 563000 Tote, darunter 350000 Zivilisten zu beklagen.)

24 W. Benjamin, Das Kunstwerk im Zeitalter seiner technischen Reproduzierbarkeit, in: ders., Illuminationen, Frankf./M. 1955, S. 171: "Auf die merkantile Verwertbarkeit ihrer Kunstwerke legten die Dadaisten viel weniger Gewicht als auf ihre Unverwertbarkeit als Gegenstände kontemplativer Versenkung. “

25 G. Hugnet, L'esprit Dada dans la peinture, in: Cahiers d'art 7, 1932, S. 60-62.

26 T. Tzara, Euvres complètes, Bd. 1, Paris 1975, S. 75-84 und 638-640; vgl. dazu P. Bürger, Der französische Surrealismus, Frankf./M. 1971, S. 37-47.

27 T. Tzara, ebd. S. 360.

28 P. Bürger, Der französische Surrealismus, S. 41/2: "Dada begreift sich als totale Negation der bürgerlichen Daseins- und Denkweise; aussprechen kann sich jedoch die totale Negation nur, indem sie etwas Bestimmtes verneint; die bestimmte Negation ist aber immer zugleich Affirmation des Gegenteils des Negierten. Um diesem Dilemma zu entkommen, muß Tzara, wo immer das möglich ist, die eigene Aussage wiederum aufzuheben versuchen. [...] Er ist eine Bewegung, die ihrem Wesen nach zur Selbstaufhebung tendiert. "

29 T. Tzara, CEuvres complètes, Bd. 1, S. 360.

30 Lettres de Jacques Vaché, in: Littérature 5-7, 1919.

31 Breton hat sich mehrfach über Vaché und sein Verhältnis zu ihm geäußert, z. B.: La confession dédaigneuse, in: ders., Les Pas perdus, S. 7-21, Zitat S. 8; Jacques Vaché, ebd., S. 56-60; Pour dada, ebd., S. 69-76.

Inwieweit es sich bei Vaché um einen von Breton selbstfabrizierten Mythos handelt und nicht um die historische Wahrheit, ist für die Wirkung auf den Surrealismus sekundär; vgl. dazu M. Sanouillet, Dada à Paris, S. $81 \mathrm{ff}$.

32 "La fortune de Jacques Vaché est de n'avoir rien produit. Toujours il repoussa du pied l'œuvre d'art, ce boulet qui retient l'âme après la mort. " (A. Breton, Pour dada, in: ders., Les Pas perdus, S. 71)

33 Ebd., S. 17.

34 M. Duchamp, Marchand du sel: Écrits, Paris 1958.

35 "Libre n'était pas à Duchamp d'abandonner la partie qu'il jouait aux environs de la guerre pour une partie d'échecs interminable qui donne peut-être une idée curieuse d'une intelligence répugnant à servir mais aussi - toujours cet exécrable Harrar [Rimbauds] - paraissant lourdement affligée de scepticisme dans la mesure où elle refuse de dire pourquoi." (Manifestes, S. 130)

36 Vgl. die bei W. S. Rubin (Dada und Surrealismus, Stuttgart 1972, S. 38 ff.) versuchte Deutung und die dort angegebene Literatur. 
37 Breton hat sich immer wieder mit diesem Werk beschäftigt; er veröffentlichte Äußerungen Duchamps zu seinem Glasbild in: Le Surréalisme au service de la Révolution No. 5, 1933, S. 1-2 und nach dem Erscheinen von Duchamps, Boîte verte (1934) einen längeren Beitrag, Phare de la Mariée, in: Minotaure 1935, S. 45-49.

38 A. Breton, ebd., S. 48.

39 A. Breton, Les Chants de Maldoror, in: ders., Les Pas perdus, S. 64-65.

40 A. Breton, Après dada, in: ders., Les Pas perdus, S. 101.

41 Protokoll in: Littérature 20, 1921.

42 Aus dem Pamphlet: Le Cœur à barbe (April 1922), S. 8.

43 Vgl. das Vorwort von M. Bonnet zum Reprint der Zeitschrift Littérature, 2 Bde., Paris 1978, I, S. 5-20.

44 Dazu das Protokoll einer Redaktionssitzung in: Littérature 17, 1920, S. $2-4$.

45 "Une certaine obscurité enveloppe aujourd'hui ce tournant de l'histoire de LITTERATURE où, pour ainsi dire, Dada prit possession d'une petite revue à couverture jaune qui avait joui à ses débuts d'une considération distinguée. Il est évidemment fâcheux que l'arrivée à Paris de Tristan Tzara ne semble pas étrangère à cette modification [...] « (A. Breton, Clairement, in: Littérature. Nouv. Série 4, 1922, S. 1.

46 Ebd., S. 1-2.

47 Wir beschränken uns im folgenden weitgehend auf das sprachliche Bild und ziehen die Malerei nur gelegentlich zur Illustration heran.

48 L. Aragon, Discours de l'Imagination, in: ders., Le Paysan de Paris, Paris 1972 (Coll. Folio, 219), S. 80-82.

49 A. Breton, Manifestes, S. 31-33.

50 "Tout occupé que j'étais encore de Freud à cette époque (A. Breton, Manifestes, S. 33).

51 G. Steinwachs (Mythologie des Surrealismus) betont im Gegensatz zu J. Starobinski (Surrealismus und Parapsychologie) eher die Übereinstimmungen als die Unterschiede zu Freud. Vgl. auch Anm. 175.

52 Laplanche/Pontalis, Das Vokabular der Psychoanalyse, Frankfurt/M. 1972, Bd. 1, S. 78/ 79: "Tatsächlich darf die Freiheit [des Assoziierens] nicht im Sinne einer Unbestimmtheit verstanden werden: die freie Assoziation zielt zunächst darauf ab, die absichtliche Selektion der Gedanken zu eliminieren, das heißt, in den Worten der ersten Freudschen Topik, die zweite Zensur (zwischen dem Bewußten und Vorbewußten) auszuschalten. Dadurch werden die unbewußten Abwehrmechanismen enthüllt, nämlich die Tätigkeit der ersten Zensur (zwischen dem Vorbewußten und dem Unbewußten)."

53 A. Breton, Manifestes, S. 19: "Si les profondeurs de notre esprit recèlent d'étranges forces capables d'augmenter celles de la surface, ou de lutter victorieusement contre elles, il y a tout intérêt à les capter, à les capter d'abord, pour les soumettre ensuite, s'il y a lieu, au contrôle de notre raison. Les analystes eux-mêmes n'ont qu'à y gagner. Mais il importe d'observer qu'aucun moyen n'est désigné a priori pour la conduite de cette entreprise, que jusqu'à nouvel ordre elle peut passer pour être aussi bien du ressort des poètes que des savants $[\ldots]$ ".

54 Ebd., S. 40: "Mais nous, qui ne nous sommes livrés à aucun travail de filtration, qui nous sommes faits dans nos œuvres les sourds réceptacles de tant d'échos, les modestes appareils enregistreurs qui ne s'hypnotisent pas sur le dessin qu'ils tracent [...] ".

55 J. Starobinski, Surrealismus und Parapsychologie, S. 1159.

56 A. Breton, Les message automatique, in: ders., Point du jour, Paris 1970, S. 193.

57 Ebd., S. 198.

58 Ebd., S. 191.

59 J. Starobinski, Surrealismus und Parapsychologie, S. $1158 \mathrm{ff}$.

60 S. Freud, Abriß der Psychoanalyse, Frankf./M. 1972, S. $25 / 6$.

61 Anläßlich der "trouvaille" von Aschenputtels Schuh in Form eines Löffels auf dem Flohmarkt, liefert Breton nach der Schilderung der Vorgeschichte und der Fundumstände eine derartige psychoanalytische Erklärung mit Hilfe eines ersten Postskripts (1934) und sogar noch eines zweiten (1936) nach (A. Breton, Amour fou, Paris 1937, S. 42-46). 
62 P. Bürger, Der französische Surrealismus, bes. S. $157 \mathrm{ff}$.

63 A. Breton/Ph. Soupault, Les champs magnétiques suivi de S'il vous plaît et de Vous m'oublierez. Préface de Ph. Audoin, Paris 1971 (Coll. Poésie). A. Jouffroy hat Bretons Randbemerkungen zu diesem Werk von 1930 herausgegeben (En marge des Champs magnétiques, in: Change 7, 1970, S. 9-29). Breton unterscheidet darin sorgfältig zwischen den Beiträgen des inzwischen ungeliebten Soupault und seinen eigenen. (Zitiert als A. Breton, En marge.)

64 A. Breton, Manifestes, S. 49: "Le surréalisme poétique, auquel je consacre cette étude, s'est appliqué jusqu'ici à rétablir dans sa vérité absolue le dialogue, en dégageant les deux interlocuteurs des obligations de la politesse. Chacun d'eux poursuit simplement son soliloque, sans chercher à en tirer un plaisir dialectique particulier et à en imposer le moins du monde à son voisin. Les propos tenus n'ont pas, comme d'ordinaire, pour but le développement d'une thèse, aussi négligeable qu'on voudra, ils sont aussi désaffectés que possible. Quant à la réponse qu'ils appellent, elle est, en principe, totalement indifférente à l'amour-propre de celui qui a parlé. Les mots, les images ne s'offrent que comme tremplins à l'esprit de celui qui écoute. C'est de cette manière que doivent se présenter, dans Les Champs magnétiques, premier ouvrage purement surréaliste, les pages réunies sous le titre: Barrières dans lesquelles Soupault et moi nous montrons ces interlocuteurs impartiaux."

65 I histoires chanson

$\begin{array}{ll} & \text { confidences } \\ \text { II } & \text { pudeur des femmes } \\ \text { III } & \text { vous m'en direz tant }\end{array}$

quais

remorqueur

IV

cheminée rouge

rivières

naufrageurs

cheminée

étincelles des

V

forges

fumée

hiver

nuit

étincelles

forges

reverbères

VI

nocturnes

petites étoiles

VII

hiver

triste

froid

VIII

lumière

bijouterie

bijoux

66 A. Breton/Ph. Soupault, Les Champs magnétiques, S. 65-66.

67 A. Breton, En marge, S. 19.

68 A. Breton/Ph. Soupault, Les Champs magnétiques, S. 125-161.

69 Vgl. H. H. Wetzel, Zur Analyse und Deutung surrealistischer Werke (A. Breton), in: Degré Second 2, 1978, S. 137-174; darin: 157-167.

70 A. Breton/Ph. Soupault, Les Champs magnétiques, S. 27-33.

Es bleibt unklar, wie Th. M. Scheerer (Textanalytische Studien zur 'écriture automatique, Diss. Bonn 1974, S. 55) dazu kommt, "La Glace sans tain " insgesamt Soupault zuzuschrei- 
ben. Soweit aus den Anmerkungen ersichtlich, stützt er sich ausschließlich auf die schon erwähnten, von A. Jouffroy herausgegebenen Randbemerkungen von A. Breton. In der Edition des Textes sind aber nur der zweit- und der drittletzte Abschnitt von "La Glace sans tain " überhaupt abgedruckt (da mit Randbemerkungen versehen!) und dadurch als von Soupault stammend gekennzeichnet. Über den größten Teil des Textes von "La Glace sans tain " lassen sich bei der bestehenden Editionslage keinerlei Aussagen über den Autor treffen. Das gilt auch noch für weitere Textteile aus den Champs magnétiques (nicht mit Randbemerkungen Bretons versehen und daher in der Edition auch nicht wiedergegeben), die Scheerer nichts desto trotz zuordnet (S. 55-56).

71 A. Breton, En marge, S. 10. Zu "Saison " gibt Breton nicht nur das allgemeine Thema an ("c'est moi qui conte ici mes souvenirs d'enfance"), sondern er fügt auch noch Ortsangaben etc. hinzu (S. 13-17).

72 A. Breton/Ph. Soupault, Les Champs magnétiques, S. 27-28.

73 A. Jouffroy stellt in einer Anmerkung zu A. Breton, En marge, S. 22, fest, daß die erste Abteilung von "La Pagure dit ", d. h. S. 93-102 in der zitierten Ausgabe, von Breton, die zweite Abteilung (S. 103-117) von Soupault ist. Laut Breton sind die Texte nur deswegen "à la ligne " geschrieben, um die Gedichtform um so nachhaltiger zu zerstören.

74 Vgl. dazu H. H. Wetzel, Zur Analyse und Deutung, S. 151-157.

75 T. Tzara, CEuvres complètes, Bd. 1, S. 382.

76 Schon in der ersten Nummer von Littérature (März 1919) wird ein Buch von T. Tzara besprochen und ab der zweiten (April 1919) erscheinen Beiträge von ihm; also fast ein Jahr vor seinem Eintreffen in Paris.

77 Vgl. P. Bürger, Der französische Surrealismus, S. 158.

78 Ganz ähnlich, nur noch stärker eingreifend, äußert sich H. Arp (Wegweiser, Meudon 1951, S. 6): "Ich schlang und flocht leicht und improvisierend Wörter und Sätze um die aus der Zeitung gewählten Wörter und Sätze."

79 A. Breton, Manifestes, S. 34; Desnos beschränkt sich sogar auf die orale Einmaligkeit seiner "discours splendides [...] ayant mieux à faire qu'à les fixer “ (ebd., S. 42).

80 L. Aragon, Traité du style, Paris 1928, S. 187/8.

81 In Reverdys Zeitschrift Nord-Sud (März 1918); zitiert nach: P. Reverdy, Le Gant de Crin, Paris 1927, S. 32.

82 Vgl. zum ganzen folgenden Kapitel P. Ricour, La métaphore vive.

83 Neben vielfachen Erwähnungen in theoretischen Äußerungen treten Nähmaschine und Regenschirm in A. Bretons Sketch Vous m'oublierez auf. Man Ray hat das sprachliche Bild außerdem noch gezeichnet (The Image of Isidore Ducasse).

84 I. Ducasse, Comte de Lautréamont, CEuvres complètes, Paris 1961, S. 327.

85 In: A. Breton, Revolver à cheveux blancs (1932), in: ders., Clair de terre [...], Paris 1966 (Coll. Poésie), S. 137-138.

86 "Focus " und "frame" sind die Begriffe M. Blacks (Models and Metaphors, Ithaca 1962) für Bildspender und Bildempfänger als den beiden Komponenten, aus denen eine Metapher besteht. Im Gegensatz zu "Vehicle " und "Tenor " (Terminologie von I. A. Richards, The Philosophy of Rhetoric, Oxford 1936) haben "Brennpunkt " und "Rahmen " den Vorteil, daß in ihrer Metaphorik Aktivität und Bewegung nicht einseitig verteilt sind, und sie die gegenseitige dynamische Interaktion besser verbildlicht.

87 P. Ricœur, La métaphore vive, S. 195.

88 H. Weinrich, Semantik der kühnen Metapher, in: DVjS 37, 1963, S. 325-344.

89 Der Begriff stammt von M. Black (Models and Metaphors) und wird von M. Riffaterre (Le poème comme représentation, in: Poétique 1, 1970, 401-418) wieder aufgenommen.

90 L. Aragon, Le Paysan de Paris, S. 82. Aragon ist einer der ersten, der die Verwandtschaft von Metapher und Collage erkannt hat (z. B. in: ders., Collages, Paris 1965, S. 46).

91 P. Ricœur setzt mit seiner Theorie der verallgemeinerten Denotation (La métaphore vive, VIIlième étude) bei einer Beobachtung R. Jakobsons an: "Der Vorrang der poetischen Funktion vor der referentiellen löscht nicht den Bedeutungscharakter aus, sondern macht 
ihn doppeldeutig. " (Linguistik und Poetik, in: J. Ihwe, Hrsg., Literaturwissenschaft und Linguistik, 2 Bde., Frankf./M. 1971, I, S. 170.)

92 M. Riffaterre, La métaphore filée dans la poésie surréaliste, in: Langue Française 1, 1969, S. 46-60.

93 Zur Gleichsetzung von realistisch und metonymisch vgl. Anm. 3.

94 Auf diesen wesentlichen Unterschied zwischen Vergleich und Metapher weist Reverdy ebenfalls hin: "Elle [l'image] ne peut naître d'une comparaison ". Vergleich und Metapher unterbrechen beide die Isotopie des Kontextes, stellen sie aber auf unterschiedliche Weise wieder her; vgl. dazu P. Ricour, La métaphore vive, S. 236-237.

95 Aus astronomischer Perspektive dreht sich dann allerdings auch wieder Turm samt Erde um die Sonne.

96 P. Robert, Dictionnaire alphabétique \& analogique de la langue française, Paris 1967 (zitiert: Le Petit Robert), Stichwort " fil «: "Trouver le fil conducteur, saisir le fil de ma vie " (Duhamel).

97 J. Lotman, Die Struktur literarischer Texte, München 1972, S. 285: "Somit wird der literarische Text vor dem Hintergrund und im Widerstreit mit der Gesamtheit aller für den Leser und den Autor wirksamen Weltmodelle rezipiert."

98 A. Breton, Manifestes, S. 31.

99 Diesen Eindruck erweckt allerdings H. Weinrich (Semantik der kühnen Metapher). Dagegen setzt er die These: je kleiner die Bildspanne, desto kühner die Metapher. Bei der Bestimmung der Bildspanne verfällt Weinrich trotz dem Bemühen, unzulässige Ontologisierungen zu vermeiden, darauf, die Bildspanne nach der "Ordnung der vorgefundenen Wirklichkeit " (S. 333) zu bemessen, die er in Wortfeldern fixiert sieht. So ist für ihn die Bildspanne zwischen "weißer Milch" (Ordnung der vorgefundenen Wirklichkeit) und "Schwarzer Milch der Frühe..." (Celan) gering, da sie "nur einen kleinen Schritt zu einer anderen Farbe " (S. 335) tut. Obwohl zuerst angeblich außersprachlich argumentiert wird, wird dann in Wahrheit eine willkürliche linguistische Klassifizierung ontologisiert: im gleichen Wortfeld liegend, also seinsmäßig naheliegend. (Warum wird schwarz nicht dem Wortfeld 'Tod` und weiße Milch dem Wortfeld 'Leben zugerechnet? Leben und Tod kann man auch zum gleichen Wortfeld rechnen und dennoch dürften sie eine große Bildspanne abgeben.) Dieser Fehlschluß ist nur möglich, wenn man ein Wort vom situativen Kontext (hier das Gedicht und sein zeitgeschichtlicher Hintergrund) und vom sprachhistorischen (verschiedene fixierte Bedeutungen eines Wortes, auch erstarrte Metaphern) abstrahiert. $\mathrm{Da}$ die Metapher aber vom Zusammenspiel von Wort und Kontext (dazu gehört nicht nur der verbale, sondern auch der weitere sozio-kulturelle) lebt, hat andererseits $\mathrm{H}$. Weinrich selbst mehrfach betont: "Wort und Kontext machen zusammen die Metapher." (ders., Semantik der Metapher, in: Folia linguistica 1, 1967, S. 5)

100 M. Riffaterre, Le poème comme représentation, S. 418.

101 M. Riffaterre, La métaphore filée, S. 48 u.ö.

102 Dieser Vergleich stammt von J. Lotman, Die Struktur literarischer Texte, S. $56 \mathrm{ff}$.

103 A. Breton scheint sogar der Ansicht zu sein, daß man sie, wenn auch mit Mühe, in die Normalsprache ("langage pratique ") übersetzen können müsse: "Pour moi, la plus forte est celle qui présente le degré d'arbitraire le plus élevé, je ne le cache pas; celle qu'on met le plus longtemps à traduire en langage pratique [...]" (Manifestes, S. 52).

104 L. Aragon, Traité du style, S. 192.

105 Ausgehend von der lautlichen Äquivalenz im Reim wird dieses Prinzip der Übertragung von der Achse der Similarität auf die Achse der Kontiguität in Anlehnung an R. Jakobson "Äquivalenzprinzip « genannt und als der Grundmechanismus der poetischen Sprachfunktion angesehen.

106 M. Foucault, Raymond Roussel, Paris 1963, S. 22.

107 P. Eluard/B. Péret, 152 proverbes mis au goût du jour, Paris 1925.

108 W. Spies, Max Ernst Collagen. Inventar und Widerspruch, Köln 1974, S. 82; das primär kunstgeschichtliche Werk enthält eine Fülle von Anregungen auch für den Literaturwissenschaftler. Die Unterscheidung metonymisch-metaphorisch ließe sich auch zur 
Erklärung des Unterschieds zwischen kubistischem Papier collé und surrealistischer Collage verwenden. Das Papier collé ist nur in bezug auf das Material metaphorisch, in bezug auf die inhaltlichen Bildelemente jedoch metonymisch; für die Collage ist dagegen der metaphorische Prozeß zwischen den Bildelementen entscheidend, Unterschiede im Material werden, wenn überhaupt vorhanden, vertuscht (so die Klebe- und Schnittstellen).

109 Eine meta-ästhetische Problematisierung des Zusammenhangs zwischen Wort und Bild stellt R. Magrittes La clé des songes dar. In provokativer Inkongruenz werden die fraglosen Schautafeln von ABC-Schützen parodiert und in Frage gestellt.

110 A. Breton, Nadja, Paris 1928; alle Zitate nach der 2. erweiterten und verbesserten Auflage von 1963.

111 Th. W. Adorno, Philosophie der neuen Musik (Ges. Schriften, 12), Frankf./M. 1975, S. 37.

112 P. Bürger, Theorie der Avantgarde, S. 77.

113 P. Bürger, Der französische Surrealismus, S. 130.

114 H. Blumenberg, Wirklichkeitsbegriff und Möglichkeit des Romans in: H.-R. Jauß, Hrsg., Nachahmung und Illusion (Poetik und Hermeneutik I), München 1964, S. 9-27.

$115 \mathrm{Vgl}$. Anm. 89.

116 R. Jakobson, Der Doppelcharakter der Sprache; vgl. Anm. 2.

117 Auf das Adjektiv "organisch " werde ich im weiteren Verlauf der Erörterung möglichst verzichten, da es von Breton selbst widersprüchlich verwendet wird. Er lehnt einerseits einen "organischen Lebensplan " (Nadja, S. 18) ab, andererseits ist er fasziniert vom "organischen Charakter « automatischer Bilder (Manifestes, S. 32).

118 M. Carrouges (Le hasard objectif, in: F. Alquié, Hrsg., Entretiens sur le surréalisme, Paris 1968, S. 272): "le hasard objectif est l'écriture automatique du destin dans les faits apparemment bruts."

119 So wie die automatische Schreibweise das "reale Funktionieren des Denkens " (Manifestes, S. 37) wiedergeben soll, so die in Nadja angewendete Reihung von unverbundenen Fakten den realen Lebenslauf mit seinem (noch) verborgenen Sinn.

120 "J'aimerais enfin qu'on ne ramenât point de tels accidents de la pensée à leur injuste proportion de faits divers [...] " (Nadja, S. 23).

121 M. Beaujour, Qu'est-ce que 'Nadjar?, in: NRF 1967, S. 780: "une stratégie du discontinu et de l'apparent désordre ".

122 Breton schreibt im Aug. 1927 im Manoir d'Ango Ereignisse auf, die sich seit 1918 abgespielt haben (1. Teil). Besonders genau dokumentiert werden die Tage der Begegnung mit Nadja im Oktober 1926 (2. Teil). Ende Dezember 1927 fügt er noch den dritten und letzten Teil an, der teilweise von synchronen Fakten berichtet.

123 " [...] de menus événements s'étant articulés les uns aux autres d'une manière déterminée “ (Nadja, Avant-dire, S. 5). Der in Klammern angefügte Hinweis auf den Philosophen J. Lequier und seine "feuille de charmille " unterstreicht den nicht-willkürlichen Charakter dieser Ereignisstruktur.

124 M. Beaujour (Qu'est-ce que 'Nadjar?, S. 781) denkt an Ergänzungen durch P.-L. Palaus Stück Les Détraquées (ersch. in: Le Surréalisme, même 1, 1956, S. 73-117) oder Briefe Nadjas. Man fragt sich allerdings, warum Breton sie bei der Neuauflage im Gegensatz zu anderen Ergänzungen nicht aufgenommen hat. W. Spies (Max Ernst Collagen, S. 173) hat im Hinblick auf Les Détraquées richtig bemerkt: "Die rätselhafte Stimmung schafft erst die verfremdende Verkürzung, die das Stück durch Bretons Interpretationszwang erfährt. "Beaujours Vergleich der einzelnen Episoden mit Spielkarten, die beliebig zu einem "nombre illimité de réussites" $(S .782)$ gemischt werden könnten, ist zwar poetisch gelungen ("battant comme une porte" - "battre un jeu de cartes"), aber leider im vorliegenden Fall falsch.

125 G. Steinwachs, Mythologie des Surrealismus, S. 77.

126 Ebd., S. 82; der Gedanke einer "Deklination des objektiven Zufalls in allen [!] fünf Fällen " ist zwar verführerisch formuliert, es mangelt ihm jedoch an Stringenz. Die angeführten Breton'schen Äquivalente für die fünf Fälle - seit wann hat das Französische fünf Fälle? 
das Deutsche? das Lateinische? oder gar das Leben? - sind dazu ungenügend gegeneinander abgegrenzt.

127 R. Jakobson, Der Doppelcharakter der Sprache; vgl. Anm. 2.

128 P. Ricœur, La métaphore vive, S. 252: "Comme Roman Jakobson, en effet, mais en un sens différent de lui, nous formons un concept de sprocès métaphorique pour lequel le trope de la rhétorique joue le rôle de révélateur. Mais, à la différence de Roman Jakobson, ce qui dans la métaphore peut être généralisé, ce n'est pas son essence substitutive, mais son essence prédicative. Jakobson généralisait un phénomène sémiotique, la substitution d'un terme par un autre; nous généralisons un phénomène sémantique, l'assimilation l'une à l'autre de deux aires de signification par le moyen d'une attribution insolite. Du même coup, le spôle métaphorique du langage, étant d'essence nettement prédicative ou attributive, n'a pas pour contrepartie un pôle métonymique. La symétrie des deux pôles est rompue. La métonymie - un nom pour un autre nom - reste un procès sémiotique, peutêtre même le phénomène substitutif par excellence dans le domaine des signes. La métaphore - attribution insolite - est un procès sémantique, au sens de Benveniste, peut-être même le phénomène génétique par excellence dans le plan de l'instance de discours “; vgl. auch S. 222-230.

129 Vgl. dazu auch L. Jenny, La surréalité et ses signes narratifs, in: Poétique 4, 1973, S. $148-154$

130 A. Breton, Nadja, S. 6: "[...]l'abondante illustration photographique a pour objet d'éliminer toute description - celle-ci frappée d'inanité dans le Manifeste du Surréalisme [...] «.

131 M. Beaujour, Qu-est-ce que ,Nadjar?, S. 786.

132 Auch der Lebenssinn anderer Leute (und, bescheiden wie er ist, wählt sich Breton nicht gerade die unbekanntesten) läßt sich nach seiner Meinung aus kurzen modellhaften Szenen und Sprüchen besser erkennen als aus mit biographischen Einzeldaten noch so vollgestopften Biographien und Interpretationen. Die Erwähnung der Namen Hugo, Flaubert, Courbet erfolgt im Rahmen dieser theoretischen Diskussion der Möglichkeiten biographischer Darstellung und noch nicht als erste Paradigmata der Begegnung.

133 A. Breton, Nadja, S. 55: "Rien ne sert d'être vivant, le temps qu'on travaille. L'événement dont chacun est en droit d'attendre la révélation du sens de sa propre vie, cet événement que peut-être je n'ai pas encore trouvé mais sur la voie duquel je me cherche, $n$ 'est pas au prix du travail «.

134 "La rencontre d'une causalité externe et d'une finalité interne «: zitiert in: A. Breton, Amour fou, S. 23; vgl. dort zum Problem des Zufalls und der Begegnung S. 22-31.

135 Breton erwähnt zwar auch Nantes (wohl in Erinnerung an seine dortigen ersten Eskapaden zusammen mit Vaché), doch mit deutlichen Einschränkungen: "Nantes: peut-être avec Paris la seule ville de France où j'ai l'impression que peut m'arriver quelque chose qui en vaut la peine" (Nadja, S. 27).

136 "Je ne vois guère, sur ce rapide parcours, ce qui pourrait, même à mon insu, constituer pour moi un pôle d'attraction, ni dans l'espace ni dans le temps. " (Nadja, S. 30)

137 A. Breton, Nadja, S. 44, Note: "Je m'accuse là d'avoir failli à ,l'attraction passionneller. “

138 Wie die Homonymie (vgl. Anm. 106) ist die "image double" oder "multiple" eine Art Metapher in einem Bild. Vgl. dazu auch M. Ernst, Comment on force l'inspiration, in: Le Surréalisme au service de la Révolution 6, 1933, S. 43-45.

139 In den von M. Ernst zitierten Diaconales ou Manuel secret du confesseur ist vom "vase naturel " die Rede: (M. E.), Danger de pollution, in: Le Surréalisme au service de la Révolution 3, 1931, S. 22-25.

140 Das Klischee, die tote Metapher, wird bei ihm wieder lebendig; vgl. J. Gracq, A. Breton, Paris 1948, S. 67.

141 A. Breton, Les mots sans rides, in: ders., Les Pas perdus, S. 131-134; hier S. 134.

142 "Les lettres de Nadja, que je lisais de l'œil dont je lis toutes sortes de textes poétiques" (Nadja, S. 137).

143 "Il est impardonnable que je continue à la voir si je ne l'aime pas. "(Nadja, S. 88); "Tout ce qui fait qu'on peut vivre de la vie d'un être, sans jamais désirer obtenir de lui plus que ce 
qu'il donne, qu'il est amplement suffisant de le voir bouger ou se tenir immobile, parler ou se taire, veiller ou dormir, de ma part n'existait pas non plus, n'avait jamais existé: ce n'était que trop sûr." (Nadja, S. 126)

144 "Elle ne fait aucun mystère du moyen qu'elle emploierait, si je n'existais pas, pour se procurer de l'argent. " (Nadja, S. 91)

145 Ebenso beurteilt Breton die in der Anmerkung S. 143 (von 1962) erwähnte Episode, in der Nadja versuchte, mit ihm gemeinsam in den Tod zu gehen, als "application d'un principe de subversion totale", als Ausdruck ihrer unbedingten Liebe ("Quelle épreuve pour l'amour, en effet. "), dem er von seinem gegenwärtigen Standpunkt aus nicht mehr in jedem Fall widerstehen könnte.

146 "L'essentiel est que pour Nadja je ne pense pas qu'il puisse y avoir une extrême différence entre l'intérieur d'un asile et l'extérieur. " Die Ungeheuerlichkeit seiner Behauptung scheint ihm aber selbst aufgefallen zu sein, denn er fügt sofort an: "Il doit, hélas, y avoir tout de même une différence, à cause du bruit agaçant d'une clé qu'on tourne dans une serrure [...]" (Nadja, S. 128).

147 Diese 'vernünftige Mäßigung kontrastiert mit der provokatorischen Aufforderung aus dem Zweiten Surrealistischen Manifest, man solle mit Revolvern in den Händen auf die Straße gehen und blind in die Menge schießen (A. Breton, Manifestes, S. 78).

148 A. Breton, Nadja, S. 135: "selon les moyens dont chacun dispose "; daß damit nicht zuletzt die finanziellen Mittel gemeint sind, führt Breton S. 134 aus.

149 »Ne touche-t-on pas là au terme extrême de l'aspiration surréaliste, à sa plus forte idée limite? « (A. Breton, Nadja, S. 74)

150 Die im Zusammenhang mit Nadja öfters auftauchende (Feuer-)Hand symbolisiert dagegen Breton selbst (vgl. Nadja, S. 100-101).

151 A. Breton, Nadja, S. 146: "une main merveilleuse et intrahissable m'a désigné il n'y a pas encore assez longtemps une vaste plaque indicatrice bleu ciel portant ces mots: LES AUBES. « Ein Photo der Lokalität von seiner Reisebegleiterin Valentine Hugo ist beigefügt.

152 A. Breton, Nadja, S. 146-147: "N'empêche que s'il faut attendre, s'il faut vouloir être sûr, s'il faut prendre des précautions, s'il faut faire au feu la part du feu, et seulement la part, je m'y refuse absolument. Que la grande inconscience vive et sonore qui m'inspire mes seuls actes probants dispose à tout jamais de tout ce qui est moi."

153 In den seither zitierten Interpretationen etwa scheint dieser dritte Teil für die Interpreten gar nicht zu existieren.

154 M. Beaujour (Qu'est-ce que 'Nadja<?, S. 94) spricht von einer "activité de découpage", P. Bürger (Der französische Surrealismus, S. 135/6) von einer "Fragmentierung der Wirklichkeit ".

155 Fbd., S. 134.

156 Vgl. dazu M. Nadeau, Histoire, bes. S. 95 ff.; R. S. Short, Die Politik der Surrealistischen Bewegung 1920-1936, in: W. Laquer/G. L. Mosse, Hrsg., Linksintellektuelle zwischen den beiden Weltkriegen, München 1967, S. 7-41; J.-P. A. Bernard, Surréalisme et communisme, in: ders., Le parti communiste français et la question littéraire, Paris 1972, S. $83-112$.

157 Am bekanntesten sind die offenen Briefe und Aufrufe: in La Révolution Surréaliste 2, 1930, S. 18: Ouvrez les prisons, Licenciez l'armée; in 3, 1931, S. 11: Lettre aux Recteurs des Universités Européennes; S. 16: Adresse au Pape; S. 17: Adresse au Dalai-Lama; S. 22: Lettre aux écoles de Bouddha; S. 29: Lettre aux Médecins-Chefs des Asiles de Fous.

Der Leitartikel A. Bretons in der zweiten Nummer (La dernière Grève, S. 1-3) hält die Forderungen nach Arbeits- und Lohnverbesserungen für nicht revolutionär genug und spekuliert über die Folgen eines Produktions-Streiks aller wahren Künstler und Denker. Nach der Zusammenarbeit mit der Zeitschrift Clarté erscheinen nur einige wenige Artikel von deren Mitarbeitern zu politischen Themen.

158 L. Aragon, Avez-vous déjà giflé un mort?, in: Un cadavre, in: M. Nadeau, Histoire, S. $199-200$.

159 In: La Révolution surréaliste 2, 1925, S. 32. 
160 A. Breton, Légitime Défense, in: La Révolution surréaliste 8, 1926, S. 30-36.

161 P. Naville, Que peuvent faire les Surréalistes?, in: ders., La Révolution et les intéllectuels, Paris 1926.

162 A. Breton, Légitime Défense, S. 34/5.

163 Ebd., S. 32.

164 Au grand jour (Paris 1927) enthält fünf Briefe der neu in die Partei Eingetretenen an Freunde und Gesinnungsgenossen, die ihnen den Schritt erklären sollen (in: M. Nadeau, Histoire, S. 262-274). Darin heißt es unter anderem: "concilier à tout prix le point de vue du non-conformisme absolu et d'un certain conformisme relatif. " (S. 265)

165 Zuerst abgedruckt in der letzten Nummer von La Révolution surréaliste (12. Dez. 1929, S. 1-17); zitiert nach der erweiterten Neuauflage von 1946 (in: A. Breton, Manifestes, S. 65-157).

166 A. Breton, Manifestes, S. 98/99.

167 Die Dokumente zur Affäre Aragon sind abgedruckt in: M. Nadeau, Histoire, S. 333-364.

168 In: Le Surréalisme au service de la Révolution 3, Dez. 1931, S. 2-8.

169 Du Temps que les surréalistes avaient raison, in: A. Breton, Position politique du surréalisme, Paris 1971, S. 116/7.

170 A. Breton/L. Trotsky, Pour un art révolutionnaire indépendant, in: A. Breton, La clé des champs, Paris 1967, S. 43.

171 L. Aragon, Postface zu Monde réel, in: L. Aragon/E. Triolet, CEuvres croisées, Bd. 26, Paris 1967, S. 319.

172 Ebd., S. 318: "la poésie est la mathématique de toutes les écritures. "

173 J.-P. Sartre, Avantgarde? Wovon und von wem?, in: ders., Was kann Literatur? Interviews, Reden, Texte 1960-1976, Reinbek 1979, S. 92.

174 Zum Vergleich der Psychoanalyse mit Textinterpretation: P. Ricœur, De l'interprétation, essai sur Freud, Paris 1965; ders., Le conflit des interprétations, Paris 1969.

175 J.-L. Houdebine, Le "concept « d'écriture automatique: sa signification et sa fonction dans le discours idéologique d'André Breton, in: La nouvelle critique 39 bis, 1970, S. 178-185; ders., Méconnaissance de la psychoanalyse dans le discours surréaliste, in: Tel Quel 46, 1971, S. 67-82.

176 Aragon hielt einen solchen Drahtseilakt auch psychisch nicht mehr durch. Der lebenslangen Bindung an $\mathrm{E}$. Triolet und der unbedingten Anhängerschaft gegenüber der KPF ging der Selbstmordversuch von Venedig (1928) voraus.

177 H. M. Enzensberger, Die Aporien der Avantgarde, S. 79.

\section{Biblingraphie}

Literatur über den Surrealismus in (knapper) Auswahl. Zur umfassenderen bibliogr. Information vgl.: P. Prigioni, A. Breton et le surréalisme devant la critique, in: Roman. Jahrbuch 13, 1962, S. 119-148; H. S. Gershman, A Bibliography of the Surrealist Revolution in France, Ann Arbor 1969; M. Sheringham, A. Breton: a bibliography (Research Bibliographies \& Checklistes, 2) London 1972.

C. Abastado, Introduction au surréalisme, Paris 1971.

Th. W. Adorno, Rückblickend auf den Surrealismus, in: ders., Noten zur Literatur I, Frankfurt 1958, S. 155-162.

S. Alexandrian, Le surréalisme et le rêve, Paris 1974.

F. Alquié, Philosophie du surréalisme, Paris 1955.

F. Alquié, Hrsg., Entretiens sur le surréalisme, Paris 1968.

A. Balakian, Surrealism. The Road to the Absolute, New York ${ }^{2} 1970$.

W. Benjamin, Der Surrealismus (1929), in: ders., Angelus Novus, Frankfurt/M. 1966, S. 200-215.

W. Benjamin, Zum gegenwärtigen gesellschaftlichen Standort des französischen Schriftstellers (1934), in: ders., Angelus Novus, Frankfurt/M. 1966, S. 264-291. 
J.-P. Bernard, Surréalisme et communisme, in: ders., Le parti communiste français et la question littéraire, Paris 1972, S. 83-112.

M. Blanchot, Réflexions sur le surréalisme, in: ders., La part du feu, Paris 1949.

M. Blanchot, L'inspiration, le manque d'inspiration, in: ders., L'espace littéraire, Paris 1955.

A. Breton, Entretiens (1913-1952), Paris ${ }^{2} 1969$ (Coll. Idées, 284).

P. Bürger, Der französische Surrealismus. Studien zum Problem der avantgardistischen Literatur, Frankfurt/M. 1971.

P. Bürger, Theorie der Avantgarde, Frankfurt/M. 1974.

M. Eigeldinger, Hrsg., André Breton. Essais receuillis par M. E., Neuchâtel, 2. verb. Auflg. 1970.

J. Gracq, André Breton. Quelques aspects de l'écrivain, Paris 1948, repr. 1966.

E. Lenk, Der springende Narziß. André Bretons poetischer Materialismus, München 1971.

M. Nadeau, Histoire du Surréalisme suivie de Documents surréalistes, Paris 1964 (zuerst 2 Bände, Paris 1945 und 1948).

W. S. Rubin, Dada and Surrealism, New York 1968 (dt.: Stuttgart 1972).

M. Sanouillet, Dada à Paris, Thèse Paris 1965.

J. P. Sartre, Situation de l'écrivain en 1947, in: ders., Situations II, Paris 1948 (= Qu'est-ce que la littérature?).

G. Steinwachs, Mythologie des Surrealismus oder Die Rückverwandlung von Kultur in Natur, Neuwied 1971. 